\title{
Estudo taxonômico de Leschenaultia Robineau-Desvoidy (Diptera, Tachinidae) ${ }^{1}$
}

\author{
Ronaldo Toma ${ }^{2}$ \\ José Henrique Guimarães ${ }^{2}$
}

\begin{abstract}
Taxonomic study of Leschenaultia Robineau-Desvoidy (Diptera, Tachinidae). The genus Leschenaultia Robineau-Desvoidy, 1830 is redescribed. Two genera are considered as its junior synonyms: Echinomasicera Townsend, 1915 syn. nov. and Parachaetopsis Blanchard, 1959 syn. nov. Thirty two especies are treated, as follows: 18 described as new, Leschenaultia aldrichi, sp. nov. (Brazil, Santa Catarina), L. arnaudi sp. nov. (Haiti, La Salle), L. bergenstammi sp. nov. (Peru, San Martin), L. bessi sp. nov. (Brazil, Santa Catarina), L. bigoti sp. nov. (Peru, Huanuco), L. blanchardi sp. nov. (Equador, Cuenca), L. braueri sp. nov. (Brazil, Mato Grosso), L. brooksi sp. nov. (Brazil, Rio de Janeiro), L. coquilletti sp. nov. (Brazil, Santa Catarina); L. cortesi sp. nov. (Venezuela, Maracay), L. currani sp. nov. (Brazil, São Paulo), L. loewi sp. nov. (Mexico, Vera Cruz), L. macquarti sp. nov. (U. S. A., Arizona), L. reinhardi sp. nov. (Canada, Quebec), L. sabroskyi sp. nov. from (U. S. A., California), L. schineri sp. nov. (U. S. A., California), L. thompsoni sp. nov. (Mexico, Mexico City), $L$. townsendi sp. nov. (Mexico, Puebla), and 14 known species, for these, diagnoses are given: L. adusta (Loew, 1872); $L$. americana (Brauer \& Bergenstamm, 1893); L. bicolor (Macquart, 1846) = L. fusca (Townsend, 1916) syn. nov.; = Parachaetopsis proseni Blanchard, 1959 syn. nov.; L. ciliata (Macquart, 1848); L. exul (Townsend, 1892); L. fulvipes (Bigot, 1887); L. grossa Brooks, 1947; L. halisidotae Brooks, 1947; L. hospita Reinhard, 1952; L. hystrix (Townsend, 1915) comb. nov., L. jurinioides (Townsend, 1895); L. leucophrys (Wiedemann, 1830) = Leschenaultia latifrons (Walker, 1852) syn. nov. = Parachaeta nigricalyptrata (Macquart, 1855) syn. nov.; L. montagna (Townsend, 1912); L. nuda Thompson, 1963. One species was not examined, Leschenaultia nigrisquamis (Townsend, 1892), and two were not recognized, L. trichopsis (Bigot, 1887) and L. hirta Robineau-Desvoidy, 1830. Keys for Nearctic and Neotropical species (only for males) are provided, as well as geographical distribution and illustrations for each species.
\end{abstract}

KEYWORDS. Diptera; Harrisiini; Leschenaultia; Tachinidae; taxonomy

\section{INTRODUÇÃO}

O gênero Leschenaultia foi proposto por RoBINEAUDesvoIDY (1830) para as espécies: L. cilipes Robineau-Desvoidy, 1830 e L. hirta Robineau-Desvoidy, 1830. MACQUART (1835) sinonimizou os gêneros Leschenaultia, Harrisia e Macromya de Robineau-Desvoidy, 1830 e estabeleceu um novo gênero, Gymnostylia Macquart, 1835, para substituí-los. Posteriormente, em 1843, o mesmo autor erigiu o novo gênero Blepharipeza Macquart, 1843 sobre Leschenaultia cilipes Robineau-Desvoidy, 1830, descrevendo-a como uma espécie nova, Blepharipeza rufipalpis Macquart, 1843.

SCHINER (1868) transferiu Tachina leucophrys Wiedemann, 1830 para Blepharipeza e afirmou que essa espécie e $B$. rufipalpis Macquart, 1843 eram sinônimas.

Brauer \& Bergenstamm (1893) estabeleceram o gênero Rileya para Rileya americana Brauer \& Bergenstamm, 1893. TownsEND (1893a) propôs o nome novo Rileymyia para Rileya, nome pré-ocupado em Hymenoptera.

CoQuillett (1897) colocou Rileymyia Townsend, 1893 como sinônimo júnior de Blepharipeza Macquart, 1846. O gênero Rileymyia foi posteriomente retirado da sinonímia e colocado na sinonímia de Blepharipeza por diversas vezes.

Coquillett (op. cit.) estabeleceu Parachaeta para a espécie Blepharipeza bicolor Macquart, 1846. Esse gênero foi colocado como sinônimo júnior de Blepharipeza Macquart, 1835 por ALDRICH (1905) e, posteriormente, retirado da sinonímia deste por CoQuiLletT (1910).

TownSEND (1915) propôs o gênero Echinomasicera para a espécie Echinomasicera hystrix Townsend, 1915. Nenhuma espécie foi acrescentada a esse gênero após a sua descrição.

Townsend (1916) designou a espécie-tipo de vários gêneros, com o intuito de assegurar a validade de seus nomes, designando Leschenaultia cilipes Robineau-Desvoidy, 1830 como espécie-tipo do gênero Leschenaultia RobineauDesvoidy, 1830, Harrisia scutellaris Robineau-Desvoidy, 1830

1. Contribuição n 1344 do Departamento de Zoologia, UFPR. Parte da Tese de Doutorado ( $1^{\circ}$ autor) desenvolvida no Departamento de Zoologia da Universidade Federal do Paraná (auxílio CNPq).

2. Museu de Zoologia, Universidade de São Paulo. Caixa Postal 42694, 04299-970 São Paulo-SP, Brasil (primeiro autor bolsista da FAPESP; segundo autor bolsista do CNPq). 
como espécie-tipo de Harrisia Robineau-Desvoidy, 1830, e Macromya depressa Robineau-Desvoidy, 1830 como espécietipo de Gymnostylia Macquart, 1935 e Macromya RobineauDesvoidy, 1830, colocando ambos como sinônimos. Macromyia está atualmente alocado em Tachininae.

Townsend (1927) descreveu Harrisiopsis para a espécie $H$. spinosa Townsend, 1927 e, posteriormente, em 1931, sinonimizou Harrisiopsis Townsend, 1927 e Blepharipeza Macquart, 1843 sob Leschenaultia Robineau-Desvoidy, 1830, afirmando que as espécies $H$. spinosa Townsend, 1927, B. leucophrys (Wiedemann, 1830) e L. cilipes Robineau-Desvoidy, 1830 eram sinônimas. No mesmo trabalho, escolheu Leschenaultia leucophrys (Wiedemann, 1830) como espécietipo do gênero.

TOWNSEND (1936) comentou a tentativa de MACQUART (1835) de se apossar dos gêneros de Robineau-Desvoidy (1830), sinonimizando-os e depois erigindo novos gêneros para substituí-los; citou o caso de Leschenaultia que foi duplamente alvo dessas atitudes de Macquart e ainda comentou que Blepharipeza persistiu na literatura, indevidamente por quase um século, em detrimento de Leschenaultia. TownSEND (1936) comentou também o caso no qual MACQUART (1843) erigiu o gênero novo Blepharipeza Macquart, 1843 sobre Leschenaultia cilipes Robineau-Desvoidy, 1830, descrevendoa como uma espécie nova, B. rufipalpis Macquart, 1843, e citou que Macquart alterou e re-etiquetou alguns exemplares-tipos de Robineau-Desvoidy no Museu de Paris. Townsend (1936) arrolou Leschenaultia em sua tribo Harrisiini, sendo essa classificação reiterada nos trabalhos de autores subsequentes. Essa tribo pertence a um grupo dentro de Goniinae, cujas fêmeas depositam ovos microtipos embrionados sobre a plantaalimento do hospedeiro. Esses ovos, após serem ingeridos, sofrem a eclosão da larva no intestino do hospedeiro.

BROOKs (1947) revisou as espécies neárticas de Harrisiini em três gêneros: Leschenaultia Robineau-Desvoidy, 1830, Parachaeta Coquillett, 1897 e Rileymyia Townsend, 1893.

Blanchard (1959) estabeleceu Parachaetopsis para a espécie P. proseni Blanchard, 1959, permanecendo esse gênero monotípico.

SAbroski \& Arnaud (1965), catalogando as espécies neárticas de Harrisiini, listaram oito espécies para Leschenaultia: L. adusta (Loew, 1872), L. americana (Brauer \& Bergenstamm, 1893), L. exul (Townsend, 1892), L. fulvipes (Bigot, 1887), L. grossa Brooks, 1947, L. halisidotae Brooks, 1947, L. hospita Reinhard, 1952, L. leucophrys (Wiedemann, 1830); duas para Parachaeta: $P$. bicolor (Macquart, 1846) e $P$. fusca Townsend, 1916. O Gênero Rileymyia foi colocado novamente como sinônimo de Leschenaultia.

GUIMARÃEs (1971), catalogando as espécies neotropicais de Harrisiini, listou nove espécies para Leschenaultia: L. ciliata (Macquart, 1848), L. hospita Reinhard, 1952, L. jurinioides (Townsend, 1895), L. leucophrys (Wiedemann, 1830), L. latifrons (Walker, 1852), L. montagna (Townsend, 1912), L. nuda Thompson, 1963, L. nigrisquamis (Townsend, 1892), L. trichopsis Bigot, 1887 (como não reconhecida); duas para
Parachaeta: P. bicolor (Macquart), 1846 e P. nigricalyptrata (Macquart, 1855); uma para Echinomasicera: E. hystrix Townsend, 1915. Nesse catálogo, não listou Parachaetopsis proseni Blanchard, 1959, sendo essa espécie catalogada posteriormente por GUIMARÃES (1977) em Harrisiini.

Wood (1987), em sua chave para os gêneros neárticos de Tachinidae, incluiu Parachaeta em Leschenaultia. Posteriomente, O'HARA \& WoOD (1998) formalizaram essa sinonímia.

Leschenaultia possui distribuição restrita ao Novo Mundo, sendo o maior gênero da tribo Harrisiini. Algumas de suas espécies são parasitóides de lagartas de Arctiidae, Saturniidae, Sphingidae, Lymantriidae e Lasiocampidae (Lepidoptera). É um gênero bem representado nas coleções. No entanto, excetuando o trabalho de Brooks (op. cit.), poucos estudos foram feitos para esse grupo, principalmente para a Região Neotropical. Suas espécies foram descritas à parte de um trabalho de revisão e estão espalhadas pela literatura, dificultando sua identificação.

O presente trabalho traz um estudo taxonômico de 32 espécies (14 conhecidas e 18 novas), com apresentação de chaves de identificação para as espécies neárticas e neotropicais, descrições dos táxons novos e diagnoses e comentários para as espécies já conhecidas.

\section{MATERIAL E MÉTODOS}

Os acrônimos usados no texto indicam as instituições: AMNH, American Museum of Natural History, New York; BMNH, The Natural History Museum, Londres; CNCI, Canadian National Collection of Insects, Ottawa; DZUP, Coleção de Entomologia Pe. Jesus Santiago Moure, Departamento de Zoologia, Universidade Federal do Paraná, Curitiba; MCZC, Museum of Comparative Zoology, Havard University, Cambridge; KSUC, Kansas States University, Manhatan; MACN, Museu Argentino de Ciencias Naturales "Bernardino Rivadavia", Buenos Aires; MNHN, Muséum National d'Histoire Naturelle, Paris; MZSP, Museu de Zoologia, Universidade de São Paulo, São Paulo; OSUC, Insect Collection, Department of Entomology, Ohio States University, Columbus; CISC, University of California, Berkeley; UICM, University of Idaho, College of Agriculture Department of Plants soil and Entomological Sciences, Moscow; UM, Département des Sciences Biologiques, Université de Montreal, Montreal; USNM, National Museum of Natural History, Washington D.C.

A terminologia empregada foi a de MCALPINE (1981), exceto o termo pró-fronte retirado de CROSSKEY (1984).

As medidas de proporções entre partes da cabeça foram tomadas sempre com as extremidades das estruturas focadas em estereomicroscópio: largura do vértice em relação à largura da cabeça é representada pela distância entre as margens internas dos olhos sobre a distância entre as extremidades externas dos mesmos, em vista dorsal; largura da parafrontália em relação à largura da fronte é tomada no ponto mediano da última; largura da pró-fronte em relação à largura da fronte no 
ponto mediano desta última; largura da parafaciália em relação à largura do flagelômero é realizada em dois pontos: logo abaixo da última cerda frontal e na altura subapical do flagelômero; altura da gena em relação à altura do olho é a distância entre a base da cabeça até o ponto mais inferior do olho em relação à altura do olho, em vista lateral.

As espécies que ocorrem nas Regiões Neártica e Neotropical foram incluídas nas duas chaves. A apresentação de chaves para espécies com base apenas nos machos é devido à falta de conhecimento de boa parte das fêmeas, principalmente das espécies novas, aliado à dificuldade de associá-las aos machos.

Leschenaultia Robineau-Desvoidy, 1830

Leschenaultia Robineau-Desvoidy, 1830:324 (espécie-tipo: Leschenaultia cilipes Robineau-Desvoidy, 1830:325, designação subsequente) (= Tachina leucophrys, Wiedemann, 1830); Macquart, 1835:216 (Gymnostylia partim); Townsend, 1916:7 (designação da espécietipo e revalidação), Townsend, 1927:247 (chave), Townsend, 1931:175 (sinonímia); Curran, 1934:449,451 (chave); Townsend, 1936:189 (chave), Townsend, 1941:79 (redefinição); Brooks, 1947:171 (revisão); Sabrosky \& Arnaud, 1965:1082 (catálogo); Guimarães, 1971:185 (catálogo); Wood, 1987:1213 (chave); Poole \& Lewis, 1996:287 (lista remissiva).

Blepharipeza Macquart, 1843:211 (1843:54, ver referências) (espécietipo: Blepharipeza rufipalpis Macquart, 1843:158, monotipia) (= Tachina leucophrys Wiedemann, 1830); Townsend, 1893b:9 (catálogo); Coquillett, 1897:123 (revisão); Aldrich, 1905:472 (catálogo); Townsend, 1931:175 (sinonímia).

Rileymyia Townsend, 1893:277 (novo nome para Rileya Brauer \& Bergenstamm, 1893 pré-ocupado por Ashmead, 1888 Hymenoptera) (espécie-tipo: Rileya americana Brauer \& Bergenstamm, 1893, monotipia); Coquillett, 1897:123 (sinonímia); Townsend, 1908:105 (revalidação); Coquillett, 1910: 514 (sinonímia); Townsend, 1927:247 (revalidação); Townsend, 1936:189 (chave); Townsend, 1941:84 (redefinição); Brooks, 1947:169 (revisão); Sabrosky \& Arnaud, 1965:1082 (sinonímia).

Parachaeta Coquillett, 1897:123 (espécie-tipo: Blepharipeza bicolor Macquart, 1846:286 (1846:158, ver referência), monotipia); Aldrich, 1905:472 (sinonímia); Coquillett, 1910 (revalidação e desinação errônea de Blepharipeza inermis Bigot, 1888); Townsend, 1936:189 (chave); Townsend, 1941:81 (redefinição); Brooks, 1947:173 (revisão); Sabrosky \& Arnaud, 1965:1083 (catálogo); Guimarães, 1971: 186 (catálogo); Wood, 1987:1213 (sinonímia).

Echinomasicera Townsend, 1915:413 (espécie-tipo: Echinomasicera hystrix 1915:413, monotipia); Townsend, 1936:189 (redefinição); Guimarães, 1971:185 (catálogo); Cortés, 1983:380 (chave). Syn. nov.

Harrisiopsis Townsend, 1927:247 (espécie-tipo: Harrisiopsis spinosa Townsend, 1927:313, monotipia) (= Tachina leucophrys, Wiedemann, 1830); Townsend, 1931:175 (sinonímia).

Parachaetopsis Blanchard, 1959:163 (espécie-tipo: Parachaetopsis proseni Blanchard, 1959:163, monotipia); Guimarães, 1977:14, 63 (catálogo hopesdeiro e parasitóide). Syn. nov.

Redescrição. Cabeça: olho em geral glabro; pró-fronte, em vista lateral, levemente projetada pouco acima da metade da altura do olho; palpo maxilar levemente clavado; arista ligeiramente espessa na base, afilando-se gradualmente; cerdas ocelares presentes; pós-ocelares paralelas; macho em geral com um par de cerdas orbitais reclinadas e sem cerdas proclinadas, com exceção de algumas espécies; fêmeas com dois pares de cerdas orbitais proclinadas; fileira de cerdas frontais estendendo-se geralmente até o terço superior da parafaciália, na altura do final de pedicelo; cerdas verticais internas espessas e paralelas; cerdas verticais externas variáveis; parafrontália com pêlos interna e externamente às frontais; parafaciália, na porção abaixo das cerdas frontais, glabra, pilosa ou cerdosa; faciália com cerdas de tamanho e espessura variáveis, estendendo-se de 0,30 a 0,90 da distância da vibrissa até a base da antena; vibrissas espessas e cruzadas; gena cerca de 0,27 a 0,50 da altura do olho; epistoma, em vista lateral, levemente projetado; pêlos occipitais geralmente brancos.

Tórax: preto, pruinosidade geralmente cinza; escuto com quatro ou cinco faixas longitudinais de pruinosidade. Padrão da quetotaxia: prosterno cerdoso; pró-episterno nu; catepisterno em geral com três cerdas; pós-pronoto (Fig. 3) com três cerdas basais alinhadas e uma anterior menor posicionada entre as cerdas basais mediana e interna; acrosticais 3:3; dorsocentrais 3:4 ou 4:4; intra-alares 1:3; duas supra-alares; pré-alar maior e mais espessa do que a primeira dorsocentral pós-sutural; pré-sutural forte. Escutelo (Fig. 1) com um par de cerdas basais; três pares de cerdas laterais (sub-basais, medianas e subapicais); um par de cerdas apicais variáveis; geralmente com cerdas presentes entre o par de cerdas discais, na maioria das vezes, mais afiladas próximo à base escutelar. Perna: coloração variável; fêmur anterior com pruinosidade cinza na lateral externa; porção ântero-dorsal da tíbia posterior com uma fileira de cerdas espessas, em geral achatadas, afastadas umas das outras por não mais que duas vezes a largura de uma cerda; garra tarsal anterior em geral maior que o segundo tarsômero da mesma perna. Asa geralmente subialina; quarto basal escurecido; álula fosca.

Abdome com coloração variando do castanho-alaranjado ao castanho-escuro; a maioria das espécies neárticas com uma faixa preta longitudinal-central; pruinosidade variável. Cerdas marginais medianas presentes no sintergito $1+2$, exceto $L$. bicolor Macquart.

Comentários. Leschenaultia pode ser separado dos demais gêneros da tribo Harrisiini pelos seguintes caracteres: de Pterotopeza Townsend, 1908 pela presença de cerdas ocelares e asas subialinas, escurecidas no quarto basal; de Moreiria Townsend, 1932 pela presença, em geral, de um par de cerdas orbitais reclinadas, se dois pares, então somente três cerdas catepisternais e surstilos não robustos e não subtriangulares; de Proparachaetopsis Blanchard, 1942 pela ausência de uma fileira de cerdas mais ou menos alinhadas e contínuas às cerdas frontais na parafaciália; de Proparachaeta Townsend, 1928 pela cerda pós-pronotal anterior posicionada entre as cerdas basais mediana e interna, nunca à frente da cerda basal póspronotal interna; de Thysanopsis Townsend, 1917 pela presença de cerdas marginais medianas no sintergito $1+2$ e cercos sem um processo mediano-anterior.

Não foi possível detectar um caráter que fosse supostamente exclusivo de Leschenaultia. Há dúvidas quanto a validade de um padrão morfológico dos cercos e surstilos para esse gênero, sendo definido pela combinação de caracteres.

Algumas espécies neárticas apresentam um padrão de 
coloração no tórax: porção pré-escutelar e, às vezes, laterais do escuto e escutelo, castanho-alaranjados. No entanto, não é possível afirmar se as espécies com esse padrão são próximas, visto que algumas delas são mais assemelhadas às outras que não o possuem. Por outro lado, entre as espécies com tal padrão de coloração, L. americana, L. exul, L. fulvipes e mais duas espécies novas, Leschenaultia sabroskyi e Leschenaultia schineri, apresentam duas características que as distinguem das demais espécies: parafaciália mais cerdosa que pilosa e escutelo com cerdas finas e suberetas entre o par de cerdas discais (Fig. 2). Dentre as espécies sem o padrão de coloração supra citado, não foi diagnosticada nenhuma característica que permitisse a formação de grupos de espécies.

RoBINEAU-Desvoidy (1830) estabeleceu o gênero Harrisia para duas espécies: H. scutellaris Robineau-Desvoidy, 1830 e H. brasiliensis Robineau-Desvoidy, 1830. TownSEND (1916) designou a primeira como espécie-tipo do gênero. Nenhuma outra espécie foi acrescentada ao gênero. Os exemplares-tipo das espécies que compõem Harrisia estão perdidos, segundo Dr. Loïc Matile, MNHN, (com. pessoal). A identificação das espécies não é possível através das descrições originais. Por outro lado, com base na descrição original de Harrisia, na sua redescrição feita por TownSEND (1941) e nos caracteres de chaves empregados por TownSEND (1927 e 1936) para sua identificação, acreditamos que esse gênero seja um sinônimo de Leschenaultia Robineau-Desvoidy, 1830. No entanto, decidimos aqui não formalizar essa sinonímia. Ambos foram descritos no mesmo trabalho, sendo Harrisia anterior a Leschenaultia. A decisão acima foi tomada porque $H$. scutellaris, espécie-tipo de Harrisia, é uma species inquirenda, enquanto que a de Leschenaultia, L. cilipes R\&D, é bem conhecida.

Echinomasicera Townsend, 1915 apresenta as características listadas no presente trabalho para Leschenaultia e é aqui sinonimizado.

\section{Caracteres dos adultos de Leschenaultia e seu valor taxonômico.}

Coloração do corpo. Varia do castanho-alaranjado ao castanho-escuro. Algumas espécies neárticas de Leschenaultia apresentam o abdome, escutelo, região anterior ao escutelo e, às vezes, a lateral do escuto, castanho-alaranjados. $\mathrm{O}$ abdome em algumas espécies exibe uma faixa preta, longitudinal-central.

Pruinosidade. É um caráter que varia tanto na coloração quanto na densidade, podendo ser importante na definição de espécies. A maioria das espécies é dotada de uma pruinosidade de colorido cinéreo, podendo o amarelo e o marrom-ferrugíneo estarem presentes. A coloração da pruinosidade das caliptras é importante na identificação de algumas espécies.

Quetotaxia. Cabeça. As cerdas orbitais proclinadas estão presentes quase que exclusivamente nas fêmeas, no entanto, em algumas espécies, elas ocorrem também nos machos. A presença ou ausência de pêlos e/ou cerdas na parafaciália e a extensão da fileira de cerdas da faciália em relação à distância da vibrissa até a base da antena são utilizadas nas definições de algumas espécies. O olho na maioria das espécies é praticamente glabro, excetuando L. ciliata (Macquart,1848), que o exibe distintamente piloso. Tórax. Excetuando o escutelo, o tórax apresenta um padrão de quetotaxia pouco variável. A perna exibe uma característica marcante, a porção ântero-dorsal da tíbia posterior apresenta uma fileira de cerdas espessas, em geral achatadas, afastadas umas das outras por não mais que duas vezes a largura de uma cerda. Abdome. A quetotaxia abdominal, apesar de variar intra-especificamente em algumas espécies, exibe um certo padrão dentro de outras. A quetotaxia abdominal é importante para a definição das espécies. As cerdas abdominais das fêmeas de uma maneira geral são mais espessas que as dos machos.

Asas. A venação das asas é pouco variável. A célula R5 é aberta, terminando antes do ápice. A veia $\mathrm{M}$ apresenta uma curvatura bastante acentuada. A maioria das espécies apresenta asas subialinas com o quarto basal castanho-escuro e álulas foscas.

Terminália. A variação da forma dos cercos e surstilos foi empregada como caráter diferencial para a separação das espécies. As espécies de Leschenaultia podem ser caracterizadas por apresentar os cercos e surstilos geralmente alongados, estreitando-se da base para o ápice; cercos com curvatura variável e porção látero-anterior com uma depressão; surstilos estreitando-se da base para o meio, como nas Figs. 34-62. Edeago (Fig. 5) estreito do epifalo ao acrofalo; basifalo não curvado para o dorso. Gonópodos com o ápice e a lateral externa levemente curvados em direção ao hipândrio (Fig. 4).

Chave para as espécies neárticas (apenas machos):

1. Sintergito $1+2$ e tergito 3 sem cerdas marginais medianas (Fig. 94); garra tarsal anterior em geral curta, menor que o segundo tarsômero da mesma perna. (Do Canadá: Ontario, Quebec, até a Argentina, Buenos Aires) L. bicolor (Macquart)

Sintergito $1+2$ com cerdas marginais medianas e tergito 3 com ou sem cerdas marginais medianas (Figs. 92, 93, 95-119); garra tarsal anterior de tamanho variável, em geral maior que o segundo tarsômero da mesma perna

2

2. Região pré-escutelar com coloração igual ao escuto; abdome geralmente castanho ou castanho-escuro

Região pré-escutelar com coloração castanho-alaranjada ou castanho-avermelhada, diferindo do escuto; abdome variando do castanho ao castanhoavermelhado .. 11

3. Cerdas orbitais proclinadas ausentes (Figs. 14, 17, 18).

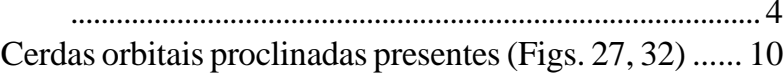


4. Tergitos 3 e 4 com ou sem cerdas discais, quando presentes não muito conspícuas, espaçadas e em pequeno grupo (Fig. 109, 115).

Tergitos 3 e 4 sempre com cerdas discais, estas presentes em grupo ou fileira 7

5. Escutelo com mescla de pruinosidade branca e marromferrugínea. (Canadá: Ontário e Quebec; Estados Unidos: Oregon, Idaho, California, Tennessee)

\section{L. reinhardi sp. nov.}

Escutelo com pruinosidade marrom-ferrugínea .... 6

6. Garra tarsal anterior em geral maior que o segundo tarsômero da mesma perna; cercos sub-retos (Fig. 52). (Do México até o Sudeste do Brasil: São Paulo)

L. brooksi sp. nov.

Garra tarsal anterior relativamente curta, ligeiramente menor que o segundo tarsômero da mesma perna; cercos levemente curvados para trás na porção posterior (Fig. 51). (Do México, Tenosique, ao Sul do Brasil, Santa Catarina) .......... Leschenaultia braueri sp. nov.

7. Tergito 4 com cerdas discais em fileira (Fig. 100); abdome castanho-alaranjado com uma faixa preta longitudinalcentral. (Estados Unidos, New Mexico; México: Oaxaca, Morelos e Michoacan) .... L. hospita Reinhard

Tergito 4 com cerdas discais em grupo (Fig. 103); abdome castanho-escuro ... 8

8. Cabeça com densa pruinosidade cinza e levemente amarelada (Do México até a região Centro-oeste do Brasil) L. bigoti sp. nov.

Cabeça com pruinosidade cinza .9

9. Cercos, relativamente alongados, curvados para trás no terço apical e em seguida para frente, ápice estreitado (Fig. 44). (Do México, San Luis Patosi, até o Uruguai) L. leucophrys (Wiedemann)

Cercos, sub-retos, largura subigual na metade apical e estreitando-se suavemente próximo ao ápice (Fig. 52). (Do México até o Sudeste do Brasil: São Paulo) L. brooksi sp. nov.

10. Tergito 3 com cerca de quatro pares de cerdas marginais medianas médias e curtas e um grupo bastante reduzido de cerdas discais curtas e espaçadas (Fig. 113). (México: Vera Cruz) L. loewi sp. nov.

Tergito 3 com uma fileira de cerdas marginais medianas sublongas e médias e um grupo de cerdas discais médias e espessas (Fig. 118). (México: Puebla)

L. townsendi sp. nov.

11. Parafaciália cerdosa abaixo das cerdas frontais, cerdas no mínimo até o terço inferior da parafaciália (Figs. 6, 7, $10,11,30)$ 12

Parafaciália mais pilosa do que cerdosa, extensão bastante variável (Figs. 12, 13, 28, 31) 17

12. Cerdas orbitais proclinadas geralmente presentes (Fig. 6); garra tarsal anterior curta, menor que o segundo tarsômero da mesma perna. (Estados Unidos: California, Arizona e New Mexico; México: Durango e Sonora)

L. adusta (Loew)

Cerdas orbitais proclinadas ausentes (Figs. 7, 10, 11, 30); garra tarsal anterior de tamanho variável, em geral maior que o segundo tarsômero da mesma perna ... 13

13. Tergito 3 com um par de cerdas marginais medianas submédias, com ou sem um par de cerdas menores e mais fracas mais interno (Fig. 96). (Canada: Saskatchewan, British Columbia; Estados Unidos: Idaho, California, Arizona, Wyoming, New Mexico, Texas) L. fulvipes (Bigot)

Tergito 3 com três ou mais pares de cerdas marginais medianas submédias e curtas (Figs. 93, 95, 116) ..... 14

14. Escutelo com dois pares de cerdas laterais (Fig. 2); cercos e surstilos como nas Figs. 35, 64. (Canada: British Columbia, Alberta; Estados Unidos: Oregon, Montana, California, Idaho e Arizona)

L. americana (Brauer \& Bergenstamm)

Escutelo com três ou mais pares de cerdas laterais, se dois pares de laterais, então cercos não como acima ...... 15

15. Pernas castanho-alaranjadas com tarsos e base dos fêmures escurecidos. (Estados Unidos: Oregon, California e Idaho) L. schineri sp. nov.

Pernas variando do castanho-avermelhado ao castanhoescuro, nunca com o padrão de coloração acima .... 16

16. Surstilos moderadamente alongados em comparação aos cercos (Figs. 38, 67). (Canada: Ontario, Quebec, New Brunswick; Estados Unidos: Ohio, Virginia, Maine, New York, Hampshire, Massachusetts, Connecticut, New Jersey, Maryland) ................... L. exul (Townsend)

Surstilos bem alongados em comparação aos cercos (Figs. 59, 88). (Estados Unidos: California e Arizona)

L. sabroskyi sp. nov.

17. Garra tarsal anterior curta, em geral menor que o segundo tarsômero da mesma perna. (México: Cidade do México e Chiapas) L. thompsoni sp. nov.

Garra tarsal anterior variável, em geral maior que o segundo tarsômero da mesma perna 18

18. Caliptra com pruinosidade marrom-ferrugínea-escura; pêlos da parafrontália estendendo-se até pouco além da metade da parafaciália (Fig. 12). (Estados Unidos: Nevada, Arizona, New Mexico) ......... L. grossa Brooks

Caliptra com pruinosidade marrom-ferrugínea-clara; se preta, então pêlos da parafrontália estendendo-se até pouco antes ou até a metade da parafaciália (Figs. 13, 
28)

19. Flagelômero mais de duas vezes o comprimento do pedicelo (Fig. 13). (Canada: British Columbia, Ontario, Quebec; Estados Unidos: Minesota, Maine, New York, Massachusetts, Wisconsin, Pennsylvania, Ohio, New Jersey, California e Arizona) ...... L. halisidotae Brooks Flagelômero no máximo duas vezes o comprimento do pedicelo (Fig. 28) (Estados Unidos: Arizona)

L. macquartisp. nov.

Chave para as espécies neotropicais (apenas machos):

1. Cerdas orbitais proclinadas presentes (Figs. 15, 16, 19, 27, 32) ... 2 Cerdas orbitais proclinadas ausentes (Figs. 8, 9, 14, 17, 18, 20-26, 28)

2. Tergito 4 em geral sem cerdas discais (Fig. 118); se presentes, então curtas e em número bem reduzido (Fig. 113)

Tergito 4 com cerdas discais (Figs. 101, 102, 105)

3. Tergito 3 com uma fileira de cerdas marginais e um grupo de cerdas discais médias e espessas (Fig. 118). (México: Puebla) ............................ L. townsendi sp. nov.

Tergito 3 com cerca de quatro pares de cerdas marginais medianas médias e curtas, sem formar uma fileira completa, e um grupo reduzido de cerdas discais curtas e espaçadas (Fig.113). (México: Vera Cruz) ...... L. loewi sp. nov.

4. Parafaciália cerdosa na metade superior (Fig. 15); tergito 4 com cerdas discais limitadas à porção central (Fig. 101). (Peru: Matucana) ................ L. hystrix (Townsend)

Parafaciália mais pilosa que cerdosa, não alcançando a metade superior da parafaciália (Figs. 16, 19); tergito 4 com uma ou mais fileiras de cerdas discais (Figs. $102,105)$

5. Tergito 4 com duas fileiras de cerdas discais desalinhadas (Fig. 102). (Jamaica: Chinchona e Treluraus) ............. L. jurinioides (Townsend)

Tergito 4 com uma fileira de cerdas discais, desalinhada e interrompida no centro (Fig. 105). (Haiti: La Selle e Port-au-Prince)

L. arnaudi sp. nov.

6. Tórax preto, região pré-escutelar com mancha castanhoalaranjada

Tórax preto, região pré-escutelar sem mancha castanhoalaranjada

... 9

7. Garra tarsal anterior curta, menor que o segundo tarsômero da mesma perna; parafrontália cerca do dobro da largura da fronte. (México: Cidade do México e Chiapas). L. thompsoni sp. nov.
Garra tarsal anterior em geral maior que o segundo tarsômero da mesma perna; parafrontália no máximo uma vez e meia a largura da fronte 8

8. Abdome castanho; tergito 3 com um grupo de cerdas discais curtas (Fig. 107). (Equador) ...

L. blanchardi sp. nov.

Abdome castanho-alaranjado; tergito 3 geralmente sem cerdas discais (Fig. 97). (Colômbia)

L. ciliata (Macquart)

9. Sintergito $1+2$ e tergito 3 sem cerdas marginais e sem cerdas discais (Fig. 94). (Do Canadá: Ontario, Quebec, até a Argentina, Buenos Aires) ........... L. bicolor (Macquart)

Sintergito $1+2$ e tergito 3 com cerdas marginais presentes (Figs. 100, 103, 104, 106-112); cerdas discais presentes ou não 10

10. Tergito 4 sem cerdas discais, se presentes, então um pequeno grupo de cerdas espaçadas (Figs. 104, 107110) 11

Tergito 4 com cerdas discais em grupo ou em fileira (Figs. $103,106,111,112)$ 16

11. Tergito 3 com um pequeno grupo de cerdas discais curtas, bem próximo às cerdas marginais (Figs. 104, 107) ... 12

Tergito 3 sem cerdas discais, se presentes, então quase não distintas da cerdosidade do tergito (Figs. 108110)

12. Tergito 3 com cerdas marginais medianas submédias e curtas (Fig. 107); pruinosidade do escuto, em vista dorso-posterior, cinza e levemente marrom. (Equador) L. blanchardi sp. nov.

Tergito 3 com cerdas marginais medianas curtas (Fig. 104); pruinosidade do escuto cinza. (Brasil: São Paulo e Santa Catarina) L. aldrichi sp.nov

13. Sintergito $1+2$ com cerca de quatro pares de cerdas marginais medianas curtas e conspícuas, e tergito 3 geralmente com cinco pares de cerdas marginais medianas curtas, espessas, alinhadas e uniformes (Fig. 110). (Brasil: Santa Catarina)

L. coquilletti sp. nov.

Sintergito $1+2$ com um ou dois pares de cerdas marginais medianas curtas, pouco distintas da cerdosidade do tergito, e tergito 3 geralmente com menos de cinco pares de cerdas marginais, se tão fortes, não tão alinhadas nem uniformes (Figs. 108, 109) 14

14. Tergito 3 com cerdas marginais medianas curtas, porém conspícuas (Fig. 108); cercos estreitando-se bem mais acentuadamente a partir do terço apical (Fig. 50). (Brasil: Santa Catarina; Peru: San Martin) L. bergenstammi sp. nov.

Tergito 3 com cerdas marginais medianas curtas e pouco 
conspícuas (Fig 109); cercos não como acima (Figs. $51,52)$ 15

15. Garra tarsal anterior em geral maior que o segundo tarsômero da mesma perna; cercos sub-retos (Fig 52). (Do México até o Sudeste do Brasil: São Paulo)

L. brooksi sp. nov.

Garra tarsal anterior relativamente curta, ligeiramente menor que o segundo tarsômero da mesma perna; cercos levemente curvados para trás na porção posterior (Fig. 51) (Do México, Tenosique, ao Sul do Brasil, Santa Catarina)

L. braueri sp. nov.

16. Tergito 4 com cerdas discais dispostas em fileiras, alinhadas ou não (Figs. 100, 106, 111) ...................................... 17

Tergito 4 com cerdas discais dispostas em grupo, concentradas mais no disco do que nas laterais (Figs. $103,112)$ .. 19

17. Pêlos da parafrontália estendendo-se até logo abaixo da metade superior da parafaciália (Fig 26); duas catepisternais. (Venezuela: Maracay)

L. cortesi sp. nov.

Pêlos da parafrontália estendendo-se até pouco antes da metade superior da parafaciália (Figs. 14, 20); três catepisternais 18

18. Abdome castanho-alaranjado com uma faixa preta longitudinal-central; flagelômero menos de duas vezes o comprimento do pedicelo (Fig 14). (Estados Unidos: New Mexico; México: Nochixtlan e Morelos)

L. hospita Reinhard

Abdome castanho-escuro sem faixa preta longitudinalcentral; flagelômero o dobro ou mais do comprimento do pedicelo (Fig 20). (Brasil: São Paulo e Santa Catarina) L. bessi sp.nov.

19. Cabeça com pruinosidade cinza e levemente amarelada, dependendo do ângulo de luz; pêlos occipitais amarelos. (Do México até Peru e Região Centro-Oeste do Brasil) L. bigoti sp. nov. Cabeça com pruinosidade cinza; pêlos occipitais brancos 20

20. Tergito 3 geralmente com menos de quatro pares de cerdas marginais medianas, bem curtas e delgadas, e um grupo reduzido de cerdas discais também bastante curtas. (Do México até o sudeste do Brasil: São Paulo) L. brooksi sp.nov.

Tergito 3 geralmente com cerca de quatro pares de cerdas curtas, variando de meio-espessas a espessas, e um grupo notável de cerdas discais curtas, também variando de meio-espessas a espessas 21

21. Tergito 3 geralmente com cerdas discais e marginais medianas espessas (Fig 112). (Brasil: São Paulo e Santa Catarina) L. currani sp.nov.

Tergito 3 geralmente com cerdas marginais e cerdas discais curtas e meio-espessas (Fig 103). (Do México, San Luis Patosi, até o Uruguai)

L. leucophrys (Wiedemann)

\section{Leschenaultia aldrichi sp. nov.}

(Figs. 18, 45, 74, 104)

Diagnose. Pró-fronte bem projetada; palpo preto. Dorsocentrais 4:4. Escutelo, calo pós-alar e abdome com pruinosidade marrom-ferrugínea. Sintergito $1+2$ com cerca de cinco pares de cerdas marginais medianas curtas. Tergito 3 com cerdas marginais medianas bem curtas, concentradas no meio e nas laterais; um conjunto pequeno de cerdas discais menores, próximo às cerdas marginais medianas. Tergito 4 com uma fileira de cerdas marginais medianas longas e curtas, afastadas da margem medianamente; cerdas discais ausentes.

Comprimento. $13,4 \mathrm{~mm}$.

Macho. Cabeça (Fig. 18) com parafrontália e porção superior da parafaciália pretas; demais partes castanho-avermelhadas; pruinosidade cinza; fronte castanho-escura; vértice 0,24 da largura da cabeça; pró-fronte projetada, pouco acima da metade da altura do olho; parafrontália mais ou menos igual a largura da fronte; pró-fronte cerca de duas vezes a largura da fronte; parafaciália pouco mais que uma vez e meia a largura do flagelômero logo abaixo das cerdas frontais e pouco mais larga que este na altura subapical; antena preta, flagelômero cerca de uma vez e meia ou mais o comprimento do pedicelo; palpo preto, ápice amarelado; cerdas ocelares longas e espessas; cerdas verticais externas reduzidas; em geral dois pares de cerdas reclinadas; cerdas frontais cerca de 10, estendendo-se um pouco além do final do pedicelo, abaixo do terço superior da parafaciália; pêlos externos da parafrontália estendendo-se logo abaixo das cerdas frontais; faciália com cerdas variando de 0,20 a quase 0,50 do comprimento da vibrissa, estendendose cerca de 0,50 da distância da vibrissa à base da antena, margeadas por cerdas menores; gena aproximadamente um terço da altura do olho.

Tórax preto; pruinosidade cinza na pleura e no escuto, marrom-ferrugínea no calo pós-alar e escutelo. Dorsocentrais 4:4. Cerdas escutelares: um par de basais; três pares de laterais; várias cerdas variando de pequenas a médias próximo às cerdas apicais e entre o par de cerdas discais. Perna preta. Asa: caliptra com pruinosidade marrom-ferrugínea.

Abdome (Fig. 104) preto; pruinosidade marrom-ferrugínea. Sintergito 1+2 com cerca de cinco pares de cerdas marginais medianas curtas. Tergito 3 com cerdas marginais medianas bem curtas, concentradas no meio e nas laterais; um conjunto pequeno de cerdas discais menores, próximo às cerdas marginais medianas. Tergito 4 com uma fileira de cerdas marginais medianas longas e curtas, distanciada da margem no centro; cerdas discais ausentes.

Cercos e surstilos (Figs. 45, 74). Vista lateral, cercos com a 

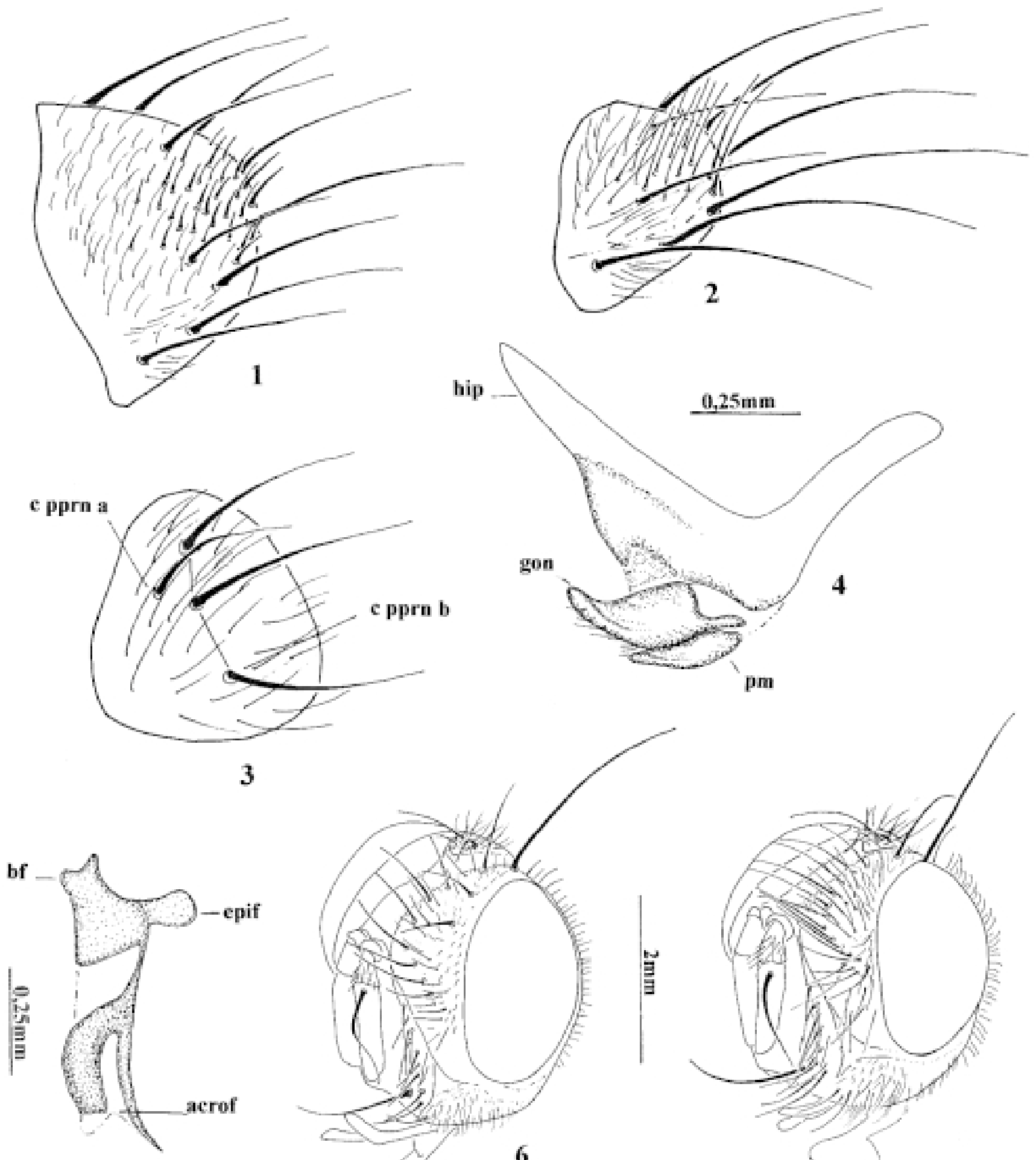

3

5
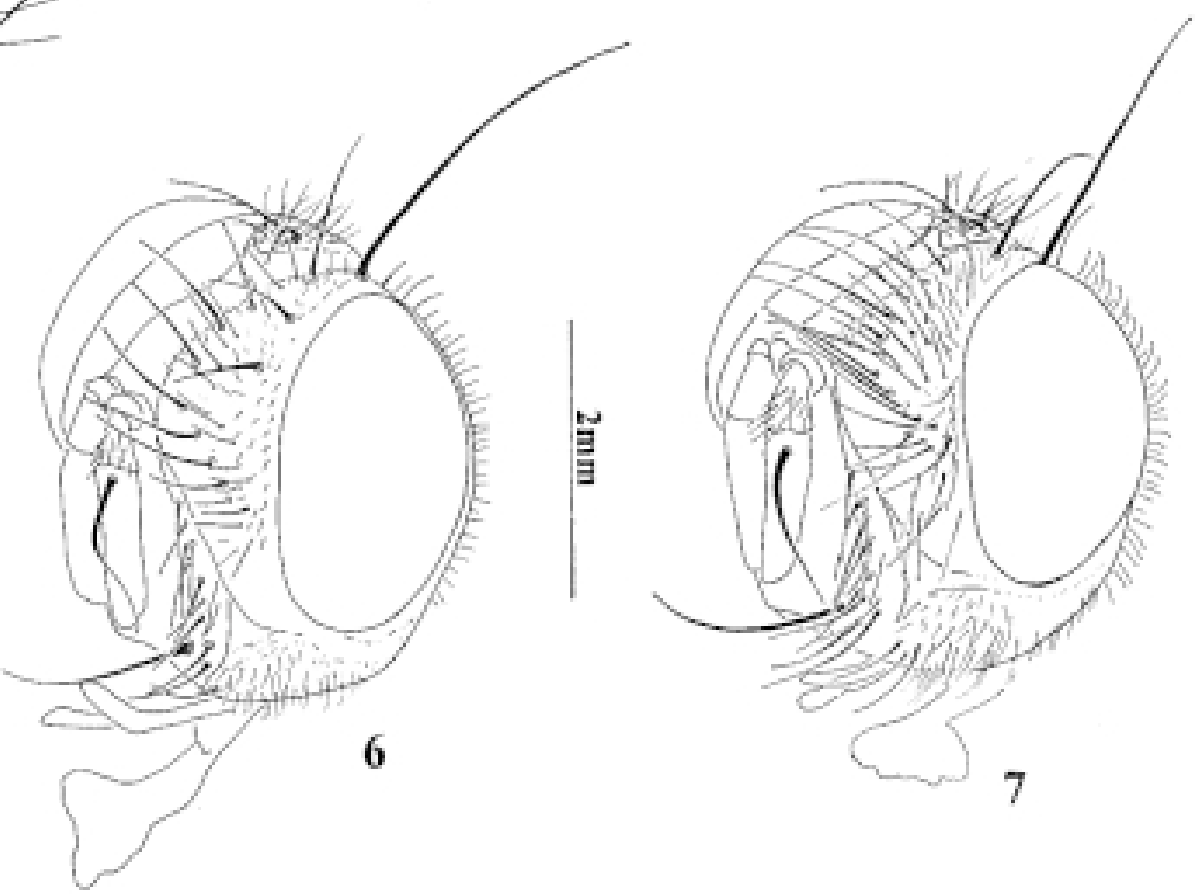

Figs. 1-3. Escutelo, vista látero-dorsal: 1, Leschenaultia leucophrys (Wiedemann, 1830); 2, L. americana (Brauer \& Bergenstamm, 1893). Póspronoto, vista látero-dorsal: 3, L. leucophrys. Figs. 4-5. Hipândrio, gonópodo, parâmero, vista lateral e edeago, vista lateral: 4, L. leucophrys; 5, L. leucophrys. Figs. 6-7. Cabeça, vista látero-frontal (macho): 6, L. adusta $($ Loew, 1872); 7, L. americana $($ Brauer \& Bergenstamm, 1893); acrof = acrofalo; bf = basifalo; c pprn a = cerda pós-pronotal anterior; c pprn b = cerdas pós-pronotais basais; epif = epifalo; gon = gonópodo; hip = hipândrio; $\mathrm{pm}=$ parâmero. 
porção posterior levemente côncava e com o ápice subarredondado; metade apical dos surstilos com largura subigual. Surstilos cerca de 0,75 do comprimento dos cercos.

Fêmea. Cabeça: verticais externas cerca de um terço das internas; cerdas frontais cerca de sete. Abdome: sintergito 1+2 com quatro a cinco pares de cerdas marginais medianas espessas, curtas e médias. Tergito 3 com uma fileira de cerdas marginais medianas espessas, curtas, médias e sublongas; um grupo pequeno de cerdas discais curtas. Tergito 4 com uma fileira de cerdas marginais medianas longas e curtas, estas mais centrais e distantes da margem; uma segunda fileira interrompida no centro.

Distribuição geográfica. Brasil (São Paulo e Santa Catarina).

Comentário. Esta espécie é semelhante a Leschenaultia blanchardi sp. nov., diferindo desta por apresentar o tergito 3 com cerdas marginais medianas curtas e escuto com pruinosidade cinza.

Material-tipo. Holótipo macho. BRASIL. Santa Catarina: Nova Teutônia, XI.1966 F. Plaumann col. (MZSP). Parátipos: idem, 3 machos, XI.1961, I.1964, IV.1964 (MZSP).

Material adicional examinado. BRASIL. São Paulo: Embú, 1 fêmea, 15.II.1946, F. Lane col. (MZSP). Santa Catarina: Nova Teutônia, 3 machos, 17 fêmeas, IV.1964-I.1971, F. Plaumann col. (MZSP).

\section{Leschenaultia arnaudi sp. nov.} (Figs. 19, 46, 75, 105)

Diagnose. Dois pares de cerdas orbitais proclinadas; antena preta; palpo castanho-alaranjado. Sintergito $1+2$ com cerca de seis pares de cerdas marginais medianas. Tergito $3 \mathrm{com}$ uma fileira de cerdas marginais; um grupo grande de cerdas discais. Tergito 4 com uma fileira de cerdas marginais; uma fileira de cerdas discais desalinhadas, interrompida no centro. Garra tarsal anterior curta, menor que o segundo tarsômero da mesma perna.

Comprimento. 11,5-13,5 mm.

Macho. Cabeça (Fig. 20) preta; pruinosidade cinza; sulco genal e face castanho-alaranjados; fronte marrom; vértice 0,26 da largura da cabeça; pró-fronte projetada, pouco acima da metade da altura do olho; parafrontália pouco mais larga que a fronte; pró-fronte cerca de uma vez e meia da largura da fronte; parafaciália estreita, cerca de uma vez e meia a largura do flagelômero logo abaixo das cerdas frontais e cerca da mesma largura ou mais deste na altura subapical; antena preta; base do flagelômero alaranjada, este cerca de três vezes o comprimento do pedicelo; palpo castanho-alaranjado; cerdas ocelares divergentes; cerdas verticais externas reduzidas; dois pares de cerdas orbitais proclinadas; cerdas frontais cerca de nove, estendendo-se até o terço superior da parafaciália, na altura do final do pedicelo, pares superiores reclinados e próximo às cerdas orbitais reclinadas; pêlos da parafrontália estendendo-se até logo abaixo das cerdas frontais, pouco abaixo do terço superior da parafaciália; faciália com cerdas cerca de 0,35 do comprimento da vibrissa, espessas, espaçadas, estendendo-se cerca de 0,70 da distância da vibrissa à base antenal; gena cerca de um terço da altura do olho.

Tórax preto; porção pré-escutelar, calo pós-alar e metade posterior da lateral pós-sutural do escuto e escutelo, castanhoalaranjados; este com pruinosidade marrom-ferrugínea. Cerdas escutelares: um par de cerdas basais; dois pares de laterais; um par de apicais médias, espessas e subdivergentes; várias cerdas curtas e médias por todas a região discal; um par de cerdas discais não conspícuas. Perna preta; garra tarsal anterior curta, menor que o segundo tarsômero da mesma perna. Asa: caliptra com pruinosidade marrom-escura.

Abdome (Fig. 105) variando do castanho ao castanhoescuro; escurecido centro-longitudinalmente, tergito 5 preto; leve pruinosidade marrom-ferrugínea-clara. Sintergito $1+2 \mathrm{com}$ cerca de seis pares de cerdas marginais medianas curtas e submédias. Tergito $3 \mathrm{com}$ uma fileira de cerdas marginais medianas médias e curtas, estas mais centrais; um grupo grande de cerdas discais curtas e médias. Tergito 4 com uma fileira de cerdas marginais medianas longas e médias; uma fileira de cerdas discais médias e curtas, desalinhada e descontínua no centro. Tergito 5 com várias cerdas discais a partir do terço basal.

Cercos e surstilos (Figs. 46, 75). Vista lateral, cercos com curvatura para trás e estreitamento bem acentuados próximo ao terço apical. Surtilos entre cerca de 0,70 a 0,75 do comprimento dos cercos.

Fêmea. Semelhante ao macho.

Distribuição geográfica. HAITI (La Selle, Port-au-Prince).

Comentário. Lescehnaultia arnaudi sp. nov. é semelhante a L. jurinioides (Townsend, 1895), diferindo desta pelo sintergito $1+2$ sem cerdas discais, pelo tergito 4 com somente uma fileira de cerdas discais e pelo par de cerdas discais escutelares não distinto das demais cerdas.

Material-tipo. Holótipo macho. HAITI. La Selle, La visite \& Vie (5700 ft.), 16-23.VII.1934, M. Bates col. (MCZC). Parátipos: idem, 1 fêmea, 16-23.VII.1934 (MCZC); idem, 1 macho (MZSP); idem, 1 macho (DZUP); Port-au-Prince, Kenskoff (4.600 ft.), 1 macho VII.1931 M. Bates col. (MCZC).

\section{Leschenaultia bergenstammi sp. nov.}

(Figs. 22, 50, 79, 108)

Diagnose. Antena preta; flagelômero mais que o dobro do comprimento do pedicelo. Sintergito $1+2$ com um ou dois pares de cerdas marginais medianas bem curtas. Tergito 3 com cerca de três pares de cerdas marginais medianas curtas, porém conspícuas; algumas cerdas discais espaçadas (não muito distinta da cerdosidade discal). Tergito 4 com um fileira de cerdas marginais medianas longas e médias. Garra tarsal anterior em geral maior que o segundo tarsômero da mesma perna

Comprimento. 12,0-13,5 mm.

Macho. Cabeça (Fig. 22) preta; pruinosidade cinza; vétice 

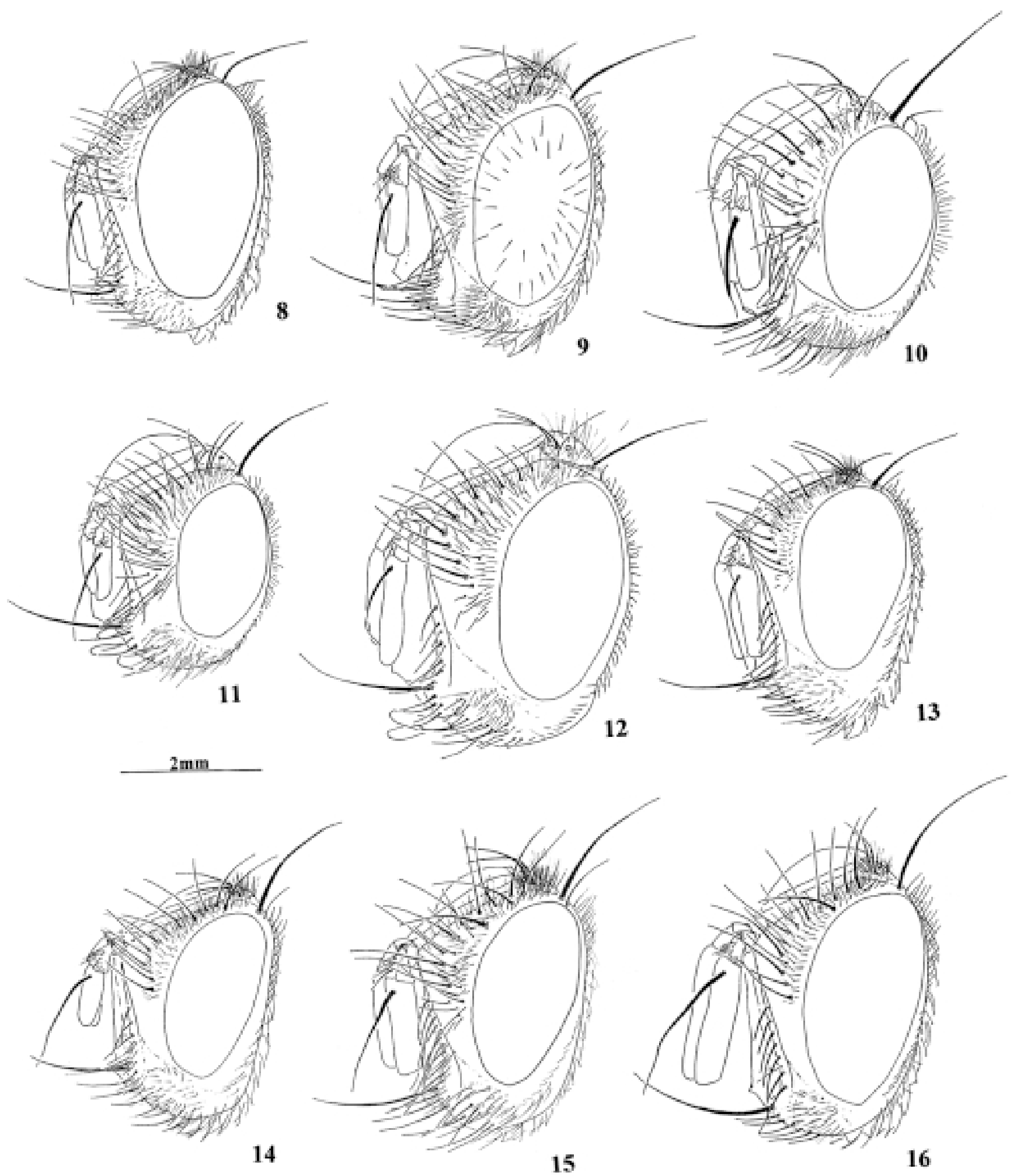

Figs. 8-16. Cabeça, vista látero-frontal (macho): 8, Leschenaultia bicolor (Macquart, 1846); 9, L. ciliata (Macquart, 1848); 10, L. exul (Townsend, 1892); 11, L. fulvipes (Bigot, 1887); 12, L. grossa Brooks, 1947; 13, L. halisidotae Brooks, 1947; 14, L. hospita Reinhard, 1952; 15, L. hystrix (Townsend, 1915); 16, L. jurinioides (Townsend, 1895). 
0,28 da largura da cabeça; pró-fronte projetada, um pouco acima da altura do olho; parafrontália pouco mais larga que a fronte; pró-fronte pouco mais que uma vez e meia a largura da fronte; parafaciália cerca de uma vez e meia a largura do flagelômero logo abaixo das cerdas frontais e pouco menos de uma vez e meia a largura deste na altura subapical; antena preta; flagelômero mais de duas vezes e meia o comprimento do pedicelo; palpo amarelo; cerdas ocelares normais e subdivergentes; cerdas frontais cerca de 10, com duas cerdas abaixo do final do pedicelo; pêlos da parafrontália estendendose até pouco abaixo do terço superior da parafaciália; faciália com uma fileira de cerdas espessas, de 0,30 a 0,40 do comprimento da vibrissa, ligeiramente espaçadas, estendendose 0,60 da distância da vibrissa à base da antena; gena cerca de 0,40 da altura do olho.

Tórax preto, mais acastanhado ou não na lateral do escuto; escutelo com pruinosidade marrom-ferrugínea. Cerdas escutelares: um par de cerdas basais; três pares de laterais (instáveis); um par de apicais curtas; várias cerdas curtas entre o par de cerdas discais. Perna castanho-escura; garra tarsal anterior em geral maior que o segundo tarsômero da mesma perna. Asa: caliptra com pruinosidade marrom-ferrugínea.

Abdome (Fig. 108) castanho-escuro; pruinosidade marromferrugínea-clara. Sintergito 1+2 com um ou dois pares de cerdas marginais medianas bem curtas. Tergito 3 com cerca de três pares de cerdas marginais medianas curtas, porém conspícuas, e algumas cerdas discais curtas espaçadas (não muito distintas da cerdosidade discal). Tergito 4 com uma fileira de cerdas marginais medianas longas e médias, estas mais centrais. Porção discal dos tergitos 3 e 4 mais cerdosa que pilosa.

Cercos e surstilos (Figs. 50, 79). Vista lateral, cercos subretos posteriormente, estreitando-se anteriormente da base para o ápice, mais acentuadamente a partir do terço apical. Surstilos entre cerca de 0,70 a 0,75 do comprimento dos cercos.

Distribuição geográfica. BRASIL (Santa Catarina) e Peru (San Martin).

Comentário. Difere de Leschenaultia braueri sp. nov. pelo tergito 3 com três pares de cerdas curtas, porém conspícuas, pela área discal dos tergitos 3 e 4 mais cerdosa que pilosa, e pela garra tarsal anterior em geral maior que o segundo tarsômero da mesma perna.

Material-tipo. Holótipo macho. PERU. San Martin: Bella Vista (1500 ft.), 9.XII.1946, J. C. Pallister \& J. Frank col. (AMNH). Parátipo. BRASIL. Santa Catarina: Corupá, 1 macho, I.1945, A. Maller, J. Frank col. (AMNH).

\section{Lescehnaultia bessi sp. nov.}

(Figs. 20, 47, 76, 106)

Diagnose. Calo pós-alar e escutelo castanhos; abdome com pruinosidade marrom-ferrugínea. Sintergito $1+2$ com cerca de três pares de cerdas marginais medianas curtas. Tergito 3 com várias cerdas marginais medianas espessas, médias e curtas; um grupo de cerdas discais espessas e curtas. Tergito 4 com uma fileira irregular de cerdas marginais medianas; uma fileira de cerdas discais.

Comprimento. 11,5-13,0 mm.

Macho. Cabeça (Fig 20): pruinosidade cinza sobre fundo preto; sulco genal castanho-avermelhado; fronte marrom; vértice 0,24 da largura da cabeça; pró-fronte projetada, acima da metade da altura do olho; parafrontália pouco mais larga que a fronte; pró-fronte cerca de uma vez e meia da largura da fronte; parafaciália pouco mais larga que o flagelômero logo abaixo das cerdas frontais e mais estreita na altura subapical deste artículo; antena preta; flagelômero o dobro ou mais do comprimento do pedicelo; palpo maxilar amarelo; cerdas ocelares normais; cerdas verticais externas reduzidas ou ausentes; cerdas frontais cerca de nove, estendendo-se até pouco abaixo do terço superior da parafaciália, mais ou menos estendendo-se até o final do pedicelo, par superior reclinado; pêlos externos da parafrontália estendendo-se até logo abaixo das cerdas frontais, estendendo-se até pouco antes da metade superior parafaciália; faciália com cerdas de 0,20 à um pouco mais de 0,30 do comprimento da vibrissa, estendendo-se um pouco mais da metade da distância da vibrissa à base da antena; gena cerca de um terço da altura do olho.

Tórax preto; calo pós-alar e escutelo castanhos, pruinosidade marrom-ferrugínea. Cerdas escutelares: um par de cerdas basais; três pares de laterais (sub-basais fracas ou ausentes); um par de apicais espessas, relativamente médias e subdivergentes; várias cerdas curtas entre o par de cerdas discais. Perna preta. Asa: caliptra com pruinosidade marromferrugínea-escura.

Abdome (Fig. 106) castanho-escuro; pruinosidade marromferrugínea. Sintergito 1+2 com cerca de três pares de cerdas marginais medianas curtas. Tergito 3 com uma fileira de cerdas marginais medianas espessas, médias e curtas, interrompida ou não nas laterais; um grupo de cerdas discais curtas e espessas. Tergito 4 com uma fileira de cerdas marginais medianas longas e médias, afastadas da margem na porção mediana; uma fileira desalinhada de cerdas discais médias e curtas.

Cercos e surstilos (Figs. 47, 76). Vista lateral, cercos bem alongados, sub-retos posteriormente, e estreitos da base para o ápice anteriomente; surstilos estreitando-se acentuadamente médio-apicalmente e cerca de 0,70 ou pouco menos do comprimento dos cercos.

Distribuição geográfica. BRASIL (São Paulo e Santa Catarina).

Comentário. Esta espécie é semelhante à L. hospita Reinhard, 1952, diferindo pelo abdome castanho-escuro e pelo flagelômero com o dobro ou mais do comprimento do pedicelo.

Material-tipo. Holótipo macho. BRASIL. Santa Catarina: Nova Teutônia, XI.1966 F. Plaumann col. (MZSP). Parátipos: idem, 3 machos (MZSP).

Material adicional examinado. BRASIL. São Paulo: Itu (Faz. Pau d'Alho), 2 machos, 25.VII.1965, U. Martins col. (MZSP). Santa Catarina: Nova Teutônia, 41 machos, IV.1964-XI.1971, F. Plaumann col. (MZSP). 

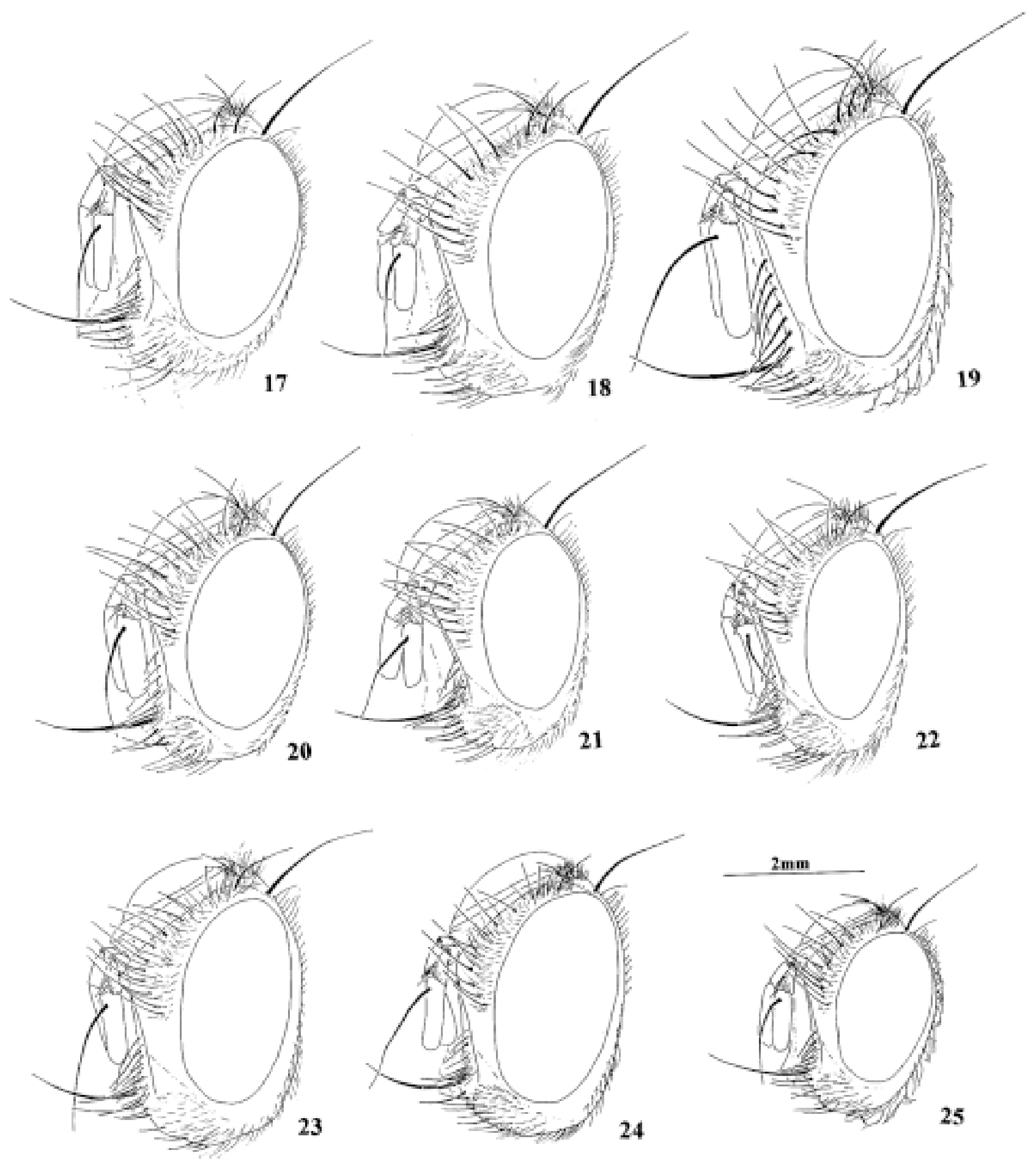

Figs. 17-25. Cabeça, vista látero-frontal (macho): 17, Leschenaultia leucophrys (Wiedemann, 1830); 18, L. aldrichi sp. nov.; 19, L. arnaudi sp.

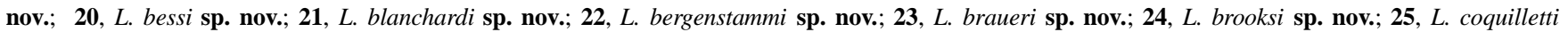
sp. nov. 


\section{Leschenaultia bigoti sp. nov.} (Figs. 48, 77)

Diagnose. Cabeça com densa pruinosidade cinza e levemente amarelada, dependendo do ângulo de luz; pêlos occipitais amarelos. Abdome castanho, escurecido centrolongitudinalmente. Sintergito $1+2$ e tergito 3 com cerca de quatro pares de cerdas marginais medianas curtas. Tergito 4 com uma fileira de cerdas marginais medianas. Tergitos 3 e 4 com um grupo de cerdas discais curtas.

Comprimento. 9,0-15,0 mm.

Macho. Cabeça com parafrontália e porção superior da parafaciália pretas; face, faciália e sulco genal pardos; densa pruinosidade cinza e levemente amarelada; fronte marromescura; vértice 0,24 da largura da cabeça; pró-fronte levemente projetada, mais ou menos na metade da altura do olho; parafrontália cerca de uma vez e meia a largura da fronte; prófronte cerca do dobro da largura fronte; parafaciália cerca do dobro da largura do flagelômero logo abaixo das cerdas frontais e pouco menos do dobro da largura deste na altura subapical; antena preta; flagelômero pouco menos que o dobro do comprimento do pedicelo; palpo amarelo; cerdas ocelares curtas; cerdas verticais externas reduzidas; cerdas frontais cerca de 12, estendendo-se até o terço superior da parafaciália, dois ou três pares superiores fracos e reclinados; pêlos da parafrontália estendendo-se até logo abaixo das cerdas frontais; faciália com cerdas finas, variando de 0,20 a 0,40 do comprimento da vibrissa, estendendo-se 0,50 ou menos da distância da vibrissa à base da antena; gena cerca de um terço da altura do olho; pêlos occipitais amarelados.

Tórax preto; calo pós-alar e escutelo castanhos, este com pruinosidade marrom-ferrugínea. Cerdas escutelares: um par de cerdas basais; três pares de laterais; um par de apicais curtas; um conjunto de cerdas curtas entre o par de cerdas discais. Perna castanha. Asa: caliptra com pruinosidade marrom-escura.

Abdome castanho, escurecido centro-logitudinalmente. Sintergito $1+2$ e tergito 3 com cerca de quatro pares de cerdas marginais medianas bem curtas. Tergito 4 com uma fileira de cerdas marginais medianas longas, médias e curtas, as últimas mais centrais. Tergitos 3 e 4 com um grupo de cerdas discais curtas.

Cercos e surstilos (Figs. 48, 77) relativamente curtos. Vista lateral, cercos curvados para trás pouco acima do terço apical, com ápice subarredondado. Surstilos cerca de 0,80 do comprimento dos cercos.

Fêmea. Cabeça com vértice 0,27 da largura da cabeça; parafrontália pouco menos do dobro da fronte; pró-fronte pouco mais que o dobro da largura da fronte; parafaciália pouco mais que uma vez e meia a largura do flagelômero logo abaixo das cerdas frontais e pouco menos que uma vez e meia na altura subapical; cerdas ocelares curtas; cerdas verticais externas curtas; cerdas frontais cerca de nove, espessas, par superior bem reclinado; faciália com cerdas estendendo-se pouco menos de 0,50 da distância da vibrissa à base da antena. Abdome: sintergito $1+2$ com três pares de cerdas marginais medianas curtas e espessas. Tergito 3 com uma fileira de cerdas marginais medianas médias e curtas, estas mais centrais; um conjunto de cerdas discais. Tergito 4 com uma fileira de cerdas marginais medianas longas e médias, estas mais centrais; uma fileira de cerdas discais médias e curtas.

Distribuição geográfica. MÉXICO; HONDURAS; COSTA RICA; EQUADOR; PERU; BRASIL (Região Centro-Oeste).

Comentário. Esta espécie é semelhante à L. leucophrys (Wiedemann, 1830), diferindo, principalmente, pela cabeça com pruinosidade cinza e levemente amarelada e pela morfologia dos cercos e surstilos (Figs. 48 e 77).

Material-tipo. Holótipo macho. PERU. Huanuco: Tingo Maria (2.200 ft.), 28.X.1946 J. C. Pallister \& J. Frank col. (AMNH). Parátipos: idem, 1 macho, 14.X.1946 (AMNH); idem, 1 macho, 27.V.1947 (MZSP).

Material adicional examinado. MÉXICO. Nayarit: Vc. Compostela, 1 fêmea, 24.VI.1933 (AMNH). HONDURAS. Tegucigalpa, 1 macho, 5.IV.1919, F. J. Dver col. (AMNH); Corocito, 1 macho, 3.IV.1924, C. H. Curran col. (AMNH). COSTA RICA. El Rodeo, 1 macho, 13.IV.1946 F.M Brown col. (AMNH); Província Alajuela, Fortuna, 1 macho, 18.II.1964, H. E. Evans col. (MCZC). BRASIL. Mato Grosso: Chapada, 1 macho, XI (AMNH; ex-coleção Willistons, S.W.); Maracaju, , AMNH II.1937 (MZSP). Goiás: Anápolis, 1 macho, II.1936 (serviço Febre Amarela, M.E.S.) (MZSP). EQUADOR. Limon, 1 fêmea, I.1946, Z. Muller col. (AMNH). Quito: Sto. Domingo, 1 fêmea, I.1971, L. E. Peña col. (MZSP). PERU. Loreto: Rio Huallaga, 1 fêmea, X.1926, H. Bassler col. (AMNH). San Martin: Moyobamaba, 1 fêmea, 5.XII.1925, H. Bassler col. (AMNH). Bella Vista, 1 macho, 8.XII.1946, J. C. Pallister \& F. Johnson col. (AMNH). Cuzco: Quiroz (Rio Paucartambo), 1 macho, 1932 (AMNH).

\section{Leschenaultia blanchardi sp. nov.} (Figs. 21, 49, 78, 107)

Diagnose. Pêlos da parafrontália estendendo-se até a metade da parafaciália; região pré-escutelar castanhoalaranjada. Sintergito $1+2$ com três a seis pares de cerdas marginais medianas curtas. Tergito 3 com cerca de cinco pares de cerdas marginais medianas submédias e curtas; um pequeno grupo de cerdas discais curtas. Tergito 4 com uma fileira de cerdas marginais medianas.

Comprimento: $11,5-13,5 \mathrm{~mm}$.

Macho. Cabeça (Fig. 21) preta; pruinosidade cinza; vértice 0,25 da largura da cabeça; pró-fronte projetada, acima da metade da altura do olho; parafrontália cerca de uma vez e meia a largura da fronte; pró-fronte cerca do dobro da largura da fronte; parafaciália cerca do dobro da largura do flagelômero logo abaixo das cerdas frontais e cerca de uma vez e meia a largura deste na altura subapical; antena preta; flagelômero uma vez e meia o comprimento do pedicelo; palpo amarelo-escurecido; cerdas ocelares subalongadas, subdivergentes; cerdas verticais externas curtas; cerdas frontais cerca de 11 , estendendo-se um pouco abaixo do final do pedicelo, pares superiores finos; pêlos da parafrontália estendendo-se até a metade da parafaciália; faciália com cerdas variando de 0,30 a pouco mais de 0,50 do comprimento da vibrissa, espaçadas, estendendo-se 0,50 da distância da vibrissa à base da antena; 

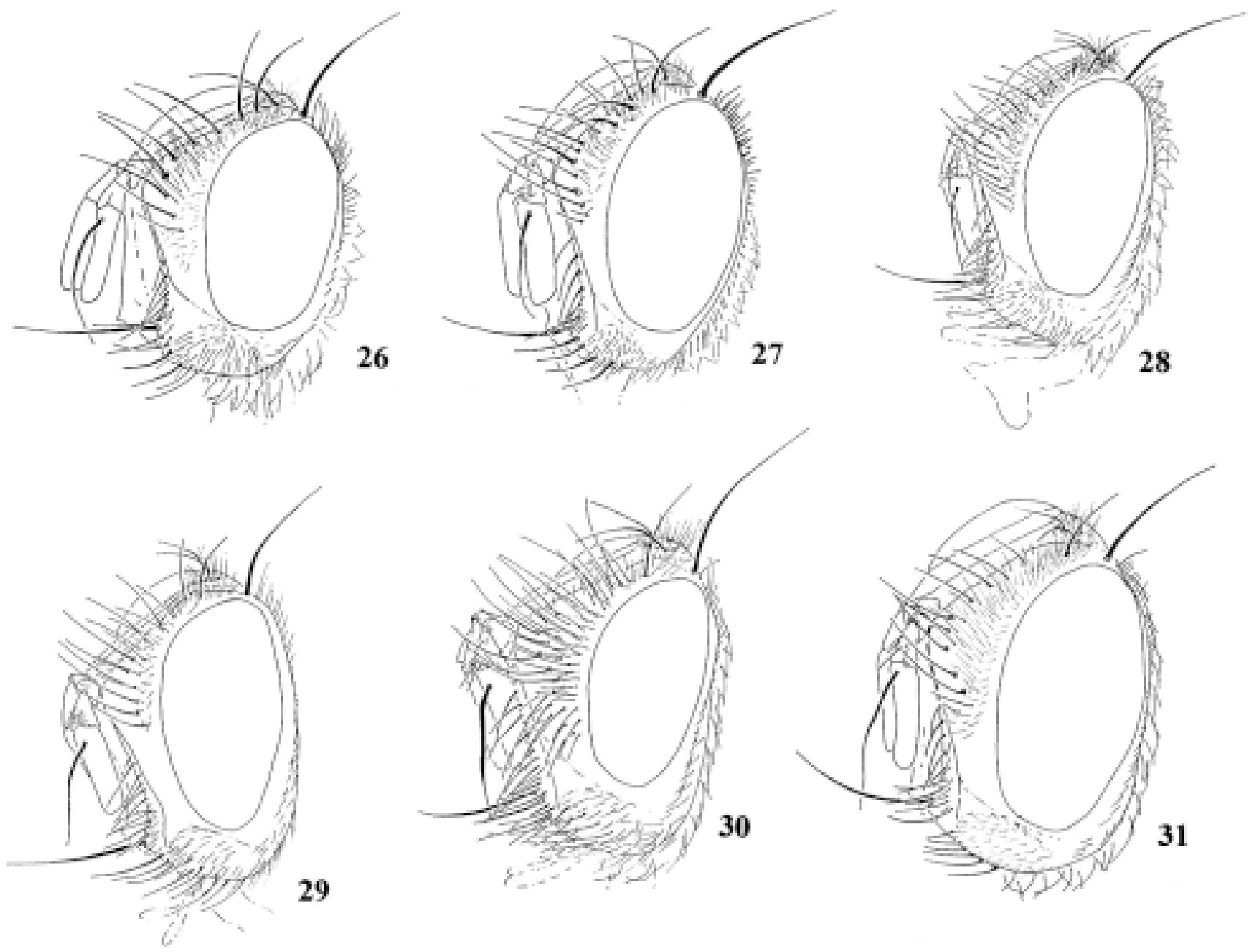

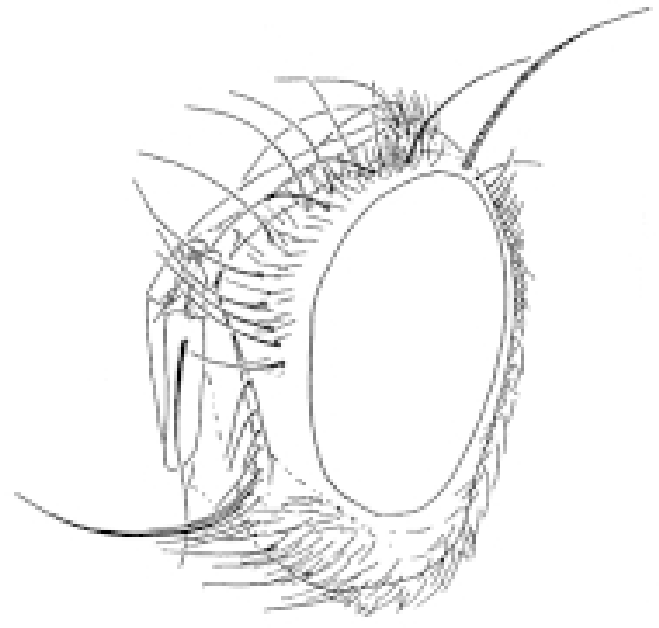

32

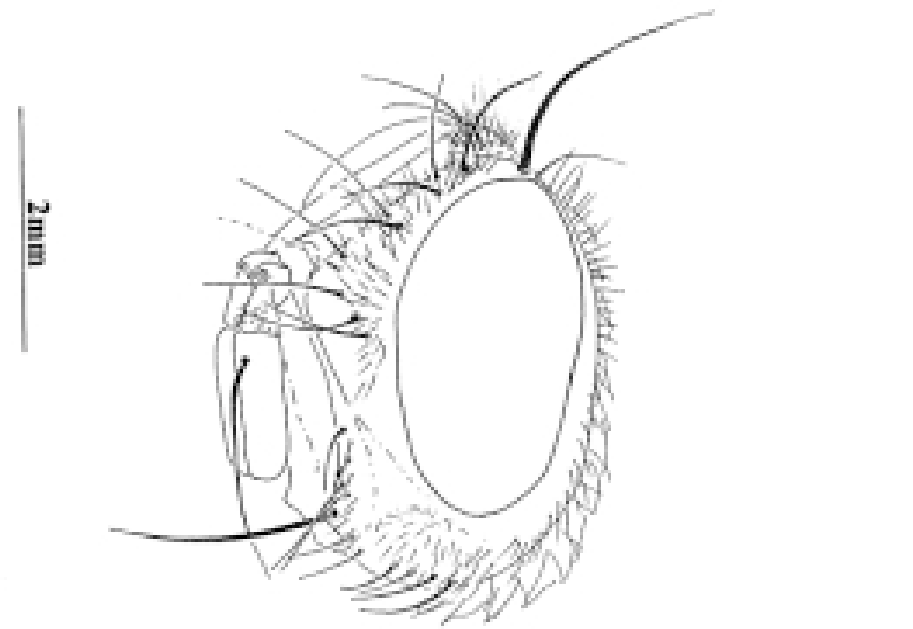

33

Figs. 26-33. Cabeça, vista látero-frontal (macho): 26, Leschenaultia cortesi sp. nov.; 27, L. loewi sp. nov.; 28, L. macquarti sp. nov.; 29, $L$. reinhardi sp. nov.; 30, L. sabroskyi sp. nov.; 31, L. thompsoni sp. nov.; 32, L. townsendi $\mathbf{s p .}$ nov.; 33 (fêmea), L. montagna (Townsend, 1912). 
cerdas finas dispostas entre e próximo às cerdas mais espessas da faciália; gena cerca de 0,40 da altura da olho.

Tórax preto; pruinosidade cinza, ligeiramente marrom em vista posterior; calo pós-alar, porção pré-escutelar e escutelo castanho-alaranjados. Cerdas escutelares:um par de cerdas basais; dois pares de laterais; um par de apicais médias, espessas e subdivergentes; várias cerdas curtas e espessas entre o par de cerdas discais e próximas às apicais. Perna preta ou castanho-escura; tíbias anterior e média mais claras. Asa: caliptra com pruinosidade marrom-escura.

Abdome (Fig. 107) castanho, escurecido centrolongitudinalmente; pruinosidade marrom-ferrugínea. Sintergito $1+2$ com três a seis pares de cerdas marginais medianas curtas. Tergito 3 com cerca de cinco pares de cerdas marginais medianas submédias e curtas, estas mais centrais, afastadas da margem; pequeno grupo de cerdas discais espessas e curtas. Tergito 4 com uma fileira de cerdas marginais medianas longas e médias, estas mais centrais, distantes da margem.

Cercos e surstilos (Figs. 49, 78) relativamente curtos. Vista lateral, cercos com porção posterior sub-reta, levemente curvados no terço apical, e porção anterior estreitando-se da base para o ápice, esse subarredondado. Surstilos entre 0,75 a 0,80 do comprimento dos cercos.

Fêmea. Cabeça com vértice 0,29 da largura da cabeça; cerdas verticais externas cerca de 0,40 das internas; cerdas adjacentes à fileira de cerdas da faciália bastante reduzidas em número. Abdome preto com quetotaxia mais forte do que a do macho.

\section{Distribuição geográfica. EQUADOR.}

Comentário. Ver comentário em Leschenaultia aldrichi $\mathbf{s p . ~}$ nov. (p. 23).

Material-tipo. Holótipo macho. EQUADOR. Cuenca, Azuay (2000m), 22.VIII.1946 Z. Muller col. (AMNH). Parátipos: idem, 1 fêmea (AMNH); idem, 1 macho (MZSP); idem, 1 macho (DZUP); Tarqui (2700m), 1 macho, 1 fêmea, VIII.1947, Z. Muller col. (AMNH); Baños, 2 machos, 20.XI.1935, F. M. Brown col. (AMNH).

\section{Leschenaultia braueri sp. nov.}

(Figs. 23, 51, 80, 109)

Diagnose. Antena preta, base do flagelômero castanhoalaranjada; escutelo castanho, pruinosidade marrom-ferrugínea. Garra tarsal relativamente curta, menor que o segundo tarsômero da mesma perna. Sintergito $1+2 \mathrm{com}$ um ou dois pares de cerdas marginais medianas bem curtas. Tergito $3 \mathrm{com}$ cerca de dois pares de cerdas marginais medianas bem curtas; cerdas discais ausentes ou pouco conspícuas e em pequeno grupo. Tergito 4 com uma fileira de cerdas marginais medianas longas e curtas.

Comprimento. 12,0-15,5 mm.

Macho. Cabeça (Fig. 23) preta; face e faciália pardas; pruinosidade cinza; fronte marrom; vértice 0,24 da largura da cabeça; pró-fronte levemente projetada, pouco acima da metade da altura do olho; parafrontália pouco mais larga que a fronte; pró-fronte pouco mais que uma vez e meia a largura da fronte; parafaciália cerca do dobro da largura do flagelômero logo abaixo das cerdas frontais e pouco menos do dobro da largura deste na altura subapical; antena preta, base do flagelômero castanho-alaranjada; este entre uma vez e meia e o dobro do comprimento do pedicelo; palpo amarelo; cerdas ocelares fracas; cerdas verticais externas reduzidas; cerdas frontais cerca de 12, estendendo-se pouco abaixo do pedicelo, pares superiores curtos, finos, ligeiramente reclinados; pêlos da parafrontália estendendo-se até pouco abaixo do terço superior da parafaciália; faciália com uma fileira de cerdas de 0,25 a 0,50 do comprimento da vibrissa, estendendo-se de 0,40 a 0,50 da distância da vibrissa à base da antena, algumas cerdas mais finas e curtas entre e próximo às cerdas da fileira principal; gena pouco mais que um terço da altura do olho.

Tórax preto; escutelo castanho, pruinosidade marromferrugínea;. Cerdas escutelares: um par de cerdas basais; três pares de laterais; um par de apicais curtas e não convergentes; várias cerdas curtas entre o par de cerdas discais. Perna castanha; garra tarsal anterior relativamente curta, menor que o segundo tarsômero da mesma perna. Asa: caliptra com pruinosidade marrom.

Abdome (Fig. 109) castanho-escuro; pruinosidade marromferrugínea, mais forte no tergito 5 . Sintergito $1+2$ com um ou dois pares de cerdas marginais medianas bem curtas. Tergito 3 com cerca de dois pares de cerdas marginais medianas bem curtas, cerdas discais ausentes ou, quando presentes, não muito conspícuas, espaçadas e em pequeno grupo. Tergito 4 com uma fileira de cerdas marginais medianas longas e curtas.

Cercos e surstilos (Figs. 51, 80) relativamente curtos. Vista lateral, cercos levemente curvados para trás na porção posterior e estreitando-se suavemente anteriormente a partir do terço apical. Surstilos cerca de 0,75 a 0,80 do comprimento dos cercos.

Distribuição geográfica: MÉXICO; VENEZUELA; BRASIL.

Comentário. Leschenaultia braueri pode ser confundida com L. bicolor (Macquart, 1846) quando examinada rapidamente. No entanto, difere desta pelas cerdas marginais medianas bem curtas nos sintergito $1+2$ e tergito 3 (Fig. 109) e pelo par de cerdas apicais escutelares curtas, espessas e não convergentes.

Material-tipo. Holótipo macho. BRASIL. Mato Grosso: Chapada, IX (AMNH; ex-coleção S. Williston). Parátipos: idem, 2 machos (AMNH); idem, 1 macho (MZSP).

Material adicional examinado. MÉXICO. Tabasco: Tenosique, 2 machos, I.1945, M. Gerra \& J. Frank, J col. (AMNH). VENEZUELA. Amazonas: Mt. Duida, 1 macho, 17.XI. 1929 (AMNH). BRASIL. Pará: C. Araguaia, 1 macho, 19-31.I.1983, J. A. Rafael col. (MZSP). Goiás: Anápolis, 1 macho, 7.X.1936 (MZSP). Mato Grosso: Maracaju, 1 macho, III.1937, Lane col. (MZSP); Chapada, 19 m, 1.IX, H. Smith col. (AMNH; ex-coleção Williston, S.). Minas Gerais: Arceburgo, 2 machos, III.1945, M. P. Barreto col. (MZSP). São Paulo: Cajuru (Cássia dos Coqueiros), 1 macho, X.1954, M. P. Barreto col. (MZSP). Paraná: Rolândia, 1 macho, IV.1948, A. Maller \& J. Frank col. (AMNH). Santa Catarina: Nova Teutônia, 2 machos, IV.1964 F. Plaumman col. (MZSP). 

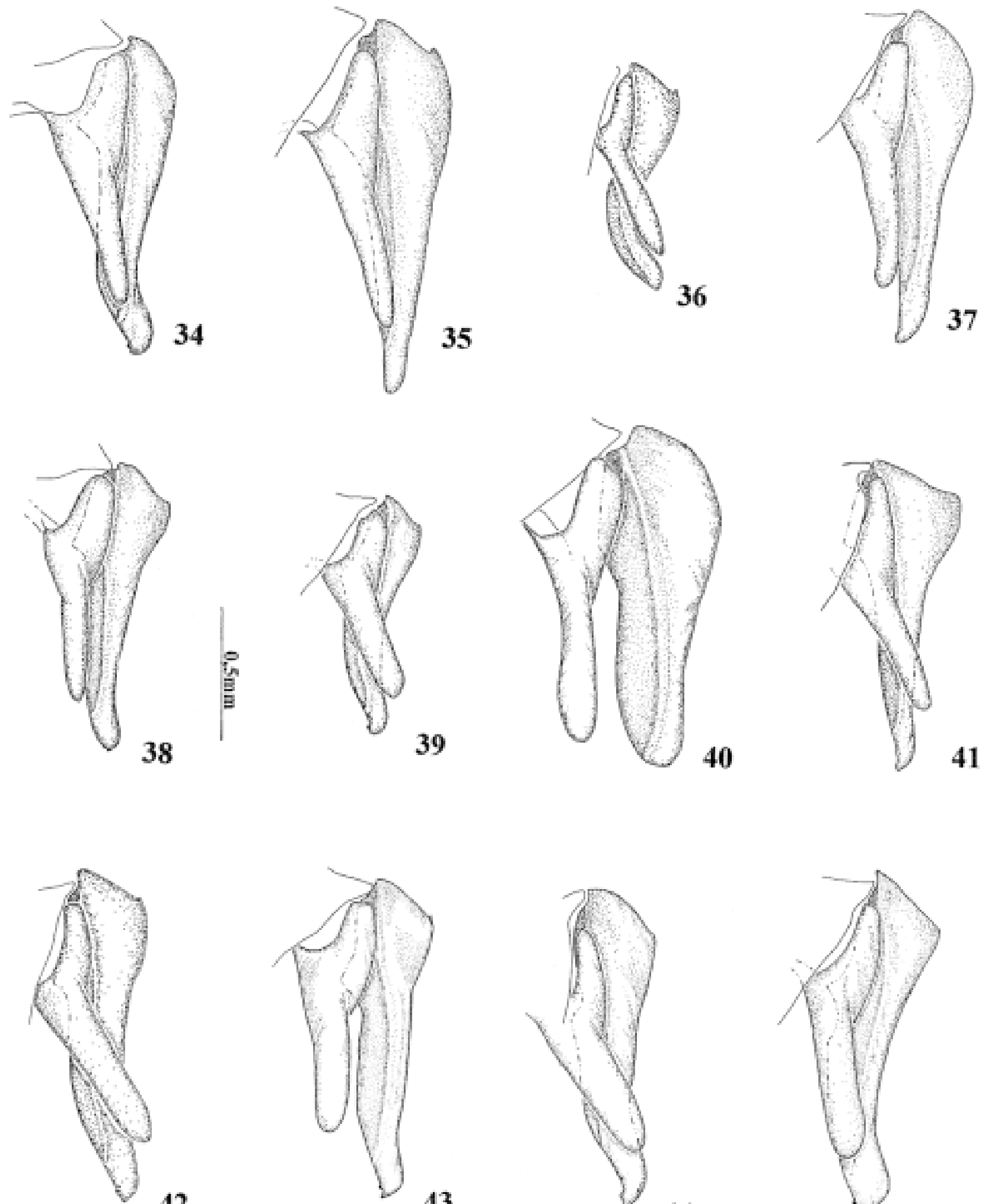

42
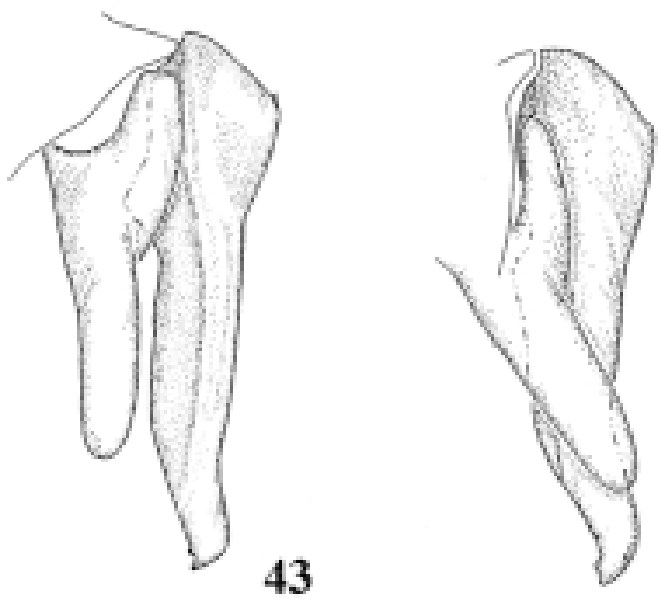

44

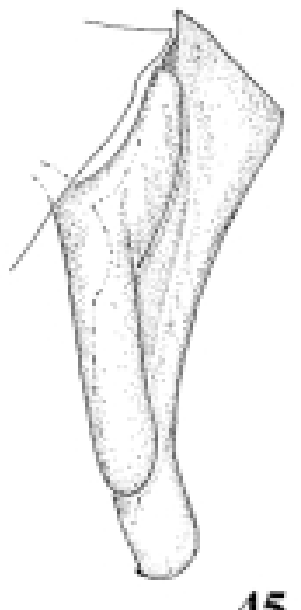

Figs. 34-45. Cercos e surstilos, vista lateral: 34, Leschenaultia adusta (Loew, 1872); 35, L. americana (Brauer \& Bergenstamm, 1893); 36, L. bicolor (Macquart, 1846); 37, L. ciliata (Macquart, 1848); 38, L. exul (Townsend, 1892); 39, L. fulvipes (Bigot, 1887); 40, L. grossa Brooks, 1947; 41, L. halisidotae Brooks, 1947; 42, L. hospita Reinhard, 1952; 43, L. jurinioides (Townsend, 1895); 44, L. leucophrys (Wiedemann, 1830); 45, L. aldrichi sp. nov. 


\section{Leschenaultia brooksi sp. nov.}

(Figs. 24, 52, 81)

Diagnose. Antena preta; flagelômero entre uma vez e meia e o dobro do comprimento do pedicelo. Garra tarsal anterior em geral maior que o segundo tarsômero da mesma perna. Sintergito $1+2 \mathrm{com}$ um par e tergito $3 \mathrm{com}$ menos de quatro pares de cerdas marginais medianas pouco conspícuas. Tergito $4 \mathrm{com}$ uma fileira de cerdas marginais medianas longas e médias

Comprimento. 10,5-14,0mm.

Macho. Cabeça (Fig. 24) preta; pruinosidade cinza; vértice 0,25 da largura da cabeça; parafaciália cerca de uma vez e meia a largura da fronte; pró-fronte cerca do dobro da fronte; parafaciália cerca do bodro da largura do flagelômero logo abaixo das cerdas frontais e uma vez e meia a largura deste na altura subapical; antena preta; flagelômero entre uma vez e meia e o dobro do comprimento do pedicelo; palpo amarelo; cerdas ocelares curtas; cerdas verticais externas reduzidas; cerdas frontais cerca de nove, estendendo-se pouco abaixo do final do pedicelo; pêlos da parafrontália estendendo-se até pouco abaixo do terço superior da parafaciália; faciália com uma fileira de cerdas de 0,11 a 0,30 do comprimento da vibrissa, estendendo-se de 0,50 a 0,60 da distância da vibrissa à base da antena, margeadas por algumas cerdas mais curtas e mais finas até a metade da fileira. Gena cerca de um terço da altura do olho.

Tórax e asa semelhantes aos de Leschenaultia braueri sp.nov. Garra tarsal anterior em geral maior que o segundo tarsômero da mesma perna.

Abdome castanho; pruinosidade marrom-ferrugínea. Sintergito $1+2 \mathrm{com}$ um par e tergito $3 \mathrm{com}$ menos de quatro pares de cerdas marginais medianas pouco conspícuas. Tergito 4 com uma fileira de cerdas marginais medianas longas e médias. Tergitos 3 e 4 com cerdas discais variáveis.

Cercos e surstilos (Figs. 52, 81) relativemente curtos. Vista lateral, cercos sub-retos, largura subigual na metade apical e estreitando-se suavemente próximo ao ápice. Surstilos cerca de 0,80 do comprimento dos cercos.

Distribuição geográfica. MÉXICO; PANAMÁ; PERU; BRASIL.

Comentário. Esta espécie apresenta dois padrões de quetotaxia abdominal, um semelhante ao de Leschenaultia braueri sp. nov., da qual difere por apresentar a garra tarsal anterior em geral maior que o segundo tarsômero da mesma perna, e outro semelhante aos de L. leucophrys (Wiedemann, 1830) e L. currani sp. nov., das quais difere pela quetotaxia abdominal mais fraca.

Material-tipo. Holótipo macho. BRASIL. Rio de Janeiro: Universidade Rural, VII. 1960, O. Tavares col. (MZSP). Parátipo: idem, 1 macho, IX.1960 (MZSP).

Material adicional examinado. MÉXICO. Vera Cruz: Poza Rica, 1 macho, 2.VIII.1955 C. Vaurie col. (AMNH). PANAMÁ. Pueblo Nuevo, 1 macho, 22.II.1945, C. D. Michener col. (AMNH). PERU. Junin: San Ramon (1000 m., Estancia Naranja), 1 macho, 20-27.VII.1965, P.
Wygodzinsky col. (AMNH). BRASIL. Mato Grosso: Chapada, 3 machos, IX/XII (AMNH; ex-coleção S. Williston). Goiás: Anápolis, 1 macho, II.1936 (Serviço Febre Amarela, M.E.S.) (MZSP). São Paulo: Araçatuba (Córrego Azul), 1 macho, II.1946, E. X. Rabello, E. X col. (MZSP).

\section{Leschenaultia coquilletti sp. nov.}

(Figs. 25, 53, 82, 110)

Diagnose. Sintergito $1+2$ com cerca de quatro pares de cerdas marginais medianas curtas; tergito 3 com cinco pares de cerdas marginais medianas curtas, espessas e uniformes; tergito 4 com uma fileira de cerdas marginais medianas.

Comprimento. 10,0-12,5 mm.

Macho. Cabeça (Fig. 25) preta; pruinosidade cinza; sulco genal castanho-avermelhado; fronte marrom-escura; vértice 0,25 da largura da cabeça; pró-fronte levemente projetada, pouco acima da metade altura do olho; parafrontália menos de uma vez e meia da largura da fronte; pró-fronte mais de uma vez e meia a largura da fronte; parafaciália cerca de uma vez e meia a largura do flagelômero logo abaixo das cerdas frontais e pouco menos de uma vez e meia a largura deste na altura subapical; antena preta; flagelômero pouco mais de uma vez e meia o comprimento do pedicelo; palpo amarelo-escurecido; cerdas ocelares normais; cerdas frontais cerca de 11, estendendo-se até logo abaixo do final pedicelo, par superior curto e subreclinado; parafrontália com pêlos estendendo-se até pouco abaixo do terço superior da parafaciália; uma fileira de cerdas bem finas próximo às frontais; faciália com cerdas de 0,25 a 0,40 do comprimento da vibrissa, estendendo-se cerca de 0,50 da distância da vibrissa à base da antena, margeadas por algumas cerdas menores; gena cerca de 0,40 da altura do olho.

Tórax preto; escutelo castanho, pruinosidade marromferrugínea. Cerdas escutelares: um par de cerdas basais; três pares de laterais (sub-basais curtas ou ausentes); um par de apicais curtas e espessas; várias cerdas curtas entre o par de cerdas discais. Perna castanho-escura. Asa: caliptra com pruinosidade marrom-escura.

Abdome (Fig. 110) castanho-escuro; pruinosidade marromferrugínea, acentuada no tergito 5 . Sintergito $1+2$ com cerca de quatro pares de cerdas marginais medianas curtas. Tergito 3 com cerca de cinco pares de cerdas marginais medianas curtas e espessas. Tergito 4 com uma fileira de cerdas marginais medianas longas, médias e curtas, estas mais centrais. Tergito 3 com ou sem pequeno grupo de cerdas discais.

Cercos e surstilos (Figs. 53, 82). Vista lateral, cercos com curvatura acentuada para trás, ligeiramente estreito medianamente e abaulado anteriormente da metade para o ápice. Surstilos cerca de 0,75 a 0,80 do comprimento dos cercos.

Distribuição geográfica. BRASIL (Santa Catarina).

Comentário. Leschenaultia coquilletti difere de $L$. bergenstammi sp. nov. e de Leschenaultia braueri sp. nov. por apresentar cerdas marginais medianas curtas, porém bem distintas, nos sintergito $1+2$ e tergito 3 .

Material-tipo. Holótipo macho. BRASIL. Santa Catarina: Nova 

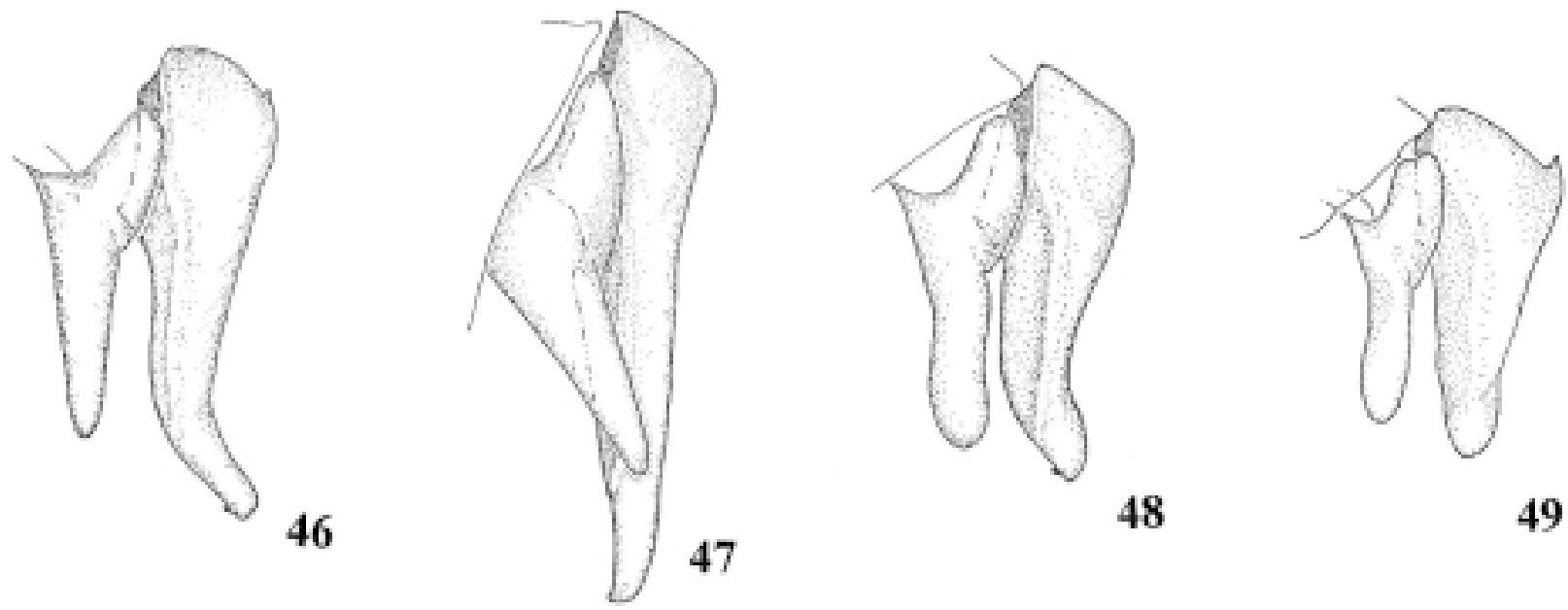

48

49
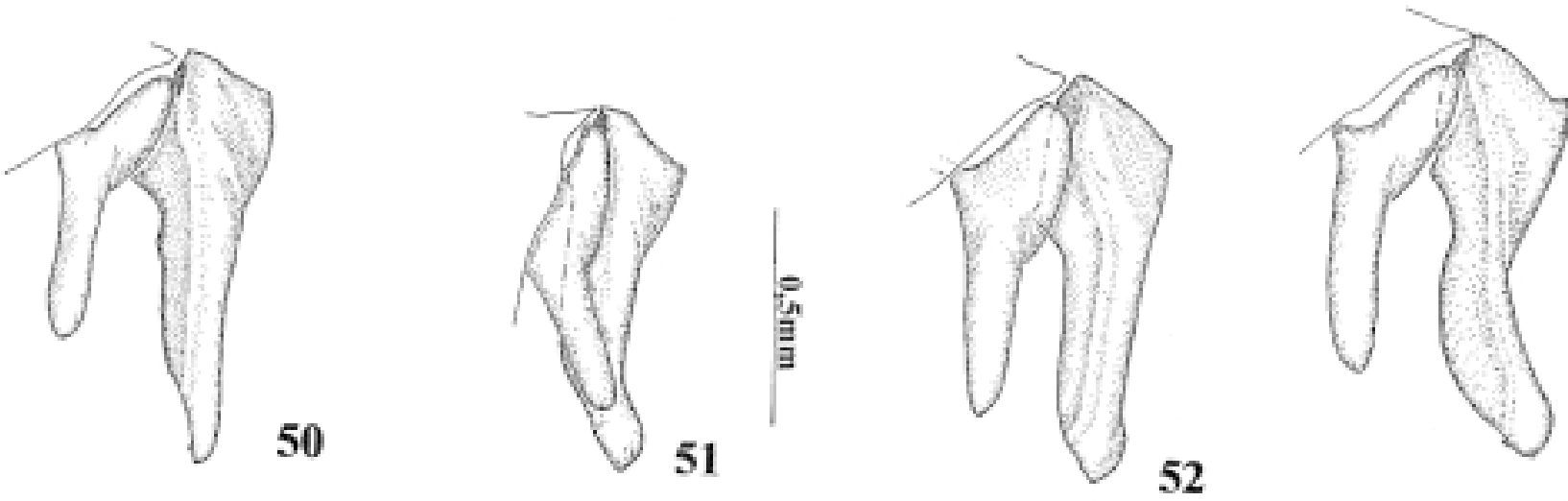

51

53
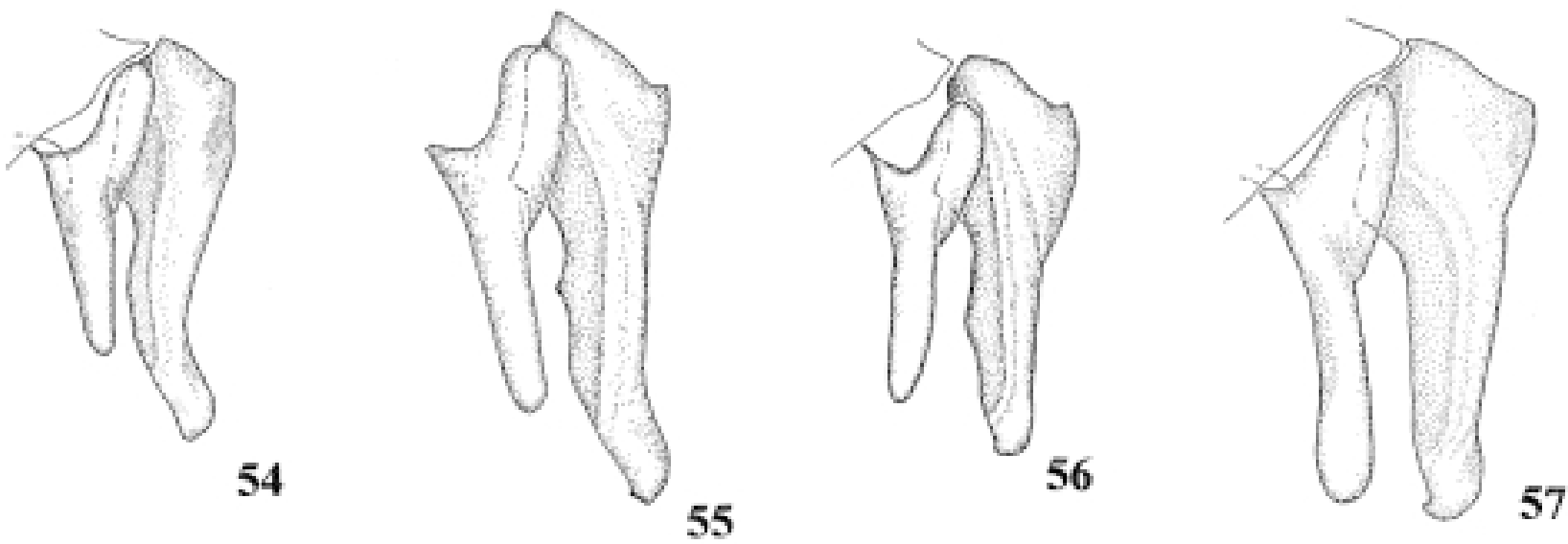

Figs. 46-57. Cercos e surstilos, vista lateral: 46, Leschenaultia arnaudi sp. nov.; 47, L. bessi sp. nov.; 48, L. bigoti sp. nov.; 49, L. blanchardi $\mathbf{\text { sp. }}$ nov.; 50, L. bergenstammi sp. nov.; 51, L. braueri sp. nov.; 52, L. brooksi sp. nov.; 53, L. coquilletti sp. nov.; 54, L. cortesi sp. nov.; 55, L. currani sp. nov.; 56, L. loewi sp. nov.; 57, L. macquarti sp. nov. 
Teutônia, VII.1967, F. Plaumann col. (MZSP). Parátipos: idem, 3 machos, I.1966-II.1971 (MZSP).

\section{Leschenaultia cortesi sp. nov.}

(Figs. 26, 54, 83, 111)

Diagnose. Cerdas frontais e ocelares espessas; pêlos da parafrontália estendendo-se até logo abaixo da metade da parafaciália; escutelo com um par de cerdas basais e dois pares de laterais. Sintergito $1+2$ com dois ou três pares de cerdas marginais medianas. Tergito $3 \mathrm{com}$ uma fileira de cerdas marginais medianas médias e curtas; um grupo de cerdas discais. Tergito 4 com uma fileira de cerdas marginais medianas longas e médias; uma fileira de cerdas discais médias e curtas.

Comprimento. $12,0 \mathrm{~mm}$.

Macho. Cabeça (Fig. 26) preta; pruinosidade cinza; face e porção inferior da parafaciália levemente mais claras; vértice 0,25 da largura da cabeça; pró-fronte projetada, acima da metade da altura do olho; parafrontália cerca de uma vez e meia da largura fronte; pró-fronte cerca de duas vezes a largura da fronte; parafaciália estreitando-se na porção inferior, cerca de duas vezes a largura do flagelômero logo abaixo das cerdas frontais e cerca de uma vez e meia a largura deste na altura subapical; antena preta, base do flagelômero alaranjada, este cerca de duas vezes o comprimento do pedicelo; palpo amareloalaranjado; cerdas ocelares longas, espessas e subdivergentes; cerdas verticais externas reduzidas; cerdas frontais cerca de oito, longas, espessas e estendendo-se logo abaixo do final do pedicelo, par superior fortemente reclinado; pêlos da parafrontália estendendo-se até logo abaixo da metade superior da parafaciália; faciália com cerdas de 0,30 a 0,50 do comprimento da vibrissa, estendendo-se 0,50 da distância da vibrissa à base da antena, margeadas por cerdas mais curtas $\mathrm{e}$ finas; gena cerca de 0,40 da altura do olho.

Tórax preto; escutelo castanho-alaranjado, pruinosidade cinza e levemente amarelada; duas ou três cerdas catepisternais. Cerdas escutelares: um par de basais; dois pares de laterais; um par de apicais relativamente curtas e subdivergentes; várias cerdas curtas e moderadamente espessas entre o par de cerdas discais. Perna castanha. Asa: caliptra com pruinosidade marrom.

Abdome (Fig. 111) castanho; pruinosidade marrom. Sintergito $1+2$ com dois ou três pares de cerdas marginais medianas curtas. Tergito 3 com uma fileira de margianais médias e curtas e um grupo de cerdas discais curtas. Tergito 4 com uma fileira de cerdas marginais medianas longas e médias, e uma fileira de cerdas discais médias e curtas, ambas desalinhadas.

Cercos e surstilos (Figs. 54, 83).Vista lateral, cercos curvados para trás pouco acima do terço apical, estreitando-se gradualmente da base para o ápice, esse subarredondado posteriormente. Surstilos cerca de 0,75 do comprimento dos cercos.

Distribuição geográfica. VENEZUELA; COLÔMBIA.

Comentário. Leschenaultia cortesi é semelhante à $L$. leucophrys (Wiedemann, 1830), diferindo desta pelos pêlos da parafrontália estendendo-se até pouco abaixo da metade superior da parafaciália; pelas cerdas ocelares espessas; pelas cerdas abdominais relativamente mais longas.

Material tipo. Holótipo macho. VENEZUELA. Maracay: Rancho Grande, 7.VII.1946 (AMNH). Parátipo, 1 macho. COLÔMBIA. Cali: Cordilheira oeste, alt. 5.500 ft., 19.XI.1935, H. F. Schawarst col. (MZSP).

\section{Leschenaultia currani sp. nov.}

(Figs. 55, 84, 112)

Diagnose. Antena preta; flagelômero cerca do dobro do comprimento do pedicelo; cerdas frontais estendendo-se pouco abaixo do terço superior da parafaciália. Sintergito $1+2 \mathrm{com}$ cerca de dois pares de cerdas marginais medianas curtas. Tergito 3 com cerca de cinco pares de cerdas marginais medianas curtas e espessas, e um grupo grande de cerdas discais curtas e espessas. Tergito $4 \mathrm{com}$ uma fileira de cerdas marginais medianas longas e um grupo de cerdas discais espessas, de tamanhos médio e curto.

Comprimento. 10,5-13,5 mm.

Macho. Cabeça com parafrontália e porção superior da parafaciália preta; demais partes, pardas ou pardo-escurecidas; pruinosidade cinza; fronte marrom-escura; vértice 0,20 da largura da cabeça; pró-fronte levemente projetada, pouco acima da metade da altura do olho; parafaciália pouco mais larga que a fronte; pró-fronte cerca de uma vez e meia ou pouco mais, a largura da fronte; parafaciália cerca de uma vez e meia a largura do flagelômero logo abaixo das cerdas frontais e pouco mais larga que este na altura subapical; antena escura; flagelômero cerca do dobro do comprimento do pedicelo; palpo amarelo; cerdas ocelares curtas; cerdas verticais externas reduzidas; cerdas frontais cerca de 12 , estendendo-se pouco abaixo do terço superior da parafaciália; pêlos da parafrontália estendendo-se até logo abaixo das cerdas frontais; faciália com cerda de 0,25 a 0,50 do comprimento da vibrissa, estendendose cerca de 0,50 da distância da vibrissa à base da antena; gena cerca de um terço da altura do olho.

Tórax preto; escutelo com pruinosidade marrom-ferrugínea. Cerdas escutelares; um par de cerdas basais; dois ou três pares de laterais; um par de apicais curtas, subespessas e paralelas; várias cerdas curtas, subespessas entre o par de cerdas discais, as mais finas próximo à base escutelar. Perna castanho-escura. Asa: caliptra com pruinosidade marrom-ferrugínea.

Abdome (Fig. 112) preto com pruinosidade marromferrugínea. Sintergito 1+2 com cerca de dois pares de cerdas marginais medianas curtas e espessas. Tergito 3 com cerca de cinco pares de cerdas marginais medianas curtas e espessas, e um grupo grande de cerdas discais curtas e espessas. Tergito 4 com uma fileira de cerdas marginais medianas longas, e um grupo de cerdas discais espessas, de tamanhos médio e curto.

Cercos e surstilos (Figs. 55, 84). Vista lateral, cercos levemente curvados para trás no terço apical, com uma pequena projeção mediana na porção anterior, estreitamento mais acentuado no terço apical. Surstilo cerca de 0,75 do 


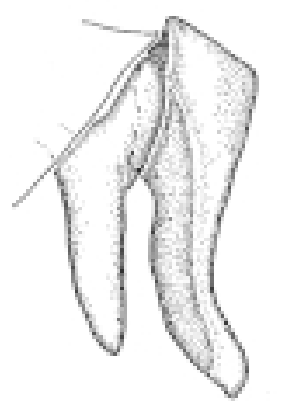

58

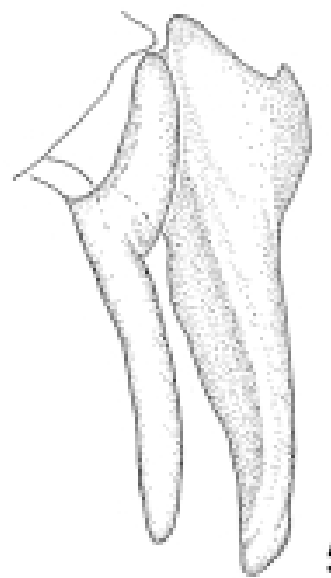

59
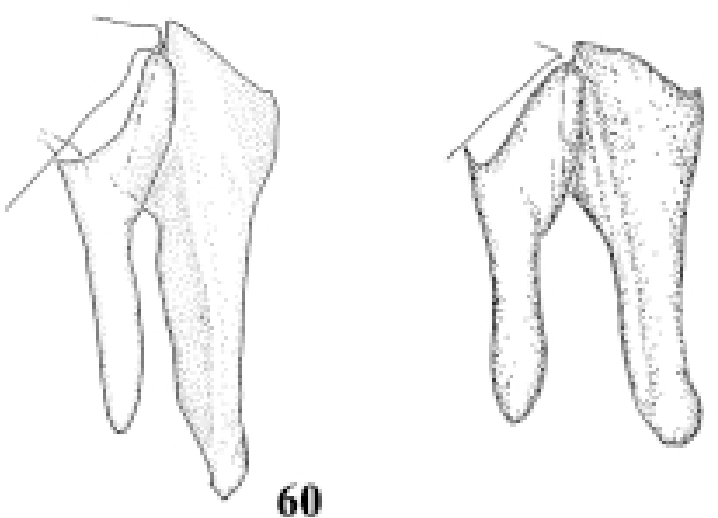

61
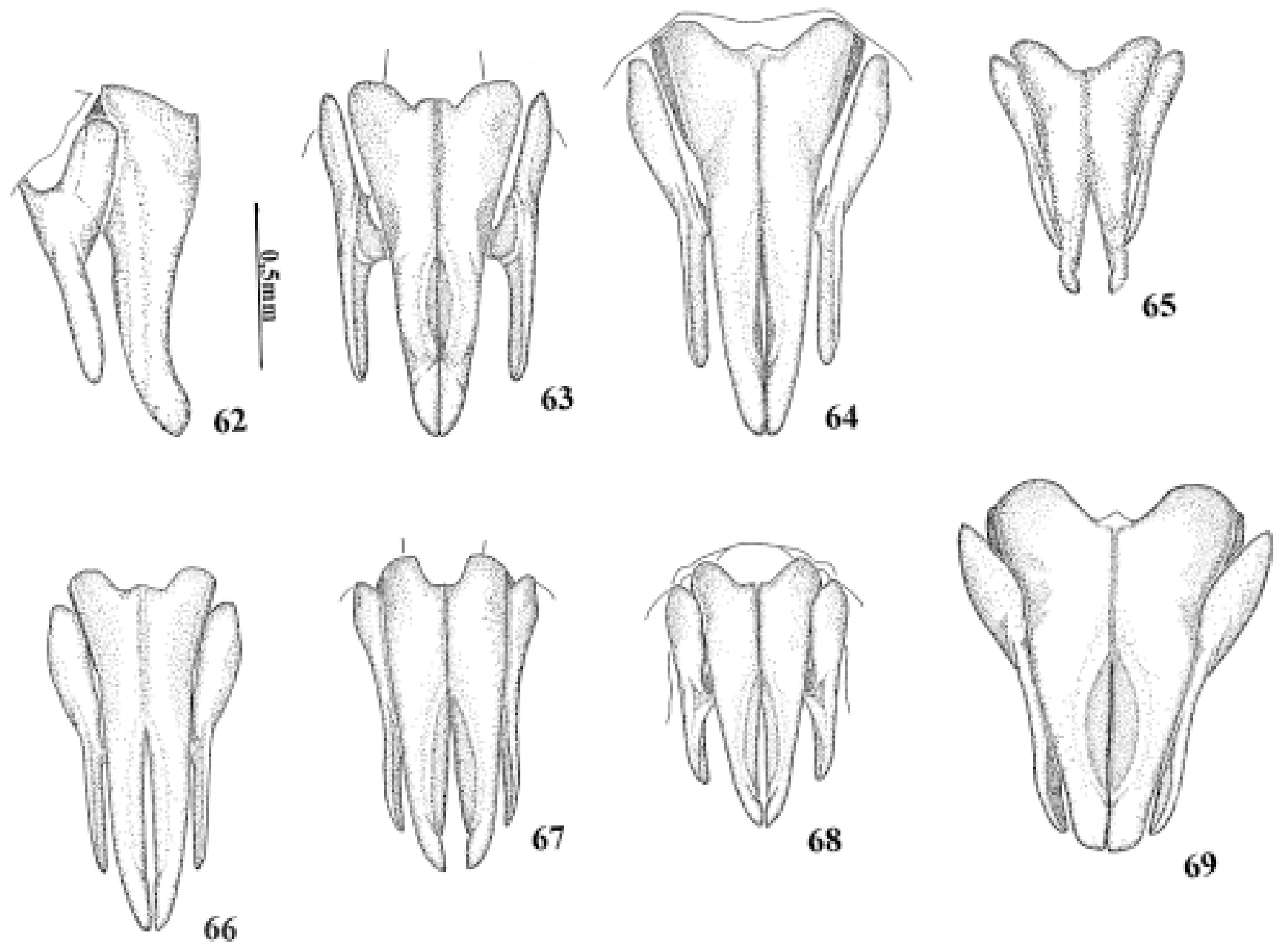

66

Figs. 58-62. Cercos e surstilos, vista lateral: 58, Leschenaultia reinhardi $\mathbf{s p . ~ n o v . ; ~ 5 9 , ~ L . ~ s a b r o s k y i ~} \mathbf{s p .}$ nov.; 60, L. schineri $\mathbf{s p .}$ nov.; 61, L. thompsoni sp. nov.; 62, L. townsendi sp. nov. Figs. 63-69. Cercos e surstilos, vista posterior: 63, L. adusta (Loew, 1872); 64, L. americana (Brauer \& Bergenstamm, 1893); 65, L. bicolor (Macquart, 1846); 66, L. ciliata (Macquart, 1848); 67, L. exul (Townsend, 1892); 68, L. fulvipes (Bigot, 1887); 69, L. grossa Brooks, 1947. 
comprimento dos cercos.

Distribuição geográfica. BRASIL (São Paulo e Santa Catarina).

Comentário. Leschenaultia currani é semelhante à $L$. leucophrys (Wiedemann, 1830) e L. brooksi sp. nov., diferindo destas, além da morfologia dos cercos e surstilos (Figs. 55,84; $44,73 ; 52,81)$, pelas cerdas abdominais mais espessas.

Material-tipo. Holótipo macho. BRASIL. São Paulo: Barueri, 20.VIII.1957, K. Lenko col. (MZSP; ex-coleção Campos Seabra). Parátipo: 1 macho, São Paulo: 6.VII.1964, J. H. Guimarães col. (MZSP).

Material adicional examinado. BRASIL. São Paulo: Campos do Jordão, 2 machos, 3-20.I.1936, F. Lane col. (MZSP); idem, 1 macho, 12.II.1958 (MZSP). Santa Catarina: Nova Teutônia, 1 macho, V.1967 , F. Plaumann col. (MZSP).

\section{Leschenaultia loewi sp. nov.} (Figs. 27, 56, 85, 113)

Diagnose. Em geral dois pares de cerdas orbitais proclinadas; cerdas da faciália 0,30 a 0,40 do comprimento da vibrissa, espaçadas, estendendo-se cerca de 0,60 da distância da vibrissa à base da antena. Sintergito $1+2$ com cerca de três pares de cerdas marginais medianas curtas. Tergito 3 com cerca de quatro pares de cerdas marginais; um pequeno grupo de cerdas discais espaçadas. Tergito 4 com uma fileira de cerdas marginais e um pequeno grupo de cerdas discais.

Comprimento. 8,0-11,0 mm.

Macho. Cabeça (Fig. 27) com parafrontália e porção superior da parafaciália pretas; face, faciália e sulco genal pardos; pruinosidade cinza; vértice 0,28 da largura da cabeça; pró-fronte levemente projetada; parafrontália pouco mais larga que a fronte; pró-fronte cerca de uma vez e meia a largura da fronte; parafaciália mais estreita em direção à gena; pouco mais larga que o flagelômero logo abaixo das cerdas frontais e mais estreita que este na região subapical; antena preta; flagelômero quase duas vezes e meia o comprimento do pedicelo; palpo amarelo; cerdas ocelares relativamente longas; em geral com dois pares de cerdas orbitais proclinadas; cerdas verticais externas reduzidas; cerdas frontais cerca de nove, estendendo-se logo abaixo do final do pedicelo; pêlos da parafrontália estendendose até o terço superior da parafaciália, logo abaixo das cerdas frontais; faciália com cerdas de 0,30 a 0,40 do comprimento da vibrissa, espessas, espaçadas, estendendo-se cerca de 0,60 da distância da vibrissa à base da antena, margeadas por pêlos; gena pouco mais que um terço da altura do olho.

Tórax (Fig. 113) preto; lateral pós-sutural do escuto e escutelo castanhos, este com pruinosidade marrom-ferrugínea. Cerdas escutelares: um par de cerdas basais; três pares de laterais; um par de apicais relativamente curtas, subdivergentes; várias cerdas curtas entre o par de cerdas discais, afiladas próximo à base escutelar. Perna castanha. Asa: caliptra com pruinosidade marrom.

Abdome castanho-escuro, mais preto na porção longitudinal-central; pruinosidade marrom-ferrugínea.
Sintergito $1+2$ com cerca de três pares de cerdas marginais medianas curtas. Tergito 3 com cerca de quatro pares de cerdas marginais medianas médias e curtas e um reduzido grupo de cerdas discais curtas e espaçadas. Tergito 4 com uma fileira de cerdas marginais medianas longas e médias e um grupo de cerdas discais como no tergito 3.

Cercos e surstilos (Figs. 56, 85). Vista lateral, cercos posteriormente sub-retos, estreitando-se anteriormente em direção ao ápice logo acima do terço apical. Surstilos cerca de 0,80 a 0,85 do comprimento dos cercos.

Distribuição geográfica. MÉXICO (Vera Cruz).

Comentário. Leschenaultia loewi pode ser separada das espécies neárticas que não possuem o padrão de manchas na porção pré-escutelar, pela presença de cerdas orbitais proclinadas nos machos.

Material-tipo. Holótipo macho. MÉXICO. Vera Cruz: San Rafael, 1902 (BMNH; ex-coleção de Townsend comprada de E. Brunetti). Parátipos: idem, 1 macho, 1903 (MZSP); 2 fêmeas, 1927 E. Brunetti, E col. (BMNH).

\section{Leschenaultia macquarti sp. nov.} (Figs. 28, 57, 86, 114)

Diagnose. Lateral do escuto, região pré-escutelar, escutelo, anepimero, porção superior do catepimero e anterior do mero, castanho-alaranjados; abdome castanho-alaranjado com um faixa preta longitudinal-central. Sintergito $1+2 \mathrm{com}$ um par de cerdas marginais medianas curtas. Tergito 3 com dois ou três pares de cerdas marginais medianas bem curtas. Tergito 4 com uma fileira de cerdas marginais medianas longas e curtas.

Comprimento. 14,5-15,0 mm.

Macho. Cabeça (Fig. 28) com parafrontália e porção superior da parafaciália pretas; face e faciália pardas; pruinosidade cinza; vértice 0,25 da largura da cabeça; pró-fronte levemente projetada, pouco acima da metade da altura do olho; parafrontália entre uma vez e meia e o dobro da largura fronte; pró-fronte entre duas e duas vezes e meia a largura da fronte; parafaciália estreitando-se na porção inferior, cerca do dobro da largura do flagelômero logo abaixo das cerdas frontais e pouco menos que o dobro da largura deste na região subapical; antena preta, ápice do pedicelo e base do flagelômero alaranjados; este, no máximo, duas vezes o pedicelo; cerdas ocelares curtas; um par de cerdas orbitais reclinadas curtas, espessas; cerdas frontais cerca de 14, duas cerdas abaixo do final do pedicelo, cerdas superiores bem fracas; parafrontália com pêlos estendendo-se até pouco antes da metade superior da parafaciália, logo abaixo das cerdas frontais, uma fileira irregular de cerdas curtas e finas próximo às frontais; faciália com uma fileira de cerdas irregulares, variando de 0,25 a 0,40 do comprimento da vibrissa, estendendo-se cerca de 0,60 da distância da vibrissa à base da antena, cerdas curtas próximo à fileira principal; gena cerca de 0,40 da altura do olho.

Tórax preto com lateral do escuto, região pré-escutelar, 

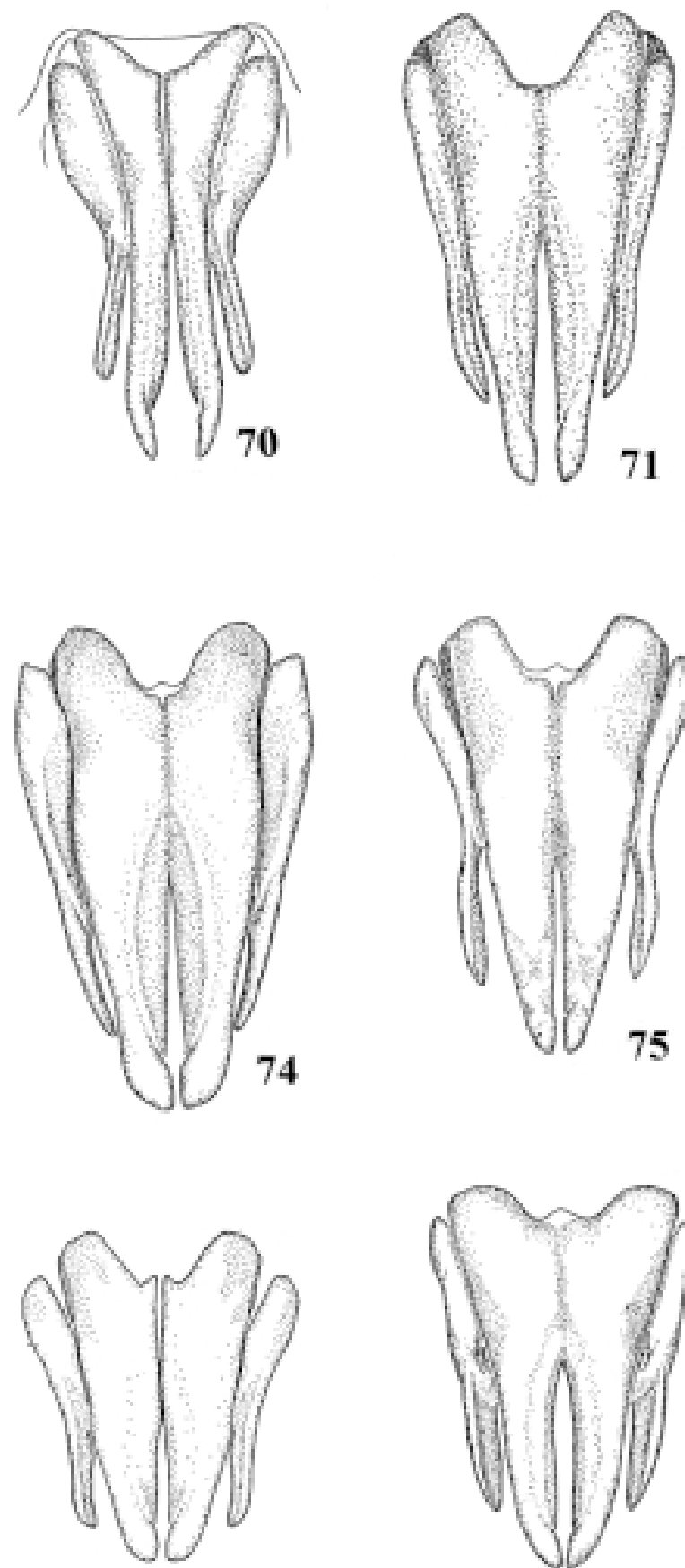

78
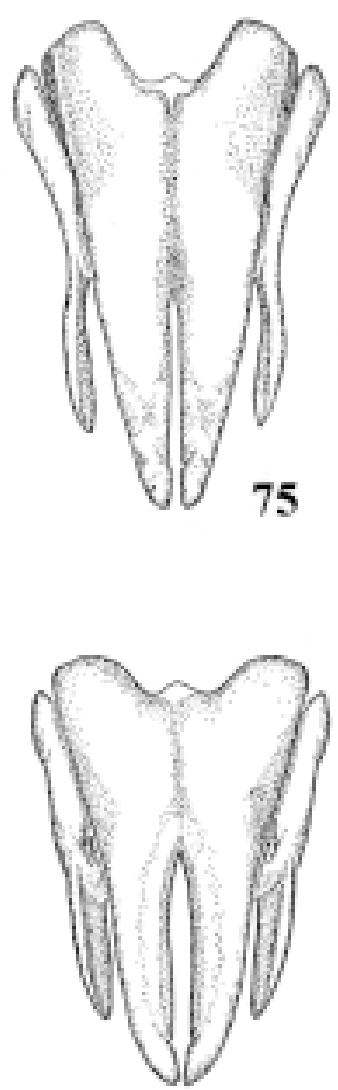

79
74
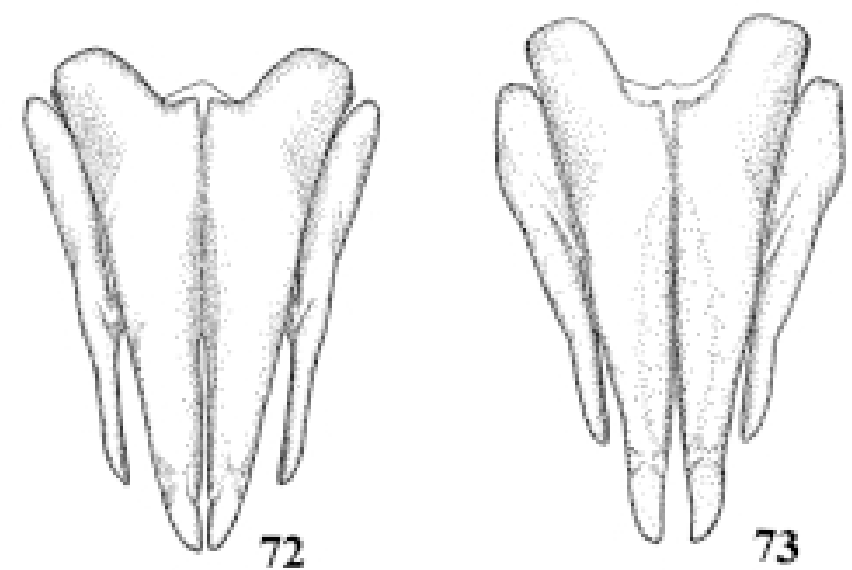

73
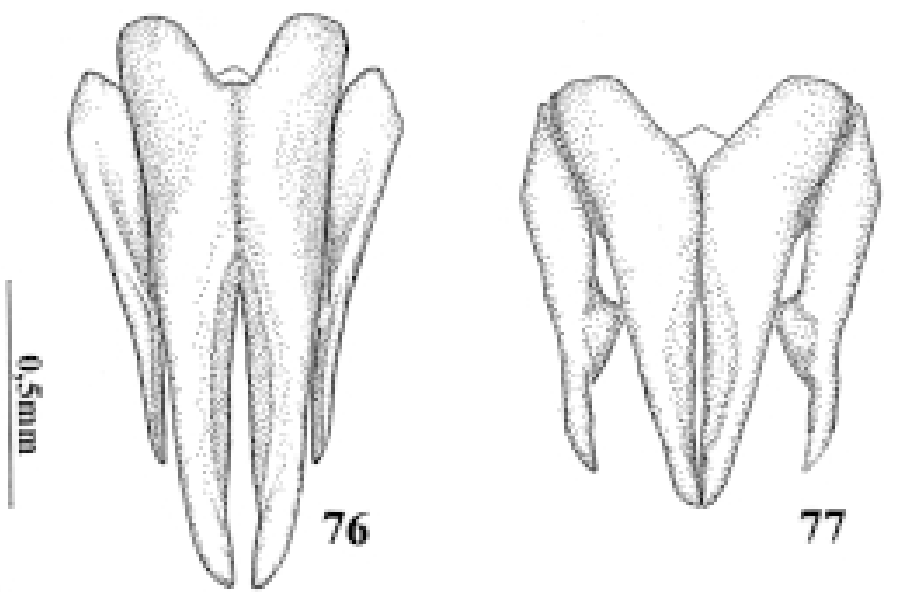

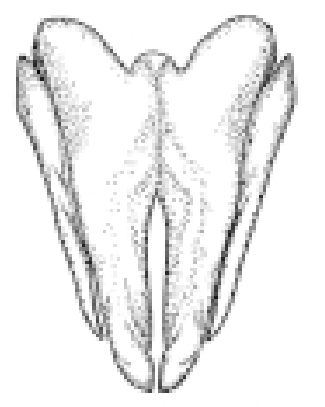

80

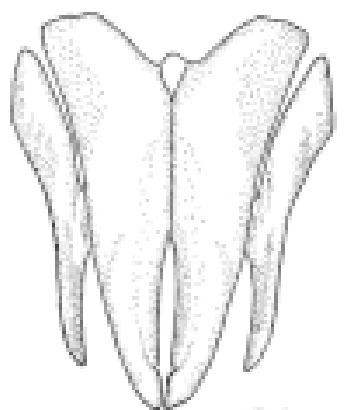

81

Figs. 70-81. Cercos e surstilos, vista posterior: 70, Leschenaultia halisidotae Brooks, 1947; 71, L. hospita Reinhard, 1952; 72, L. jurinoidesI (Townsend, 1895); 73, L. leucophrys (Wiedemann, 1830); 74, L. aldrichi sp. nov.; 75, L. arnaudi sp. nov.; 76, L. bessi sp. nov.; 77, L. bigoti sp. nov.; 78, L. blanchardi sp. nov.; 79, L. bergenstammi sp. nov.; 80, L. braueri sp. nov.; 81, L. brooksi sp. nov. 
anepimero, porção superior do catepimero e anterior do mero, castanho-alaranjados. Cerdas escutelares: um par de cerdas basais; três pares de laterais; um par de apicais curtas, espessas e subparalelas; várias cerdas curtas, subespessas, entre o par de cerdas discais. Perna preta, tíbia castanha; garra tarsal anterior em geral maior que o segundo tarsômero da mesma perna. Asa: caliptra com pruinosidade marrom-ferrugínea.

Abdome (Fig. 114) castanho-alaranjado; uma faixa preta, logitudinal-central, mais estreita em direção ao ápice; leve pruinosidade testácea. Sintergito $1+2 \mathrm{com}$ um par de cerdas marginais medianas curtas. Tergito $3 \mathrm{com}$ dois ou três pares de cerdas marginais medianas bem curtas. Tergito 4 com uma fileira de cerdas marginais medianas longas e curtas, estas mais centrais.

Cercos e surstilos (Figs. 57, 86). Vista lateral, cercos subretos na porção posterior, com levíssima curvatura para trás próximo à base e ao ápice; porção anterior estreitando-se suavemente da base para o ápice. Surstilo cerca de 0,90 do comprimento dos cercos.

Distribuição geográfica. E. U. A.: (Arizona).

Comentário. Esta espécie é semelhante à Leschenaultia halisidotae Brooks, 1947 e à L. thompsoni sp. nov., diferindo da primeira por apresentar o flagelômero não ultrapassando o dobro do comprimento do pedicelo e da segunda, porque o macho apresenta a garra tarsal anterior maior que o segundo tarsômero da mesma perna.

Material-tipo. Holótipo macho. E. U. A. Arizona: Huachuca Mts., 19.VIII.1950, J. N. Knull col. (OSUC). Parátipo: idem, 1 macho, VI., D. K. Duncan col. (AMNH).

\section{Leschenaultia reinhardi sp. nov.} (Figs. 29, 58, 87, 115)

Diagnose. Tórax preto sem o padrão de coloração das espécies neárticas; escutelo com fina mescla de pruinosidade branca e marrom-ferrugínea. Sintergito $1+2 \mathrm{com}$ um ou dois pares de cerdas marginais medianas curtas. Tergito 3 com cerca de três pares de cerdas marginais medianas. Tergito 4 com uma fileira de cerdas marginais medianas. Tergitos 3 e 4 com ou sem cerdas discais; quando presentes, espaçadas e em pequeno grupo, não muito conspícuas.

Comprimento. 9,0-11 mm.

Macho. Cabeça (Fig. 29): parafrontália e porção superior da parafaciália pretas; face e faciália pardas; sulco genal castanhoavermelhado; pruinosidade cinza; face marrom; vértice $0,22 \mathrm{da}$ largura da cabeça; pró-fronte levemente projetada, pouco acima da metade da altura do olho; parafrontália pouco mais larga que a fronte; pró-fronte cerca de uma vez e meia a largura da fronte; parafaciália estreitando-se em direção à gena, uma vez e meia a largura do flagelômero logo abaixo das cerdas frontais e cerca de uma vez e meia a largura deste na região subapical; antena preta, base do flagelômero alaranjada, este cerca do dobro do comprimento do pedicelo; palpo pardo-alaranjado; cerdas ocelares subdivergentes; cerdas verticais externas reduzidas; cerdas frontais cerca de 12 , estendendo-se até o final do pedicelo, par superior forte e sub-reclinado, próximo às cerdas orbitais reclinadas; pêlos da parafrontália estendendose até logo abaixo das cerdas frontais, alcançando o terço superior da parafaciália; faciália com fileiras desalinhadas de cerdas de 0,25 a 0,30 do comprimento da vibrissa, estendendose, mais ou menos, até 0,50 da distância da vibrissa à base da antena, margeadas por cerdas menores; gena cerca de $0,30 \mathrm{da}$ altura do olho.

Tórax preto, calo pós-alar e escutelo castanho-alaranjados, este com fina mescla de pruinosidade branca e marromferrugínea. Cerdas escutelares: um par de cerdas basais; dois pares de laterais; um par de apicais médias, espessas e subdivergentes; várias cerdas médias, curtas e espessas entre o par de cerdas discais. Perna castanha. Asa: caliptra com pruinosidade marrom.

Abdome (Fig. 115) castanho, levemente escurecido centrolongitudinalmente com pruinosidade marrom-ferrugínea. Sintergito 1+2 com um ou dois pares de cerdas marginais medianas curtas. Tergito 3 com cerca de três pares de cerdas marginais medianas médias e curtas, estas mais centrais. Tergito 4 com uma fileira de cerdas marginais medianas longas e médias. Tergito 5 com várias cerdas médias a partir do terço basal. Tergitos 3 e 4 com ou sem cerdas discais; quando presentes, espaçadas, em pequeno grupo e não muito conspícuas.

Cercos e surstilos (Figs. 58, 87) relativamente curtos. Vista lateral, cercos ligeiramente curvados para trás na porção posterior; surstilos estreitando-se gradualmente na metade apical, com cerca de 0,80 a 0,85 do comprimento dos cercos

Fêmea. Cabeça com cerca de oito cerdas frontais, par superior forte e bem reclinado; cerdas verticais externas cerca de um terço das internas; faciália com uma fileira de cerdas de 0,25 a 0,30 do comprimento da vibrissa, estendendo-se pouco menos de 0,50 da distância da vibrissa à base da antena. Abdome castanho-alaranjado. Sintergito $1+2$ com três pares de cerdas marginais medianas médias e curtas. Tergito $3 \mathrm{com}$ cerca de cinco pares de cerdas marginais medianas médias e curtas; um grupo de cerdas discais com cerdas curtas e espessas. Tergito 4 com uma fileira de cerdas longas e médias; um grupo de cerdas discais médias desalinhadas.

Distribuição geográfica. CANADÁ (Britsh Columbia, Ontario, Quebec) e E. U. A. (Oregon, Idaho, Ohio, California, Tennessee).

Comentário. Esta espécie foi descrita a partir de um exemplar macho que havia sido incluído entre os parátipos de Leschenaultia halisidotae Brooks, 1947. L. reinhardi sp. nov. difere de $L$. halisidotae por não apresentar a região pré-escutelar castanho-alaranjada e por apresentar o escutelo com uma mescla de pruinosidade branca e marrom-ferrugínea.

Material-tipo. Holótipo macho. CANADA. Quebec: Montreal, 28.VI., J. Quellet col. (UM). Parátipos: CANADA. Ontario: Orilia, 5 machos, 20-22.VII.1938, C. H. Curran col. (AMNH); Gowas Bay (St. Joseph Is.), 1 macho, 2.VIII.1949, W. J. Gertsch col. (AMNH). Quebec: La Trappe, 1 macho, 26.VII.1935, J. Quellet col. (UM); Joliette, 1 


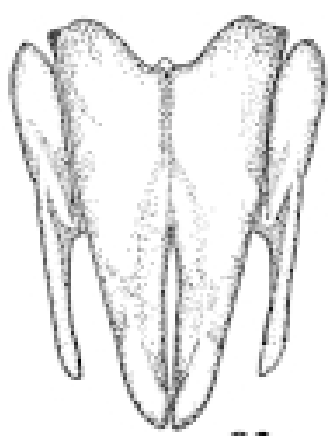

82

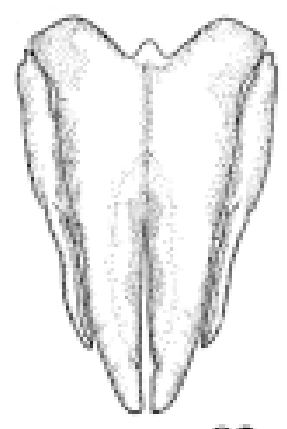

83
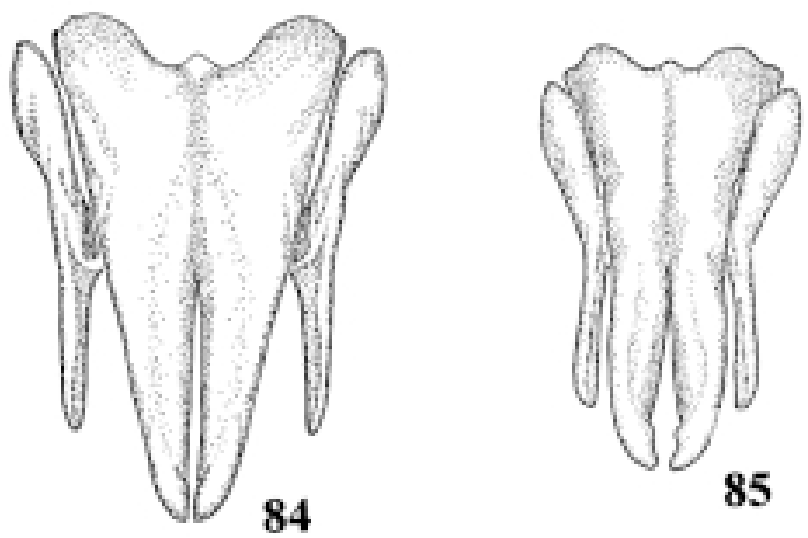

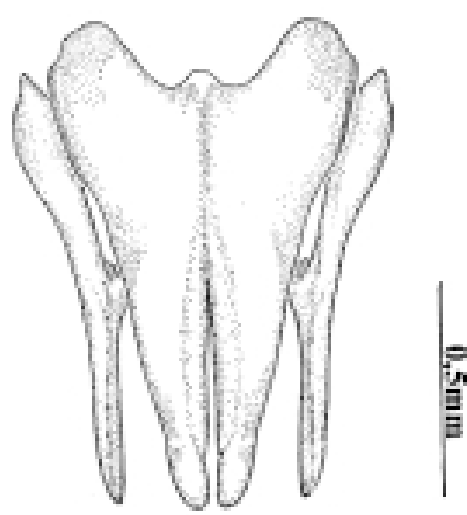

86

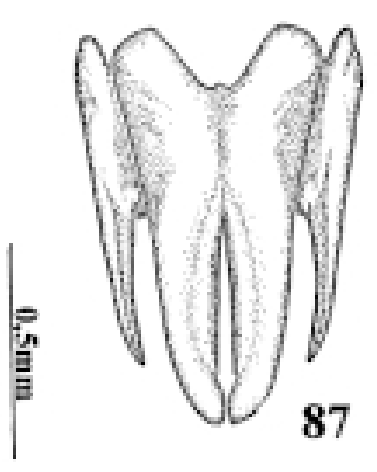

87

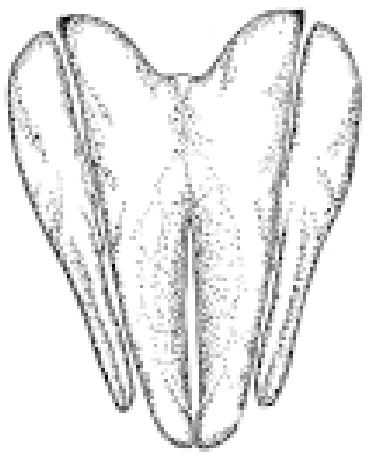

90
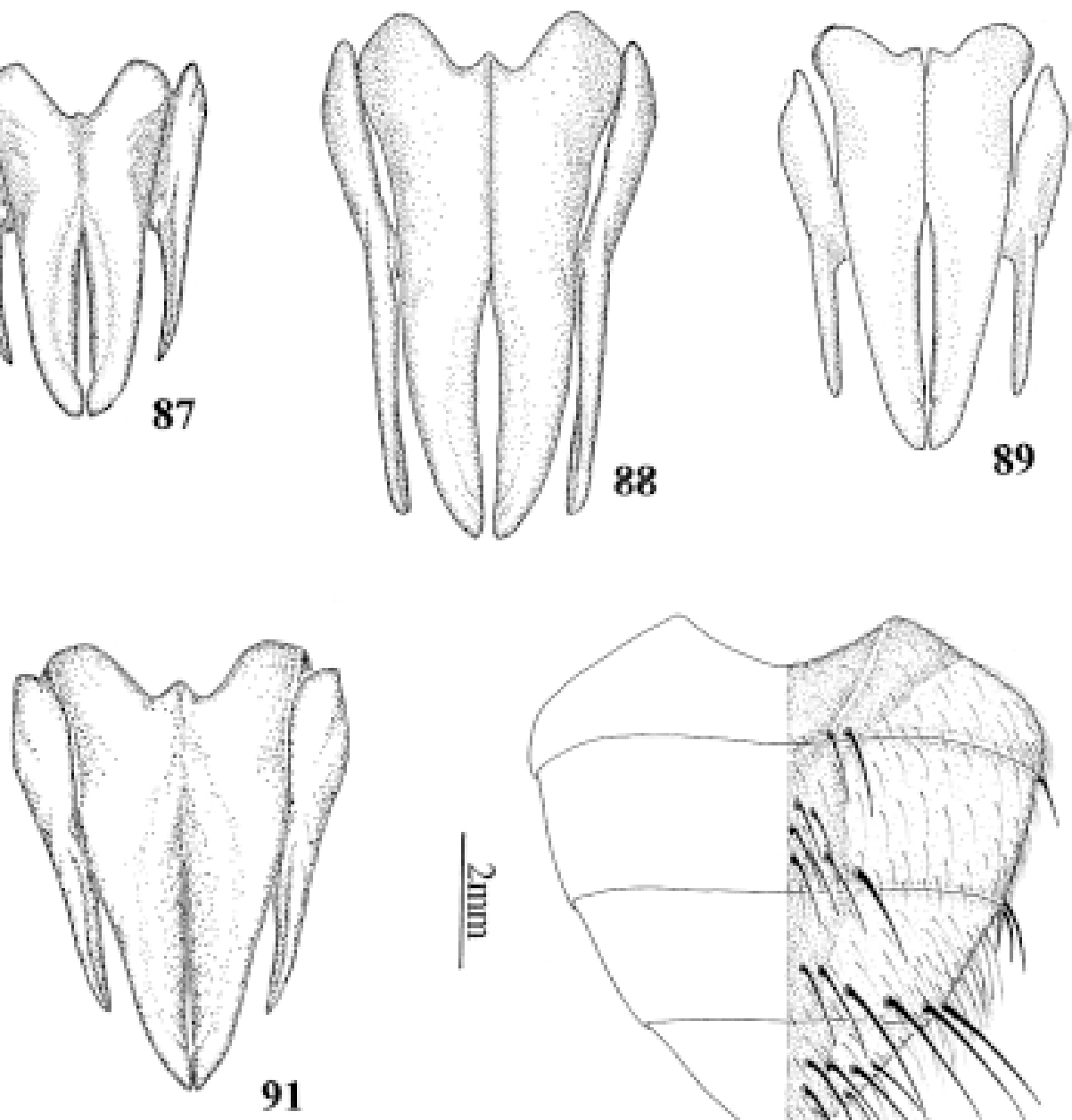

88

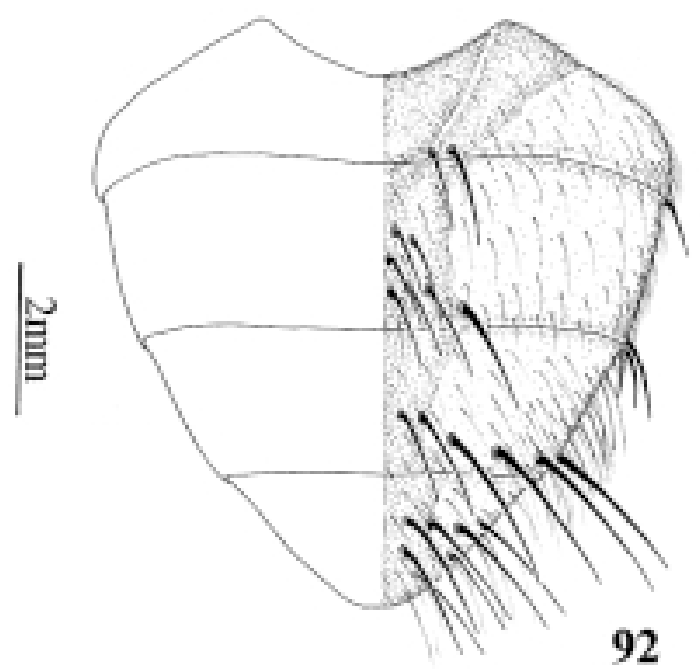

Figs. 82-91. Cercos e surstilos, vista posterior: 82, Leschenaultia coquilletti sp. nov.; 83, L. cortesi $\mathbf{s p . ~ n o v . ; ~ 8 4 , ~ L . ~ c u r r a n i ~} \mathbf{s p .}$ nov.; 85, L. loewi $\mathbf{s p .}$ nov.; 86, $L$. macquarti sp. nov.; 87, $L$. reinhardi sp. nov.; 88, $L$. sabroskyi sp. nov.; 89, $L$. schineri sp. nov.; 90, $L$. thompsoni $\mathbf{s p . ~ n o v . ; ~ 9 1 , ~} L$. townsendi sp. nov. Fig. 92. Abdome, vista dorsal (macho): L. adusta (Loew,1872). 
macho, 7.VII.1919 J. Quellet col. (UM); Aylmer, 2 machos, 1 fêmea, 29.VI-20.VII.1924, C. H. Curran col. (AMNH); idem, 1 macho, 20.VII.1924 (MZSP); idem, 1 macho, 9.VII.1924 (DZUP).

Material adicional examinado. CANADA. British Columbia: Robson, 2 machos, 9.VIII./7.IV.1968, H. R. Foxlee col. (CNCI). E. U. A. Oregon: Hood River co., South Hood River, 1 fêmea, 5.IX.1917, F. R. Cole col. (CNCI). Idaho: Latah co., Moscow Mt. (4000ft.), 1 fêmea, 2.VIII.1939, B. C. Fluke col. (UICM). Ohio: Ottawa co., Put-in Bay, 1 fêmea, 27.VII.1939, C. H. Kennedy col. (OSUC). California: Alameda co., Hills back of Oakland, 3 machos, 8.XI.1950-13.X.1951, W. C. Bentick col. (CISC). Tennessee: Knnox co., 1 fêmea, 10.VIII.1951, A. C. Cole col. (CISC).

\section{Leschenaultia sabroskyi sp. nov.} (Figs. 30, 59, 88, 116)

Diagnose. Antena preta com pedicelo castanho; lateral póssutural do escuto, porção pré-alar e escutelo castanhoavermelhados. Escutelo com um par de cerdas basais, três pares de laterais (sub-basais fracas ou ausentes). Sintergito 1+2 com um ou dois pares de cerdas marginais medianas curtas. Tergito 3 com cerca de três pares de cerdas marginais medianas. Tergito 4 com uma fileira de cerdas marginais medianas, longas e médias. Tergitos 3 e 4 com ou sem um pequeno grupo de cerdas discais. Comprimento. 11,0-13,0 mm.

Macho. Cabeça (Fig. 30) preta; face e faciália pardas; sutura genal castanho-avermelhada; pruinosidade cinza; fronte marrom; vértice 0,32 da largura da cabeça; pró-fronte bem projetada, acima da metade da altura do olho; parafrontália cerca da mesma largura ou mais da fronte; pró-fronte cerca de uma vez e meia ou mais a largura da fronte; parafaciália mais estreita na porção inferior; cerca de duas vezes e meia a largura do flagelômero logo abaixo das cerdas frontais e cerca do dobro da largura deste na região subapical; antena preta, pedicelo castanho, flagelômero cerca do dobro do comprimento do pedicelo; arista levemente espessa, afilando-se rapidamente próximo ao terço apical; palpo laranja-acastanhado; cerdas ocelares relativamente alongadas; cerdas verticais externas curtas; cerdas frontais cerca de 10, estendendo-se até o final do pedicelo, par superior fraco; parafrontália com pêlos e cerdas, estas mais próximo às frontais, estendendo-se até o terço inferior da parafaciália; faciália com cerdas de 0,30 a 0,40 do comprimento da vibrissa, espaçadas, estendendo-se de 0,60 a 0,90 da distância da vibrissa à base da antena, margeadas ou não por uma fileira irregular de cerdas mais curtas e mais fracas, estendendo-se 0,80 da fileira principal; gena cerca de 0,45 da altura do olho.

Tórax preto; lateral pós-sutural do escuto, porção préescutelar e escutelo castanho-alaranjados; leve pruinosidade cinza. Cerdas escutelares: um par de cerdas basais; três pares de laterais (sub-basais fracas ou ausentes); um par de apicais relativamente curtas, finas e suberetas; várias cerdas relativamente curtas e finas, suberetas, entre o par de cerdas discais, mais finas próximo à base escutelar. Perna preta, tíbia castanha. Asa: caliptra com pruinosidade amarelada.

Abdome (Fig. 116) castanho-avermelhado com uma faixa preta longitudinal-central. Sintergito $1+2$ com um ou dois pares de cerdas marginais medianas, relativamente médias. Tergito 3 com cerca de três pares de cerdas marginais médias e curtas. Tergito 4 com uma fileira de cerdas marginais medianas, longas e médias. Tergitos 3 e $4 \mathrm{com}$ ou sem um pequeno grupo de cerdas discais.

Cercos e surstilos (Figs. 59, 88). Vista lateral, cercos na porção posterior sub-retos da base em direção ao ápice, estreitando-se anteriormente da metade para o ápice. Surstilos cerca de 0,90 do comprimento dos cercos.

Distribuição geográfica. E. U. A. (California, Arizona).

Comentário. Leschenaultia sabroskyi é semelhante à $L$. americana (Brauer \& Bergenstamm, 1893), diferindo desta por nuanças: pedicelo mais acastanhado do que avermelhado; abdome mais avermelhado do que alaranjado; tíbia mais acastanhada do que castanho-alaranjada.

Material-tipo. Holótipo macho. E. U. A. California: San Gabriel Mts., 18.III.1950, R. C. Osburn, R.C. col. (OSUC). Parátipos: idem, 1 macho (OSUC); idem, 1 macho (MZSP).

Material adicional examinado. E. U. A. California: Alameda co., Oakland, 1 macho, 20.IV.1952, R. Schuster col. (CISC); Contra Costa co., Antioch, 1 macho, 18.III.1959 J. Powell col. (CISC); San Benito co., Pinnacles, 24.IV.1948, P. D. Hurd col. (CISC). Arizona: Coconino co., Sedona (Oak cr.), 1 macho, 17.IV.1965, J. H. Hessel col. (AMNH).

\section{Leschenaultia schineri sp. nov.} (Figs. 60, 89)

Diagnose. Cerdas da parafrontália estendendo-se até pouco abaixo do terço basal da parafaciália. Laterais pós-suturais do escuto, calo pós-alar, porção pré-escutelar e escutelo, castanhoalaranjados. Abdome castanho-alaranjado com faixa preta longitudinal-central, mescla de pruinosidade marrom-ferrugínea e branca. Perna castanho-alaranjada, com tarso e base do fêmur escurecidos. Sintergito $1+2 \mathrm{com}$ um ou dois pares de cerdas marginais medianas curtas. Tergito 3 com três ou quatro pares de cerdas marginais medianas, médias e curtas. Tergito $4 \mathrm{com}$ uma fileira de cerdas marginais medianas.

Comprimento. 10,0-11,5 mm.

Macho. Cabeça preta; face e faciália pardas; sulco genal castanho-avermelhado; pruinosidade cinza; fronte marromescura; vértice 0,27 da largura da cabeça; pró-fronte bem projetada, acima da metade da altura do olho; parafrontália cerca da mesma largura da fronte; pró-fronte entre uma vez e meia e o dobro da largura da fronte; parafaciália mais estreita na porção inferior; cerca de duas vezes e meia a largura do flagelômero logo abaixo das cerdas frontais e cerca do dobro da largura deste na região subapical; antena com escapo e pedicelo alaranjados, flagelômero preto, este uma vez e meia o comprimento do pedicelo; arista espessa na base, afilando-se rapidamente próximo ao terço basal; palpo pardo-alaranjado; cerdas ocelares longas e subdivergentes; cerdas verticais externas curtas e finas; cerdas frontais cerca de nove, longas, finas, estendendo-se mais ou menos até o final do pedicelo, pares superiores alongados e mais finos; parafrontália com 

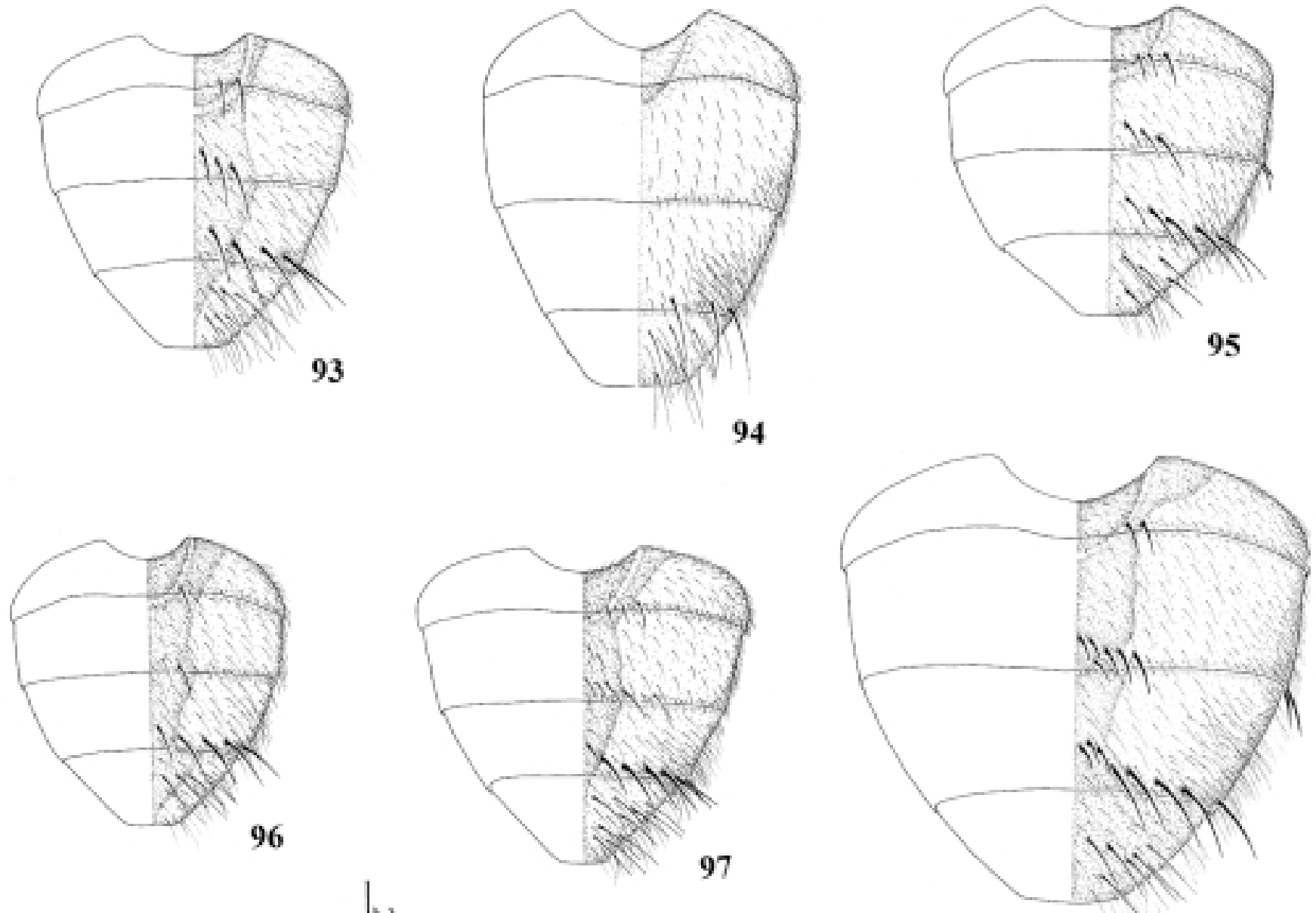

羿

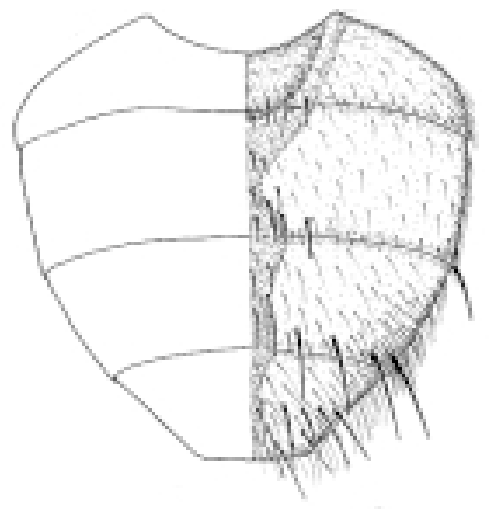

99

98
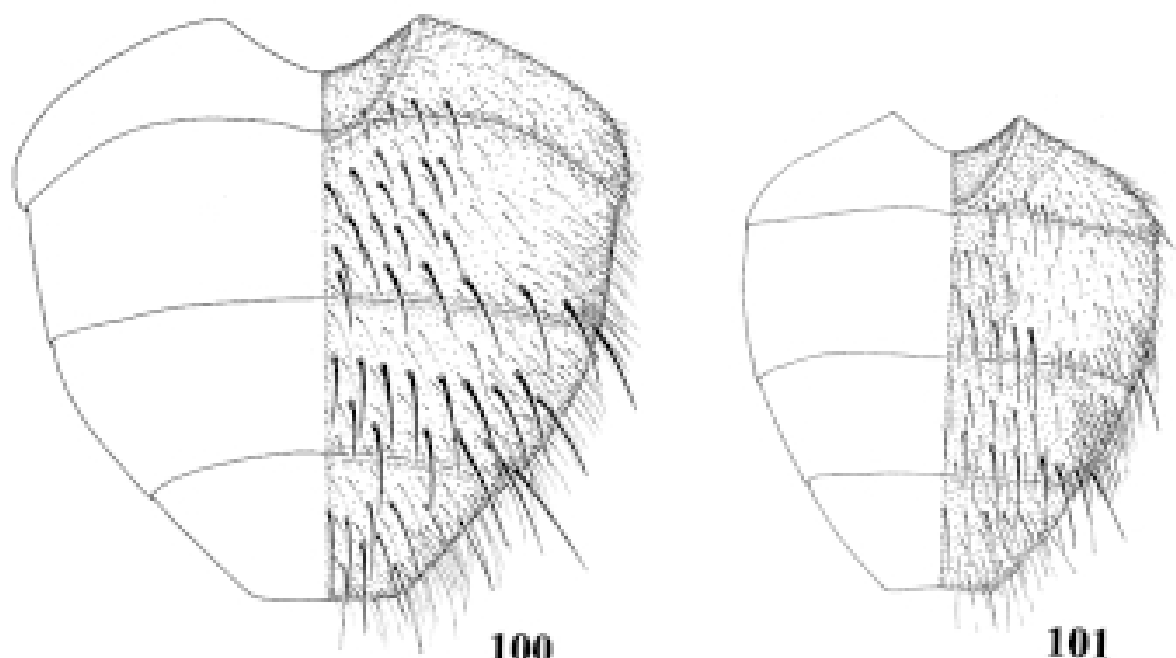

Figs. 93-101. Abdome, vista dorsal (macho): 93, Leschenaultia americana (Brauer \& Bergenstamm, 1893); 94, L. bicolor (Macquart, 1846); 95, L. exul (Townsend, 1892); 96, L. fulvipes (Bigot, 1887); 97, L. ciliata (Macquart, 1848); 98, L. grossa Brooks, 1947; 99, L. halisidotae Brooks, 1947; 100, L. hospita Reinhard, 1952; 101, L. hystrix (Townsend, 1915). 
pêlos e cerdas, estas finas, próximo às frontais, estendendo-se até pouco abaixo do terço basal da parafaciália; faciália com cerdas de 0,40 a 0,50 do comprimento da vibrissa, mais ou menos espaçadas, estendendo-se um pouco além de 0,50 da distância da vibrissa à base da antena; algumas cerdas mais curtas e fracas entre e próximo às cerdas principais; gena cerca de 0,45 da altura do olho.

Tórax preto; laterais pós-suturais do escuto, calo pós-alar, porção pré-escutelar e escutelo castanho-alarajados. Cerdas escutelares: um par de cerdas basais; dois ou três pares de laterais (sub-basais fracas); um par de apicais relativamente curtas, finas e suberetas; várias cerdas finas e relativamente curtas entre o par de cerdas discais, as mais finas próximo à base escutelar. Perna castanho-alaranjada, base do fêmur e tarso, escurecidos. Asa: caliptra com pruinosidade marrom-ferrugínea.

Abdome castanho-alaranjado com faixa preta longitudinalcentral, mescla de pruinosidade marrom-ferrugínea e branca. Sintergito $1+2$ com um ou dois pares de cerdas marginais medianas curtas. Tergito 3 com três ou quatro pares de cerdas marginais medianas, médias e curtas. Tergito 4 com uma fileira de cerdas marginais medianas..

Cercos e surstilos (Figs. 60, 89). Vista lateral, cercos subretos posteriormente e estreitando-se anteriormente a partir do terço basal. Surstilos cerca de 0,80 do comprimento dos cercos.

Distribuição geográfica. E. U. A. (Oregon, California, Idaho).

Comentário. Leschenaultia schineri é semelhante à $L$. americana (Brauer \& Bergenstamm, 1893), diferindo basicamente por nuança de coloração e pelos cercos e surstilos proporcionalmente muito menores.

Material tipo. Holótipo macho. E. U. A. California: San Gabriel Mt., 18.III.1950, R. C. Osburn col. (OSUC). Parátipo: idem, Pt. Reves, 1 macho, 28.III.1936 (AMNH; ex-coleção de M. A. Cazier).

Material adicional examinado. E. U. A. Oregon: Benton co., Corvallis, 1 macho, 29.IV.1918, F. R. Cole col. (CISC). Idaho: Nez Pence co., Lewiston, 1 macho, 10.X.1965, E. Richard Logan col. (UICM); Latah co. (Moscow Mt. face sul), 1 macho, 22.V.1963, D. S. Horning Jr. col. (UICM).

\section{Leschenaultia thompsoni sp. nov.}

(Figs. 31, 61, 90, 117)

Diagnose. Cerdas ocelares curtas; pêlos da parafrontália estendendo-se até pouco abaixo da metade da parafaciália; lateral do escuto, região pré-escutelar e escutelo, castanhoalaranjados; garra tarsal anterior curta, menor que o segundo tarsômero da mesma perna. Sintergito $1+2$ com cerca de dois pares de cerdas marginais medianas. Tergito 3 com três a quatro pares de cerdas marginais medianas bem curtas. Tergito 4 com uma fileira de cerdas marginais medianas médias e curtas; cerdas discais ausentes nos tergitos 3 e 4 .

Comprimento. 12,0-13,0 mm.

Macho. Cabeça (Fig. 31) preta; pruinosidade cinza; região da parafaciália próximo à faciália e sulco genal castanhoavermelhados; vértice 0,29 da largura da cabeça; pró-fronte projetada, acima da metade da altura do olho; parafrontália cerca do dobro da largura da fronte; pró-fronte cerca de duas vezes e meia a largura da fronte; parafaciália mais estreita em direção à gena, cerca do dobro da largura do flagelômero logo abaixo das cerdas frontais e cerca de uma vez e meia a largura deste na região subapical; antena preta, flagelômero cerca do dobro, ou mais, do comprimento do pedicelo; cerdas ocelares curtas, subdivergentes; cerdas verticais externas curtas; um par curto e forte de cerdas orbitais reclinadas; cerdas frontais cerca de 11, estendendo-se pouco abaixo do terço superior da parafaciália, pares superiores curtos; parafrontálias, com cerdas bem curtas e finas próximo às frontais e pêlos finos e curtos estendendo-se até pouco abaixo da metade superior da parafaciália; faciália com cerdas de 0,20 a 0,40 do comprimento da vibrissa, mais ou menos espaçadas, estendendo-se cerca de 0,50 da distância da vibrissa à base da antena, margeadas até a metade por cerdas mais curtas; gena cerca de 0,35 da altura do olho.

Tórax preto; lateral do escuto, região pré-escutelar e escutelo, castanho-alaranjados. Cerdas escutelares: um par de cerdas basais; três pares de laterais; um par de apicais curtas; várias cerdas curtas entre o par de cerdas discais. Perna castanho-escura; garra tarsal anterior curta, menor que o segundo tarsômero da mesma perna. Asa: caliptra com pruinosidade marrom.

Abdome (Fig. 117) castanho; preto centrolongitudinalmente; pruinosidade marrom-ferrugínea. Sintergito $1+2$ com cerca de dois pares de cerdas marginais medianas bem curtas. Tergito 3 com três a quatro pares de cerdas marginais medianas bem curtas. Tergito 4 com uma fileira de cerdas marginais medianas, médias e curtas.

Cercos e surstilos (Figs. 61, 90) relativamente curtos. Vista lateral, cercos levemente curvados para trás, com o ápice subarredondado. Surstilos cerca de 0,85 do comprimento dos cercos.

Distribuição geográfica. MÉXICO (Cidade do México, Chiapas).

Comentário. Leschenaultia thompsoni difere das espécies norte-americanas que não possuem a parafaciália cerdosa, pela garra tarsal anterior curta, menor que o segundo tarsômero da mesma perna.

Material-tipo. Holótipo macho. MÉXICO. Cidade do México: 20.X.1961, B. O. C. Gardiner col. (BMNH). Parátipos: idem, 1 macho, 15.XI.1961 (MZSP). Chiapas: San Critobal, 1 macho, 1.VIII.1952, E. E. Gilbert \& C. D. MacNeil col. (CISC).

\section{Leschenaultia townsendi sp. nov.}

(Figs. 32, 62, 91, 118)

Diagnose. Cerdas da cabeça longas; dois pares de cerdas orbitais proclinadas. Tórax preto, porção pré-escutelar pouco mais clara que o escuto; abdome castanho-escuro. Sintergito $1+2$ com cerca de seis pares de cerdas marginais medianas, submédias e curtas. Tergito 3 com uma fileira de cerdas marginais medianas, sublongas e médias. Tergito 4 com uma 


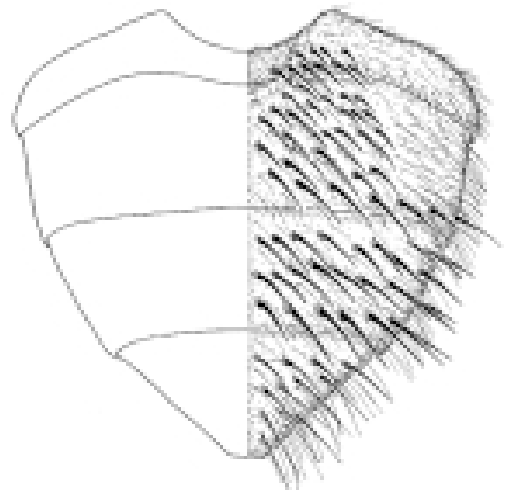

102

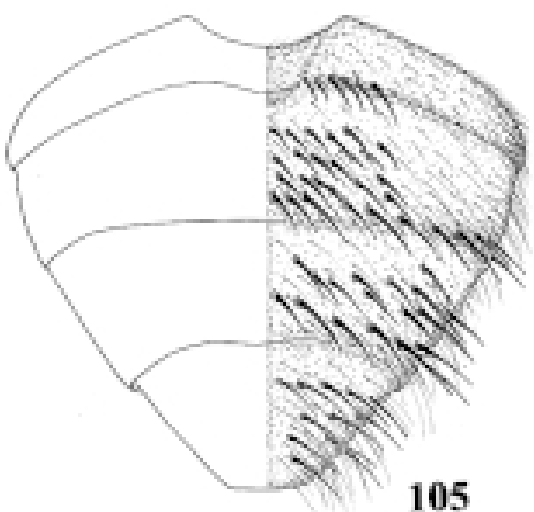

105

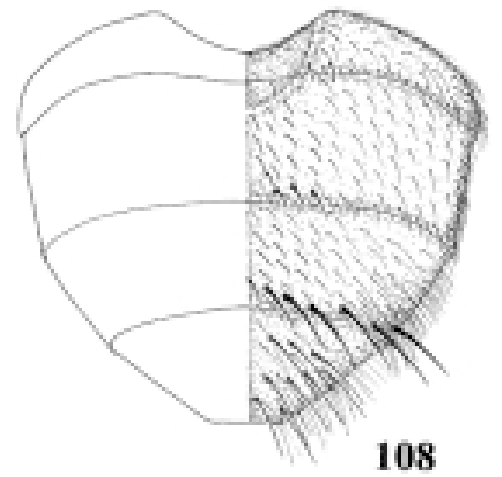

108

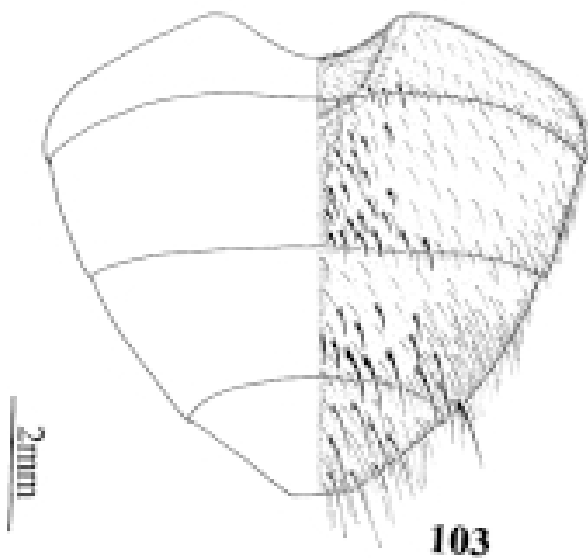

103
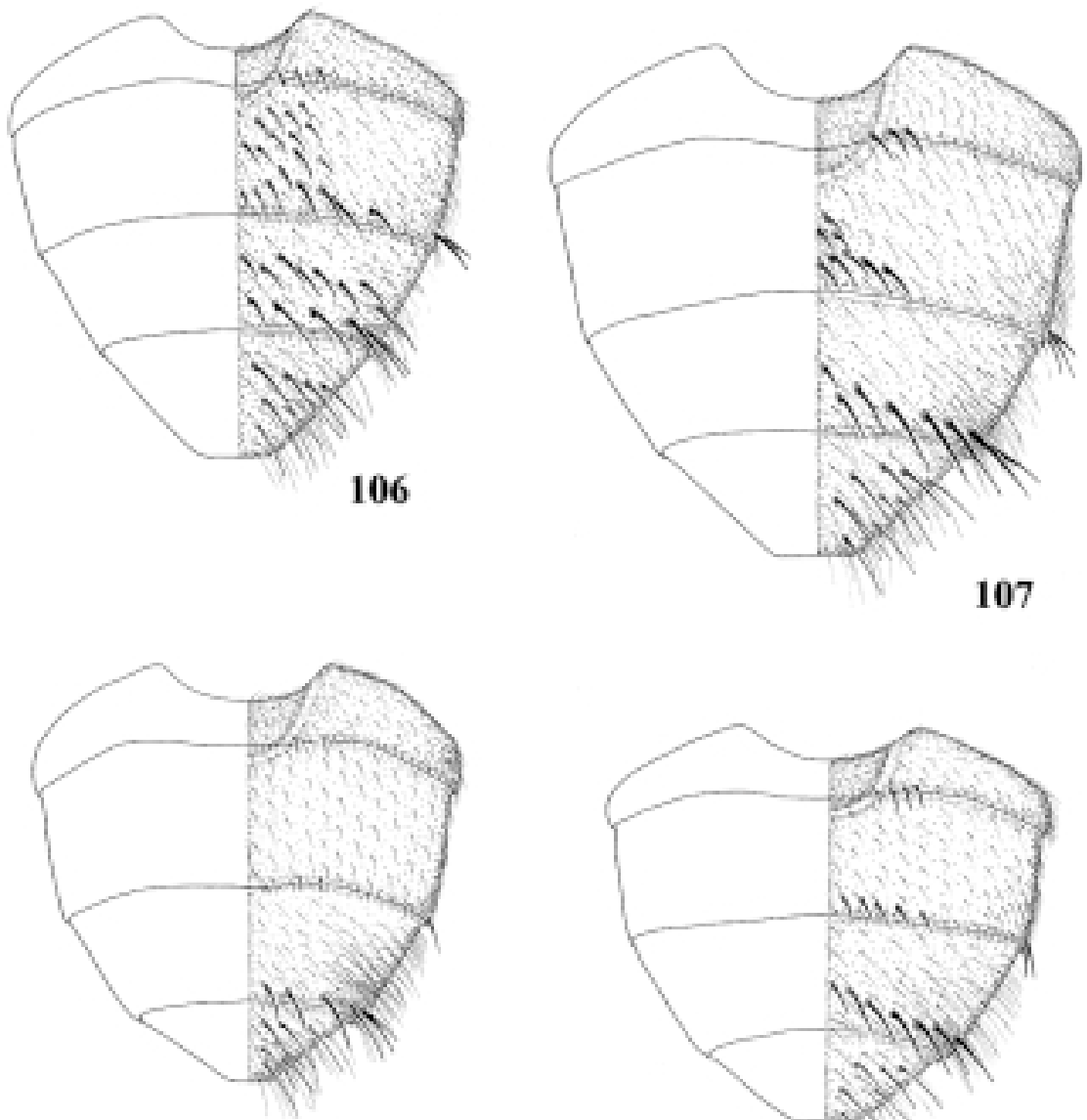

109
107
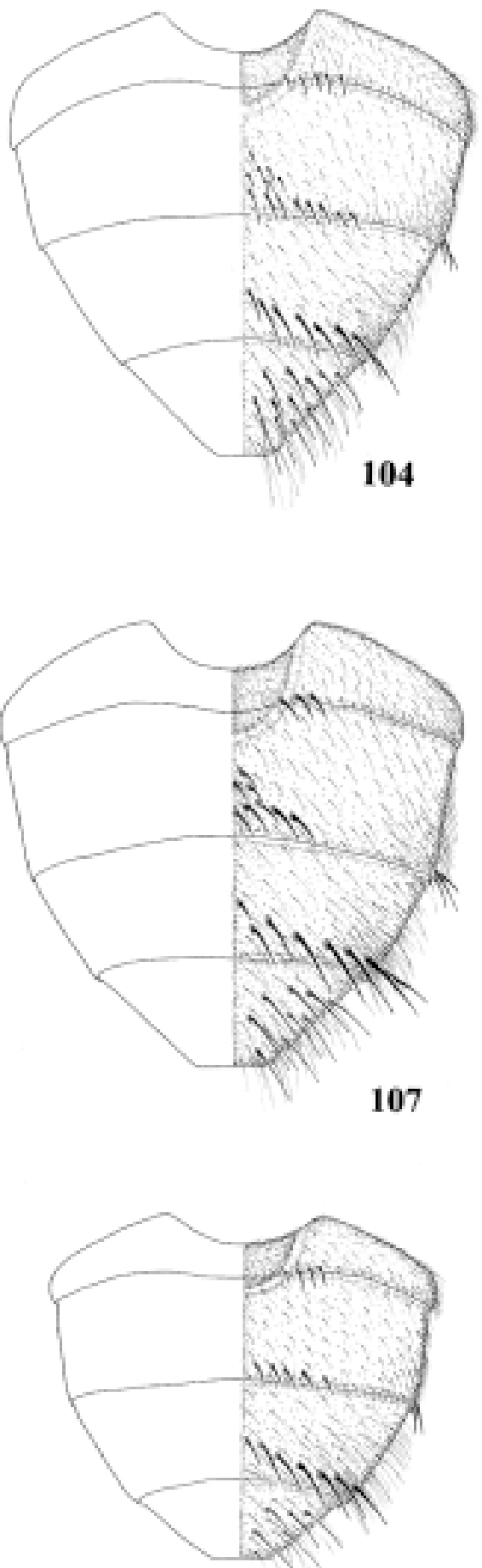

110

Figs. 102-110. Abdome, vista dorsal (macho): 102, Leschenaultia jurinioides (Townsend, 1895); 103, L. leucophrys (Wiedemann, 1830); 104, L. aldrichi sp. nov.; 105, $L$. arnaudi $\mathbf{s p .}$ nov.; 106, L. bessi sp. nov.; 107, L. blanchardi $\mathbf{s p . ~ n o v . ; ~ 1 0 8 , ~ L . ~ b e r g e n s t a m m i ~} \mathbf{s p . ~ n o v . ; ~ 1 0 9 , ~} L$. braueri $\mathbf{s p .}$ nov.; 110, L. coquilletti sp. nov.. 
fileira de cerdas marginais medianas, longas e submédias. Tergito 3 com um pequeno grupo de cerdas discais médias e espessas. Comprimento. 12,5-14,0 mm.

Macho. Cabeça (Fig. 32) preta; pruinosidade cinza; região da parafaciália próximo à faciália e sutura genal castanhoavermelhados; fronte marrom-escura; vértice 0,29 da largura da cabeça; pró-fronte projetada; parafrontália cerca da mesma da largura da fronte; pró-fronte cerca de uma vez e meia da largura da fronte; parafaciália cerca de uma vez e meia a largura do flagelômero logo abaixo das cerdas frontais e pouco menos de uma vez e meia a largura deste na região subapical; antena preta; flagelômero cerca de duas vezes e meia o comprimento do pedicelo; palpo laranja-acastanhado; cerdas ocelares longas e subdivergentes; cerdas verticais externas finas; em geral com dois pares de cerdas orbitais proclinadas; cerdas frontais cerca de 10, longas, estendendo-se até pouco acima da metade da parafaciália; parafrontália com cerdas finas e pêlos, estes estendendo-se até a metade da parafaciália; faciália com cerdas de 0,20 a 0,50 do comprimento da vibrissa, espaçadas, estendendo-se 0,50 da distância da vibrissa à base da antena; gena cerca de 0,35 da altura do olho.

Tórax preto; região pré-escutelar ligeiramente mais clara que o escutelo; este castanho, pruinosidade marrom-ferrugínea. Cerdas escutelares: um par de cerdas basais; três pares de laterais (sub-basais mais fracas); um par de apicais médias e espessas; várias cerdas médias e espessas entre o par de cerdas discais, afilando-se próximo à base escutelar. Perna castanho-escura. Asa: caliptra com polinosidade marrom.

Abdome (Fig. 118) castanho-escuro; pruinosidade marromferrugínea. Cerdas espessas. Sintergito 1+2 com cerca de seis pares de cerdas marginais medianas, submédias e curtas. Tergito 3 com uma fileira de cerdas marginais medianas, médias e sublongas e um grupo pequeno de cerdas discais médias e espessas. Tergito 4 com uma fileira de cerdas marginais medianas, longas e submédias.

Cercos e surstilos (Figs. 62, 91). Vista lateral, cercos subretos, com suave curvatura pouco antes do ápice; este subarredondado; largura da metade apical, após o estreitamento, constante. Surstilos entre cerca de 0,75 a 0,80 do comprimento dos cercos.

Fêmea. Vértice 0,30 da largura da cabeça; parafaciália cerca do dobro da largura do flagelômero logo abaixo das cerdas frontais e cerca de uma vez e meia na região subapical deste; cerdas ocelares e par superior das cerdas frontais mais espessas. Tórax com a região pré-escutelar castanho-avermelhada. Abdome com quetotaxia mais forte, pruinosidade marromferrugínea.

Distribuição geográfica. MÉXICO (Puebla).

Comentário. Leschenaultia townsendi pode ser separada das demais espécies norte-americanas pela presença de cerdas orbitais proclinadas; pelas cerdas da cabeça bem espessas; pelo tergito $3 \mathrm{com}$ uma fileira de cerdas marginais medianas espessas e um pequeno grupo de cerdas discais médias.
Material-tipo. Holótipo macho. MÉXICO. Puebla: Puebla, 3.VII.1952, E. E. Gilbert \& C. D. MacNeil col. (CISC.). Parátipo: idem, 1 macho (MZSP).

Leschenaultia adusta (Loew, 1872)

(Figs. 6, 34, 63, 92)

Blepharipeza adusta Loew, 1872:92 (localidade-tipo: E. U. A.: Califórnia); Williston, 1893:256 (nota); Coquillett, 1897:124, (revisão); Townsend, 1892a:89 (nota); Aldrich, 1905:472 (catálogo); Schaffiner \& Griswold, 1934:121 (lista hopedeiro e parasitóide).

Rileymyia adusta; Tonwnsend, 1908:106 (nota); Townsend, 1941:84 (nota); Brooks, 1947:178 (revisão).

Leschenaultia adusta; Sabrosky \& Arnaud, 1965:1082 (catálogo); Poole \& Lewis, 1996:287 (lista remissiva).

Diagnose. Em geral com cerdas orbitais proclinadas (Fig. 6); pró-fronte cerca de duas vezes e meia a largura da fronte; pêlos da parafrontália estendendo-se até pouco abaixo do terço inferior da parafaciália, os mais externos bem curtos, quase alinhados à orbita ocular; algumas cerdas curtas e espessas abaixo das cerdas frontais. Tórax preto, lateral do escuto, póspronoto, porção pré-escutelar, porção superior da pleura e abdome castanho-alaranjados; este com uma faixa preta longitudinal-central e leve pruinosidade cinza ou marromferrugínea-clara. Garra tarsal anterior curta, menor que o segundo tarsômero da mesma perna. Abdome: sintergito 1+2 com dois pares de cerdas marginais medianas curtas; tergito 3 com cerca de quatro pares de cerdas marginais medianas, médias e curtas; tergito 4 com uma fileira de cerdas marginais medianas, longas e médias; tergitos 3 e 4 com ou sem um pequeno grupo de cerdas discais (Fig. 92). Cercos e surstilos (Figs. 34, 63): vista lateral, cercos com nítida curvatura para trás no terço apical. Surstilos cerca de 0,80 do comprimento dos cercos.

Distribuição geográfica. E. U. A. (California, Arizona, New Mexico); MÉXICO (Sonora, Durango).

Comentários. Segundo o Dr. Adrian Pont, Oxford University Museum, (comunicação pessoal), a coleção de Loew está depositada no "Museum für Naturkunde der Humbolt Universität", Berlim. No entanto, o holótipo macho desta espécie não foi localizado nesta Instituição. Leschenaultia adusta foi identificada pela descrição original de LoEw (1872) e pela redescrição de BROOKs (1947). Os machos de L. adusta diferem dos machos das demais espécies norte-americanas que apresentam o mesmo padrão de mancha na porção pré-escutelar, pela presença de cerdas orbitais proclinadas e pela garra tarsal curta. Dois espécimens apresentaram os cercos um pouco mais robustos, no entanto, não foi possível separá-los dos demais exemplares dessa espécie.

Material examinado (machos e fêmeas - procedência). E. U. A. California: Alameda co. (Piemont, Oakland Hills, San Lonrezo, Berkeley), Butte co., Contra Costa co. (Antioch, Richmond, Brentwood), Monterey co., Orange co. (Costa Mess), Riverside co., San Diego co. San Francisco co., Santa Clara co. (San Jose), San Joaquim co. (Linden), San Mateo co. (Rewood, Brishane), Solano co. (Vallejo). Arizona: Gila co. (Pine), Cochise co. (Miller's Cyn, Chiricahua Mts. MÉXICO. Sonora: 


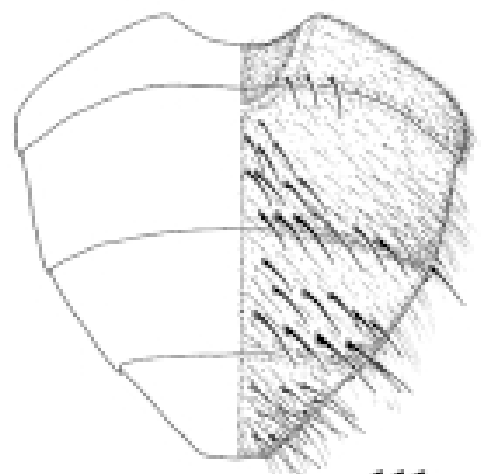

111

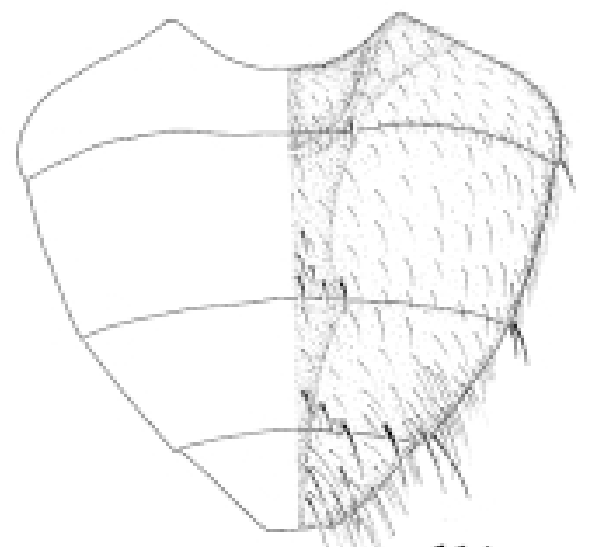

114

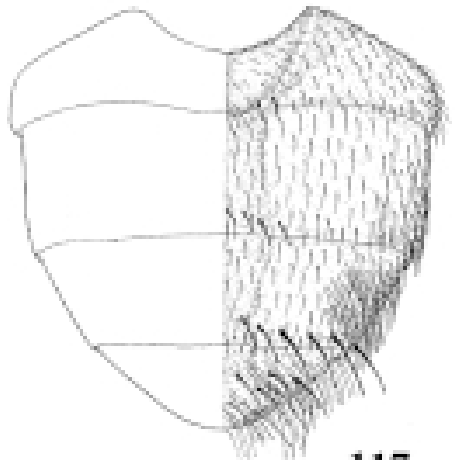

117

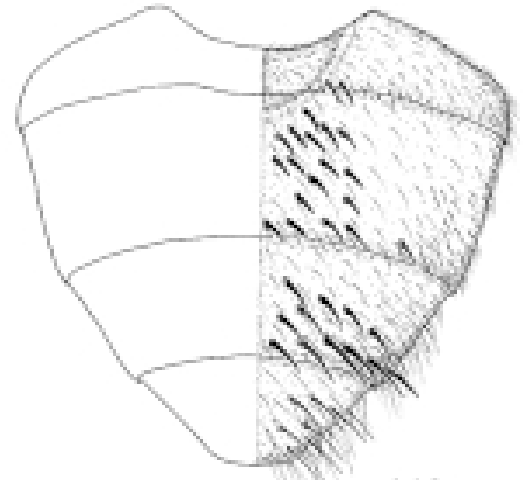

112
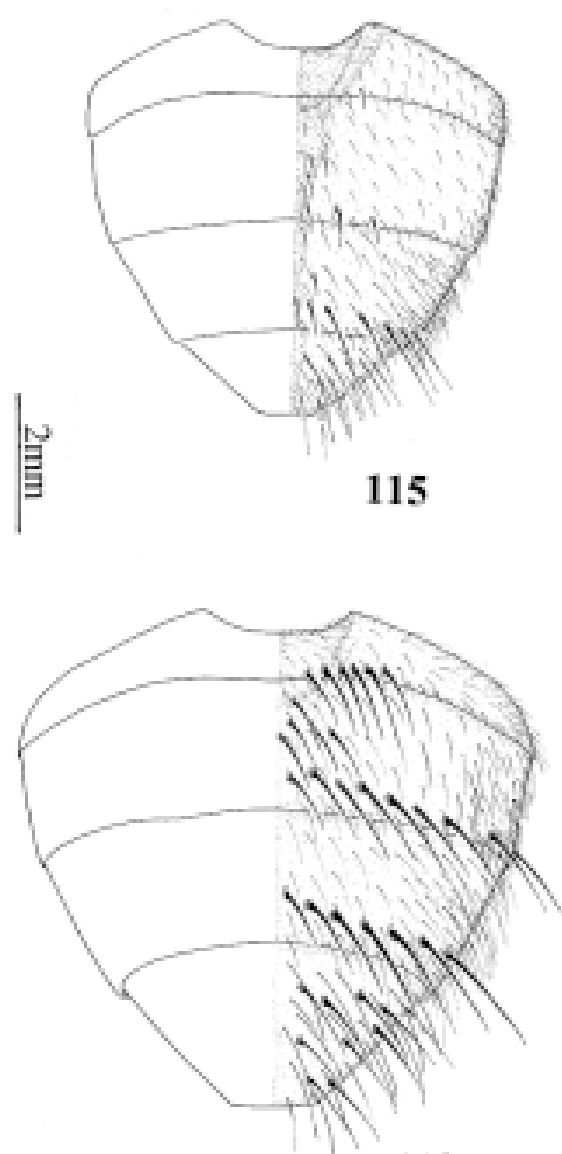

118

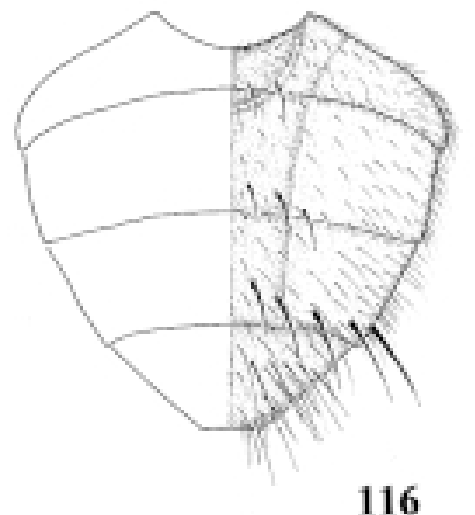

116

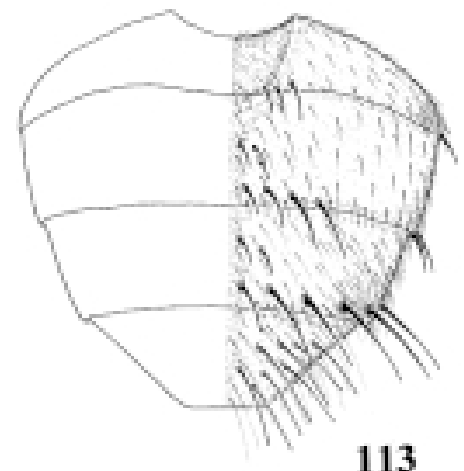

113

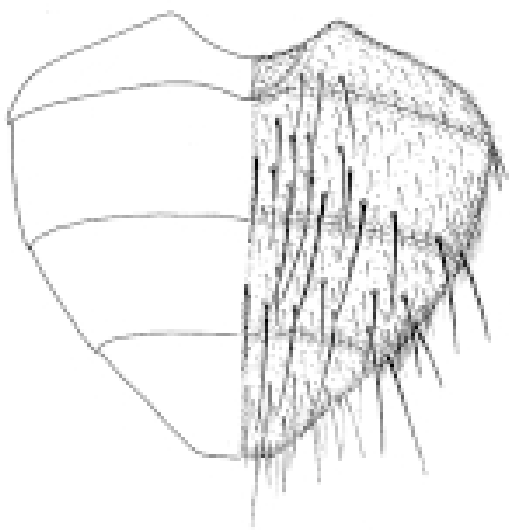

119

Figs. 111-119. Abdome, vista dorsal (macho): 111, L. cortesi sp. nov.; 112, L. currani sp. nov.; 113, L. loewi sp. nov.; 114, $L$. macquarti sp. nov.; $\mathbf{1 1 5}, L$. reinhardi $\mathbf{s p .}$ nov.; 116, $L$. sabroskyi sp. nov.; 117, L. thompsoni $\mathbf{s p .}$ nov.; 118, L. townsendi $\mathbf{s p . ~ n o v . ; ~} 119$ (fêmea), L. montagna sp. nov. 
Naco; Durango: Palos Colorado. (AMNH, CISC, MZSP, CNIC, UICM).

Leschenaultia americana (Brauer \& Bergenstamm, 1893) (Figs. 2, 7, 35, 64, 93)

Rileya americana Brauer \& Bergenstamm, 1893:116, (localidade-tipo: E. U. A.: Califórnia)

Rileymyia americana; Townsend, 1893:277; Coquillett, 1897:124, (revisão; Blepharipeza adusta partim).

Leschenaultia americana; Sabrosky \& Arnaud, 1965: 1082 (revalidação); Poole \& Lewis, 1996:287 (lista remissiva).

Rileymyia triseta Brooks, 1947: 181 (localidade-tipo: Canadá: Victoria, British Columbia) (revisão); Sabrosky \& Arnaud, 1965: 1082 (sinonímia).

Diagnose. Antena preta, pedicelo alaranjado; flagelômero quase três vezes o comprimento do pedicelo; cerdas da parafrontália estendendo-se até mais ou menos o terço inferior da paraciália (Fig. 7). Tórax preto; lateral pós-sutural do escuto, região pré-escutelar e escutelo castanho-alaranjados. Cerdas escutelares (Fig. 2): um par de cerdas basais, dois pares de cerdas laterais; um par de cerdas apicais finas, subdivergentes e suberetas, cerca da metade, ou menos, do comprimento das cerdas subapicais; várias cerdas finas e suberetas entre o par de cerdas discais. Perna castanho-alaranjada, porção basal do fêmur e tarso, escurecida. Abdome: sintergito 1+2 em geral com um par de marginal mediana submédia, com ou sem um par interno menor; tergito 3 com cerca de três pares de cerdas marginais médias e submédias, restritas à faixa preta, as cerdas submédias mais internas, e sem cerdas discais; tergito 4 com uma fileira de cerdas marginais medianas longas e médias e sem cerdas discais (Fig. 93). Fêmeas com as cerdas abdominais mais espessas. Cercos e surstilos (Figs. 35, 64): em vista lateral, cercos alongados, porção posterior sub-reta e anterior estreitando-se quase uniformente da base para o ápice. Surstilos cerca de 0,75 do comprimento dos cercos.

Distribuição geográfica. CANADÁ (British Columbia, Alberta); E. U. A. (Oregon, Montana, Idaho, California, Arizona).

Comentário. Segundo Norman Woodley, USNM, (comunicação pessoal), dois síntipos e sete espécimens da mesma procedência dos síntipos estão no USNM. No entanto, só um exemplar fêmea posssui a etiqueta de Brauer \& Bergenstamm. L. americana foi identificada através da descrição original e pela redescrição de L. triseta (Brooks). Essa espécie pode ser separada de L. fulvipes (Bigot, 1887) e de L. exul (Townsend, 1892) pela quetotaxia do escutelo e pela morfologia dos cercos e surstilos.

Material examinado (machos e fêmeas - procedência). CANADA. British Columbia: Brisco, Kleanza Creek, Terrace, Langley, Mcmurdo, Parson, Robson. E. U. A. California: Alameda co. (Sunol), Contra Costa co. (Tilden Reg. Pk.), Kern co. (Mcklttrick), Los Angeles co. (San Gabriel Mts.), Mendocino co. (Ryan Creek), Marin co. (Pt. Reyes), Santa Clara co. (Colo Cr. \& Mines Rd.), Stanislaus co. (Westley), Sonora co. (Triniti). Idaho: Nez Perce co. (Lewiston). Arizona: Sonora co. (AMNH, CISC, OSUC).
Leschenaultia bicolor (Macquart, 1846)

(Figs. 8, 36, 65, 94)

Blepharipeza bicolor Macquart, 1846:286 (localidade-tipo: E. U. A.: Texas); Schiner, 1868:336 (registro); Townsend, 1892a:64 (nota); Townsend, 1893b:9 (catálogo); Aldrich, 1905:472 (catálogo).

Parachaeta bicolor; Coquillett, 1897:124 (revisão); Townsend, 1916:11 (nota); Brooks, 1947:173 (revisão); Sabrosky \& Arnaud, 1965:1083 (catálogo); Guimarães, 1971:186 (catálogo).

Leschenaultia bicolor; Wood, 1987:1212 (chave); Poole \& Lewis, 1996:287 (lista remissiva); O’Hara \& Wood, 1998 (formalização da combinação nova).

Blepharipeza inermis Coquillett, 1910: 583 (non Bigot, 1888) (localidadetipo: E. U. A.: New York).

Parachaeta fusca Townsend, 1916:11 (nome novo para Blepharipeza inermis Coquillett 1910); Brooks, 1947:173 (sinônimo); Sabrosky \& Arnaud, 1965:1083 (revalidação); Guimarães, 1971:186 (catálogo). Syn. nov.

Leschenaultia fusca; Poole \& Lewis, 1996:287 (lista remissiva).

Parachaetopsis proseni Blanchard, 1959:163, (localidade-tipo: Argentina: Buenos Aires); Guimarães, 1977:14,63 (catálogo hopesdeiro e parasitóide). Syn. nov.

Diagnose. Fronte subarredondada em vista lateral; pêlos da parafrontália estendendo-se até o terço superior da parafaciália, logo abaixo das cerdas frontais (Fig. 8). Escutelo com um par de cerdas apicais curtas, tendendo à convergência. Garra tarsal anterior curta, menor que o segundo tarsômero da mesma perna. Cerdas discais e marginais medianas ausentes no sintergito $1+2$ e tergito 3 . Tergito 4 com uma fileira de cerdas marginais (Fig. 94). Cercos e surstilos (Figs. 36, 65): vista lateral, cercos acentuadamente curvados para trás. Surtilos cerca de 0,80 do comprimento dos cercos.

Distribuição geográfica. CANADÁ (Ontario, Quebec); E. U. A. (Ohio, Iowa, Texas); MÉXICO (Jalisco, Chiapas, Loja, Huanuco); BRASIL (Mato Grosso, Minas Gerais, Rio Grande do Sul); ARGENTINA (Buenos Aires).

Comentário. O holótipo fêmea de Blepharipeza bicolor Macquart não foi encontrado.

Coquillett (1897) descreveu o gênero Parachaeta originalmente sobre uma única espécie nominal, Blepharipeza bicolor Macquart, 1846, que para ele seria sinônimo sênior de Blepharipeza inermis Bigot, 1888. No entanto, Coquillett (1910) listou Blepharipeza inermis como espécie-tipo de Parachaeta. Decisão tomada por acreditar que sua identificação da espécie-tipo original, Blepharipeza bicolor Macquart, 1846, estivesse incorreta, influenciado pela identificação equivocada de BRAUER (1898), que afirmou ser Blepharipeza bicolor Macquart, 1846 sinônimo de Blepharipeza leucophrys (Wiedemann, 1830). TOWNSEND (1916), seguindo BRAUER (1898) e afirmando também que o exemplar de Coquillett não concordava com a descrição de Blepharipeza inermis Bigot, 1888, renomeou Blepharipeza bicolor Coquillett, 1897 non Macquart, 1846 (= Blepharipeza inermis Coquillett, 1910 non Bigot, 1888) para Parachaeta fusca Townsend, 1916.

BRooks (1947) colocou Parachaeta fusca Townsend, 1916 como sinônimo júnior de Blepharipeza bicolor Macquart, 1846. Este raciocínio é seguido neste trabalho, apesar de não ser concordante com os catálogos de SABroski \& ARNAUd (1965) e 
Guimarães (1971), nem com a lista remissiva de Poole \& LewIS (1996), que consideram Parachaeta bicolor (Macquart, 1846) diferente de Parachaeta fusca Townsend, 1916.

Parachaetopsis proseni Blanchard, 1959 é idêntica à Leschenaultia bicolor (Macquart, 1846), sendo aqui colocada como seu sinônimo júnior. Foi examinado um exemplar de Parachaetopsis proseni com os mesmos dados do holótipo e de um parátipo.

Material-tipo examinado. Holótipo macho de Blepharipeza inermis Coquillett (1910) E. U. A. New York (USNM). Holótipo(?) macho de Parachaetopsis proseni: ARGENTINA. Buenos Aires, XII.1949, Foerster col. (MACN); hospedeiro: Halisidota fuscipennis (Burmeister).

Material examinado (machos e fêmas - procedência). E. U. A. New York: Orange co. (Texudo). Iowa: Robinson Delaware co. Ohio: Fairfield co.; Hocking co., Lorain co. (Amherst), Ottawa co. Texas: Cameron co. (Brownsville). MÉXICO. Jalisco: Guadalajara (La Venta). Chiapas: Bajacu. COLOMBIA. Meta: Guayuriba. BRASIL. Amazonas: Manaus (Reserva Ducke). Mato Grosso: Chapada. Bahia: Ilheus. Minas Gerais: São João del Rei. Rio Grande do Sul: Pelotas. EQUADOR. Loja: Zamora. PERU. Loreto: Achinamisa. Huanuco: Tingo Maria, Previsto. (AMNH, BMNH, CISC, CNCI, MZSP, OSUC).

\section{Leschenaultia ciliata (Macquart, 1848)}

$$
\text { (Figs. 9, 37, 66, 97) }
$$

Phorocera ciliata Macquart, 1848:209 (localidade-tipo: Colômbia). Leschenaultia ciliata; Guimarães, 1971:185 (catálogo).

Diagnose. Olho distintamente piloso (Fig. 9); cerdosidade da parafrontália estendendo-se até o terço inferior da parafaciália. Tórax preto com lateral pós-sutural do escuto, porção pré-escutelar, escutelo, porção superior-posterior das pleuras e abdome castanho-alaranjados. Abdome: sintergito $1+2$ com cerca de quatro pares de cerdas marginais medianas curtas; tergito 3 com uma fileira de cerdas marginais medianas médias e curtas, restritas ao meio, e em geral sem cerdas discais; tergito 4 com uma fileira de cerdas marginais medianas longas e médias (Fig. 97). Fêmea com cerdas abdominais mais espessas. Cercos e surstilos (Figs. 37, 66) morfologicamente semelhantes aos de L. americana, porém relativamente menores.

Distribuição geográfica. COLÔMBIA (Bogotá).

Comentário. Alguns exemplares identificados como $L$. ciliata apresentam um pequeno grupo de cerdas discais curtas no tergito 3, diferindo nesse aspecto da descrição de MACQUART (1848).

Material-tipo examinado. Holótipo macho. COLÔMBIA (BMNH; ex-coleção Bigot). Exemplar sem o abdome.

Material examinado (machos e fêmeas - procedência). COLÔMBIA. Bogotá; Cundinamarca: Usaquén. (AMNH, BMNH).

Leschenaultia exul (Townsend, 1892)

(Figs. 10, 38, 67, 95)

Blepharipeza exul Townsend, 1892b:64; localidade-tipo: E. U. A., New
Hampshire, Coquillett, 1897:124, (revisão; Blepharipeza adusta partim); Schaffiner \& Griswold, 1934:121 (revalidação).

Rileymyia exul; Brooks, 1947:178 (revisão).

Leschenaultia exul; Bess, 1936:593 (biologia); Sabrosky \& Arnaud, 1965:1083 (catálogo); Poole \& Lewis, 1996:287 (lista remissiva). Tachina incauta Harris, 1835: 599 Nomen nudum; Sabrosky \& Arnaud, 1965:1083 (catálogo).

Diagnose. Arista afilando-se bem próximo ao terço apical; cerdas da parafrontália estendendo-se até pouco abaixo da metade da parafaciália (Fig. 10). Tórax preto, lateral pós-sutural do escuto e porção pré-escutelar castanho-alaranjados. Escutelo com um par de cerdas basais e três pares de cerdas laterais; um par de cerdas apicais finas, cerca da metade, ou menos, do comprimento das cerdas subapicais, estas subparalelas e suberetas; várias cerdas curtas, finas e suberetas entre o par de cerdas discais. Perna castanha ou castanhoescura. Abdome (Fig. 95) castanho-escuro ou castanhoavermelhado, com uma faixa preta central; pruinosidade marromferrugínea dorsal e cinza ventral. Sintergito $1+2$ com dois ou três pares de cerdas marginais medianas curtas; tergito $3 \mathrm{com}$ três ou mais pares de cerdas marginais medianas médias e curtas, estas mais centrais e distantes da margem, e com ou sem um pequeno grupo de cerdas discais; tergito 4 com uma fileira de cerdas marginais longas, média e curtas, estas mais centrais e afastadas da margem. Cercos e surstilos (Figs. 38, 67): vista lateral, cercos suavemente curvados para trás na porção posterior; surstilos cerca de 0,80 do comprimento dos cercos.

Distribuição geográfica. CANADÁ (Ontario, Quebec, New Bruswick); E. U. A. (Maine, New York, New Hampshire, Massachussetts, Connecticut, New Jersey, Maryland).

Comentário. Townsend (1892b) descreveu esta espécie baseado numa fêmea, citando mais sete espécimens, provavelmente coespecíficos, sem designar o local de depósito do material. Segundo Norman Woodley (USNM, comunicação pessoal), o holótipo fêmea provavelmente está no MCZC. Leschenaultia exul foi identificada através da descrição. Os machos desta espécie diferem dos machos de L. americana pela presença de três pares de cerdas escutelares laterais, e dos machos de L. adusta, pela garra tarsal anterior em geral maior que o segundo tarsômero da mesma perna e pela ausência das orbitais proclinadas.

Material examinado (machos e fêmeas - procedência). CANADÁ. Ontario: Ottawa, Marmora. Quebec: Parc du Mont Tremblant. New Brunswick: Hanwell. E. U. A. Maine: Waldo co. (Stockton). New York: Thompkins co. (Ithaca). New Hampshire: Grafton co. (Fronconia). Massachusetts: Middlesex co. (Melrose Hlds.); Connecticut: Fairfield co. (Stamford). New Jersey: Warren co. (Blairstown), Ocean co. (Lahaway), Bergen co. (Remsey). Maryland: Frederick co. (Lewistown). (AMNH, CISC, CNCI, MZSP, UM).

Leschenaultia fulvipes (Bigot, 1887) (Figs. 11, 39, 68, 96)

Blepharipeza fulvipes Bigot, 1887:cxl (localidade-tipo: E. U. A.: Washington); Bigot, 1888:92 (redescrição); Coquillett, 1897:124, (revisão; Blepharipeza adusta partim); Schaffiner \& Griswold, 
1934:122 (revalidação).

Rileymyia fulvipes; Brooks, 1947:181 (sinonímia).

Leschenaultia fulvipes; Sabrosky \& Arnaud, 1965:1083 (catálogo); Poole \& Lewis, 1996:287 (lista remissiva).

Blepharipeza rufescens Townsend, 1892a:90 (localidade-tipo: E. U. A.: Maryland?); Coquillett, 1897:124, (revisão; Blepharipeza adusta partim).

Rileymyia rufescens; Townsend, 1941: 84 (revalidação).

Diagnose. Escapo e pedicelo alaranjados; pró-fronte bem projetada; parafrontália com pêlos e cerdas estendendo-se até pouco abaixo da metade da parafaciália (Fig. 11). Tórax preto, com lateral pós-sutural do escuto e porção pré-escutelar castanhos. Abdome castanho-alaranjado com uma faixa preta longitudinal-central, pruinosidade marrom-ferrugínea-clara e levemente cinza. Sintergito $1+2$ com um par de cerdas marginais medianas curtas; tergito $3 \mathrm{com}$ um par de cerdas marginais medianas submédias, um par de cerdas menores internas, presente ou não; tergito 4 com uma fileira de cerdas marginais medianas longas e médias (Fig. 96). Fêmea com sintergito 1+2 com três pares de marginais curtas e centrais; tergito $3 \mathrm{com}$ quatro pares de marginais curtas e médias. Cercos e surstilos (Figs. 39, 68): vista lateral, cercos suavemente curvados para trás; ápice dos surstilos levemente abaulados. Surstilos cerca de 0.75 a 0,80 do comprimento dos cercos.

Distribuição geográfica. CANADÁ (British Columbia, Saskatchewan); E. U. A. (Washington, Idaho, Wyoming, California, Arizona, New Mexico, Texas).

Comentário. Leschenaultia fulvipes foi descrita por BIGOT (1887) como sendo um macho. No entanto, o holótipo recebido do BMNH é uma fêmea. O macho foi identificado pela redescrição de Brooks (1947). Difere das espécies que possuem a porção pré-escutelar castanho-alarajada, por apresentar o tergito 3 , em geral, com somente um par de cerdas marginais medianas.

Material-tipo examinado. Holótipo fêmea. E. U. A. Washington, (BMNH; ex-coleção Bigot).

Material examinado (machos e fêmeas - procedência). E. U. A. Idaho: Lemhi co. (Bannock Pass), Pike co. (Pike Mt.), Sunset Cone Cratera of The Moon, Nat. Mon.. California: Santa Cruz co.. Arizona: Apache co. (Greer - Phelps Bot. Area). Wyoming: Carbon co. (Rawlins). Texas: Austin co. (AMNH, CISC, CNCI, UICM).

\section{Leschenaultia grossa Brooks, 1947}

(FIGS. 12, 40, 69, 98)

Leschenaultia grossa Brooks, 1947:176 (localidade-tipo: E. U. A.: Arizona, Huachuca); Sabrosky \& Arnaud, 1965: 1083 (catálogo); Poole \& Lewis, 1996:287 (lista remissiva).

Diagnose. Pêlos da parafrontália estendendo-se pouco abaixo da metade da parafaciália (Fig. 12). Tórax preto; porção pré-escutelar, lateral pós-sutural do escuto e escutelo castanhoalaranjados. Abdome (Fig. 98) castanho-avermelhado com uma faixa longitudinal-central preta, alargada no sintergito $1+2 \mathrm{e}$ tergito 5 . Sintergito $1+2$ com dois ou três pares de cerdas marginais medianas curtas e relativamente espessas; tergito 3 com uma fileira irregular de cerdas marginais medianas curtas, restritas ao centro; tergito 4 com uma fileira de cerdas marginais medianas, longas e curtas. Fêmea: tergitos 3 e 4 com um grupo de cerdas discais curtas e espessas. Cercos e surstilos (Figs. 40,69 ) robustos; surstilos cerca de 0,85 do comprimento dos cercos.

Distribuição geográfica. E. U. A. (Nevada, Arizona, New Mexico).

Comentário. Esta espécie pode ser separada de Leschenaultia macquarti sp. nov. e de L. halisidotae Brooks, 1947 por apresentar os pêlos da parafrontália estendendo-se pouco abaixo da metade da parafaciália.

Material-tipo examinado. Holótipo macho. E. U. A. Arizona: Cochise co., Sunnyside Canyon, Huachuca Mts., 9.VII.1940, R. H. Beamer col. (KSUC).

Material examinado (machos e fêmeas - procedência). E. U. A. Arizona: Cochise co. (Huachuca Mts., Knicksville). (AMNH, CISC, CNCI).

Leschenaultia halisidotae Brooks, 1947

(Figs. 13, 41, 70, 99)

Leschenaultia halisidotae Brooks, 1947:176 (localidade-tipo: Canadá: Ontario); Sabrosky \& Arnaud, 1965:1083, (catálogo); Poole \& Lewis, 1996:287 (lista remissiva).

Diagnose. Flagelômero quase três vezes o comprimento do pedicelo; pêlos da parafrontália estendendo-se até pouco antes da metade superior da parafaciália (Fig. 13). Lateral do escuto, área pré-escutelar, calo pós-pronotal e escutelo castanhoalaranjados. Abdome (Fig. 99) castanho-alaranjado, faixa preta longitudinal-central. Sintergito $1+2$ com dois ou três pares de cerdas marginais medianas curtas e finas; tergito 3 com cerdas marginais medianas curtas e meio espessas; tergito 4 com uma fileira de cerdas marginais medianas longas e curtas, estas mais centrais; tergitos 3 e 4 com um pequeno grupo de cerdas discais. Quetotaxia abdominal da fêmea mais forte. Cercos e surstilos (Figs. 41, 70): vista lateral, cercos estreitando-se acentuadamente da base para o ápice, este bem estreito; surstilos cerca de 0,75 do comprimento dos cercos.

Distribuição geográfica. CANADÁ (British Columbia, Ontario, Quebec); E. U. A. (Minesota, Maine, New York, Massachussetts, Ohio, Wisconsin, Pennsylvania, New Jersey, California, Arizona).

Comentário. O holótipo macho (CNCI) não foi examinado. Entre os parátipos, foi encontrado um exemplar macho pertencente a uma outra espécie, $L$. reinhardi $\mathbf{s p . ~ n o v . ~ ( v i d e ~}$ pág. 51)

Leschenaultia halisidotae difere de L. grossa Brooks, 1947 por apresentar pêlos da parafrontália não ultrapassando a metade da parafaciália; de Leschenaultia reinhardi sp. nov., pela porção pré-escutelar castanho-alaranjada e escutelo sem mescla de pruinosidade; de Leschenaultia macquarti sp. nov., pelo flagelômero mais longo que o dobro do comprimento do pedicelo. 
Material-tipo examinado. Parátipos. CANADÁ. Ontario: Toronto, 1 fêmea, 19.V.1925, N. k Bigetow col. (CNCI). Ottawa, 2 machos, 16.VI.1908 (CNCI). Quebec: 1 macho, 23.VIII.1941, J. Quellet col. (UM). E. U. A. New York: Gardiner's Island, 1 fêmea, 17.VIII.1918, Bequaert col. (CNCI).

Material examinado (machos e fêmeas - procedência). CANADÁ. British Columbia: Robson. Ontario: Ottawa. Quebec: Aylmer. E. U. A. Minesota: Meeker co. (Litchfield). Maine: Penobscot co. (Bangor), Maine Fall; New York: Bronx co., Nassau co. (Inwood Pk.), Suffolk co. Massachussetts: Banstable co. (Wood Hole). Ohio: Jefferson co., Hocking co., Ottawa co. New Jersey: Bergen co. (Englewood Cliff), Forest Hill. California: Alameda co (Berkeley), Napa co., Los Angeles co. (Tambark Flat), Shasta co. (Burney Spring). Arizona: Graham co., Cochise co. (Huachuca Mts.). (AMNH, CISC, CNCI, MZSP, OSUC).

Leschenaultia hospita Reinhard, 1952

(Figs. 14, 42, 71, 100)

Leschenaultia hospita Reinhard, 1952:7 (localidade-tipo: México: Michoacan); Sabrosky \& Arnaud, 1965:1083 (catálogo); Guimarães, 1971:186 (catálogo).

Diagnose. Pêlos da parafrontália estendendo-se até pouco antes da metade superior da parafaciália (Fig. 14). Tórax preto; escutelo castanho-alaranjado, leve pruinosidade marromferrugínea. Abdome (Fig. 100) castanho-alaranjado com uma faixa preta logitudinal-central estreitando-se da base para o ápice; pruinosidade marrom-ferrugínea. Sintergito $1+2$ com cinco pares de cerdas marginais medianas, curtas e espessas; tergito 3 com uma fileira de cerdas marginais medianas, relativamente médias, e cerdas discais curtas e espessas; tergito 4 com uma fileira de cerdas marginas médias e longas, e uma fileira de cerdas discais, com cerdas mais curtas que as marginais medianas. Fêmea: sintergito 1+2 com cerca de cinco pares de cerdas marginais curtas; tergito 3 com marginais medianas restritas à porção central e um grupo de cerdas discais curtas; tergito 4 com uma fileira de cerdas marginais medianas longas e médias, estas mais centrais e afastadas da margem. Cercos e surstilos (Figs. 42, 71): vista lateral, cercos com suave curvatura na porção posterior; surstilos com largura subigual na metede apical e cerca de 0,75 do comprimento dos cercos.

Distribuição geográfica. México (Michoacan, Oaxaca, Morelos); Estados Unidos (New Mexico).

Material-tipo examinado. Parátipo fêmea, MÉXICO. Oaxaca: Nochixtlan, 6.VII, 1947, F.A, Cowan \& M.R, Wheeler col. (CNCI). O holótipo macho, depositado na mesma instituição, não foi examinado.

Material examinado (macho - procedência). MÉXICO. Morelos. (CNCI).

Leschenaultia hystrix (Townsend, 1915) comb. nov. (Figs. 15, 101)

Echinomasicera hystrix Townsend, 1915:413 (localidade-tipo: Peru: Matucana); Guimarães, 1971:185 (catálogo); Cortés, 1983:386 (descrição da fêmea).

Diagnose. Quetotaxia da cabeça forte, gena com cerdas espessas e espaçadas; dois pares de cerdas orbitais proclinadas (Fig. 15). Tórax preto, calo pós-alar e escutelo castanhoavermelhados. Abdome (Fig. 101) preto, laterais do tergito 3 castanho-alaranjados. Sintergito $1+2$ com cerca de quatro pares de cerdas marginais medianas. Tergito 3 com cerca de cinco pares de cerdas marginais; um grupo pequeno de cerdas discais. Tergito 4 com uma fileira de cerdas marginais e uma de cerdas discais, mais ou menos alinhadas.

Distribuição geográfica. PERU (Matucana).

Comentário. Leschenaultia hystrix (Townsend, 1915) é a única espécie sul-americana cujo macho apresenta cerdas orbitais proclinadas.

Material-tipo examinado. Holótipo macho. PERU. Matucana (2400 m.), 1.V.1914, Townsend col. (USNM; exemplar sem a terminália).

Leschenaultia jurinioides (Townsend, 1895) (Figs. 16, 43, 72, 102)

Blepharipeza jurinioides Townsend, 1895:71 (localidade-tipo: Jamaica: Cinchona); Aldrich, 1905:472 (catálogo).

Leschenaultia jurinioides; Guimarães, 1971:186 (catálogo).

Diagnose. Flagelômero mais que o triplo do comprimento do pedicelo (Fig. 16); com um ou dois pares de cerdas orbitais proclinadas; pêlos da parafrontália estendendo-se até logo abaixo das cerdas frontais. Tórax e abdome pretos. Escutelo com um par de cerdas basais, dois pares de cerdas laterais. Garra tarsal anterior curta, em geral menor que o segundo tarsômero da mesma perna. Abdome: sintergito 1+2 com seis pares de cerdas marginais medianas, curtas e submédias, e poucos pares de cerdas discais; tergito 3 com uma fileira de cerdas marginais e um grupo grande de cerdas discais; tergito 4 com uma fileira de cerdas marginais medianas e duas fileiras de cerdas discais desalinhadas (Fig. 102). Cercos e surstilos (Figs. 43, 72): vista lateral, cercos curvados para trás no terço apical e estreitando-se anteriomente de forma retilínea. Surstilos cerca de 0,70 do comprimento dos cercos.

Distribuição geográfica. JAMAICA (Cinchona, Treluraus).

Comentário. O holótipo é uma fêmea e foi depositado, inicialmente, na coleção particular de Townsend. Segundo Dr. Norman Woodley (comunicação pessoal), o holótipo está, agora, depositado no BMNH. Leschenaultia jurinioides foi identificada pela descrição. Esta espécie possui a quetotaxia abdominal bastante densa. Difere de L. arnaudi sp. nov., pelos seguintes aspectos: sintergito $1+2$ com cerdas discais; tergito 4 com somente uma fileira de cerdas discais; par de cerdas escutelares discais não distinto das demais cerdas.

Material examinado (machos e fêmeas - procedência). JAMAICA. Baron Hill, Cinchona, Treluraus. (AMNH, MCZC).

Leschenaultia leucophrys (Wiedemann, 1830)

(Figs. 1, 3, 4, 5, 17, 44, 73, 103) 
Tachina leucophrys Wiedemann, 1830:308 (localidade-tipo: Brasil).

Blepharipeza leucophrys; Schiner, 1868:336 (sinonímia); Williston, 1886:404 (nota); Brauer \& Bergenstamm, 1889:28 (monografia); Giglio-Tos, 1894:28 (lista de sinônimos); Röder, 1885:345 (nota); Bigot, 1888:89 (nota); Townsend, 1892a:89 (nota), Townsend, 1893b:9 (catálogo); Coquillett, 1897:124 (revisão); Aldrich, 1927:30 (redescrição);

Leschenaultia leucophrys; Townsend, 1931:175 (sinonímia); Brooks, 1947:174 (revisão); Sabrosky \& Arnaud, 1965:1082 (catálogo); Guimarães, 1971:186 (catálogo).

Leschenaultia cilipes Robineau-Desvoidy, 1830:325 (localidade-tipo: Suriname); Townsend, 1916:7 (designado como espécie-tipo de Leschenaultia); Townsend, 1931:175 (sinônimo júnior de $L$. leucophrys).

Blepharipeza rufipalpis Macquart, 1843:211 (1843:54) (localidade-tipo: México); Bigot, 1857:343 (nota); Schiner, 1868:336 (sinonímia).

Belvosia rufipalpis; Wulp, 1883:25 (revalidação da espécie); Townsend, 1892:9 (sinonímia).

Tachina latifrons Walker, 1852:284 (localidade-tipo: “América do Sul”); Townsend, 1893b:14 (catálogo); Giglio-Tos, 1894:29 (sinonímia), Syn. nov.

Leschenaultia latifrons; Guimarães, 1971:186 (revalidação).

Masicera nigricalyptrata Macquart, 1855:120 (1855:100, ver referências), (localidade-tipo: Brasil, Amazonas). Syn. nov.

Parachaeta nigricalyptrata; Guimarães, 1971:104.86 (combinação nova).

Harrisiopsis spinosa Townsend, 1927:313 (localidade-tipo: Brasil: São Paulo, Itaquaquecetuba); Townsend, 1931:175 (sinonímia).

Diagnose. Pêlos da parafrontália estendendo-se até logo abaixo das cerdas frontais (Fig. 17). Tórax e abdome pretos; este e escutelo com pruinosidade marrom-ferrugínea. Sintergito $1+2$ e tergito 3 com cerdas marginais medianas bem curtas; tergito 4 com uma fileira de cerdas marginais medianas espessas, longas e médias; tergitos 3 e 4 com um grupo de cerdas discais subespessas e bem curtas, as do tergito 4 pouco maiores (Fig. 103). Fêmea: sintergito $1+2$ com dois a cinco pares de cerdas marginais espessas, curtas e submédias; tergito 3 com uma fileira de cerdas marginais médias e espessas, interrompida, ou não lateralmente e um grupo de cerdas discais curtas e submédias; tergito 4 com uma fileira de cerdas marginais, longas e médias, e uma fileira desalinhada de cerdas discais com cerca da metade do tamanho das marginais. Cercos e surstilos (Figs. 44, 73): vista lateral, cercos curvados para trás no terço apical e em seguida para frente, estreitando-se mais acentuadamente nessa porção. Surstilos cerca de 0,70 do comprimento dos cercos.

Distribuição geográfica. Do MÉXICO; VENEZUELA; EQUADOR; BOLÍVIA; PERU; PARAGUAI; URUGUAI; BRASIL.

Comentário. É a espécie melhor representada em número de exemplares nas coleções. O material proveniente do norte do México, entretanto, identificado como L. leucophrys, refere-se à Leschenaultia reinhardi sp. nov.; é provável que $L$. leucophrys não ocorra ao Norte do México.

Lescheaultia leucophrys é semelhante a L. bigoti sp. nov., L. currani sp. nov. e L. brooksi sp. nov. Difere de L. bigoti pela coloração da pruinosidade da cabeça; de $L$. currani, pelas cerdas abdominais menos espessas; de L. brooksi, por apresentar cerca de quatro cerdas marginais e cerdas discais mais conspícuas no tergito 3 .

Os holótipos de Leschenaultia nigricalyptrata (Macquart, 1855) e Leschenaultia latifrons (Walker, 1852) foram examinados e conferem com Leschenaultia leucophrys (Wiedemann, 1830), sendo aqui considerados como sinônimos juniores.

O holótipo de Leschenaultia cilipes Robineau-Devoidy, 1830, provavelmente está perdido.

Material-tipo examinado. Lectótipo macho com etiqueta de designação de Wood de 1986 (não publicado) de Tachina leucophrys. BRASIL. Winthem col. (NHMV; ex-coleção Wiedemann). Holótipo macho de Masicera nigricalyptrata: [BRASIL?]. Amazonas, (BMNH; ex-coleção Bigot). Holótipo macho de Tachina latifrons. América do Sul (BMNH; ex-coleção Saunders). Holótipo fêmea de Harrisiopsis spinosa. BRASIL. São Paulo: Itaquaquecetuba, 10.IX (USNM).

Material examinado (procedência). MÉXICO. San Luis Potosí: Tamazunchale. VENEZUELA. Caracas: Pico del Avila, Caura Val.. BRASIL. Amazonas: Rio Caiary, Uaupes. Mato Grosso: Chapada. Mato Grosso do Sul: Corumbá, Maracajú. Goiás: Anápolis, Goiânia, Jataí. Brasília D.F. Minas Gerais: Belo Horizonte. Rio de Janeiro: Nova Friburgo; Rio de Janeiro, Represa do Cabeça, Angra dos Reis, Itatiaia. São Paulo: São Paulo, Barueri, Cajuru (Oássia dos Coqueiros), Campos do Jordão, Cantareira, Caraguatatuba, Capão Bonito (Res. Flor. I.B.D.F.), Embú, Guarujá, Jundiaí, Osasco, Ribeirão Preto (Rio Tamandaré), Rio Claro, Ilha de São Sebastião (Ilha Bela), Salesópolis. Paraná: Curitiba. Santa Catarina: Corupá, Nova Teutônia. Rio Grande do Sul, Pelotas. EQUADOR. Limon. PERU. Huanuco: Tingo Maria. Loreto: Rio Ucayali. Loreto ou Cuzco?: Rio Urubamba. Junin: Estancia Naranjal, San Ramon (1000m.). Amazonas: Rio Santiago. BOLÍVIA. Beni: Versalles. PARAGUAI. Caazapá: Buena Vista. Guaira: Villarica. URUGUAI. Tacuarembo. (AMNH, MCZC, MZSP)

\section{Leschenaultia montagna (Townsend, 1912)}

(Figs. 33, 119)

Blepharipeza montagna Townsend, 1912:351 (localidade-tipo: Peru: Ponte Uruhuasi, Rio San Gaban).

Leschenaultia montagna; Guimarães, 1971:186 (catálogo).

Diagnose. Fêmea: lateral do escuto e porção pré-escutelar castanho-alaranjadas; abdome com pruinosidade marromferrugínea. Sintergito $1+2$ com três pares de cerdas marginais medianas. Tergito 3 com uma fileira de cerdas marginais; um grupo de cerdas discais. Tergito 4 com uma fileira de cerdas marginais medianas e uma fileira de cerdas discais (Fig. 119).

Distribuição geográfica. PERU (Rio San Gaban)

Comentário. $\mathrm{O}$ holótipo fêmea assemelha-se à fêmea de $L$. leucophrys (Wiedemann, 1830), diferindo, principalmente, pela coloração do tórax e abdome e pelas cerdas abdominais mais longas e mais espaçadas. O macho de L. montagna não é conhecido.

Material-tipo examinado. Holótipo fêmea. PERU. Ponte Uruhuasi, Rio San Gaban, 15.II.1910, Townsend col. (USNM).

\section{Leschenaultia nuda Thompson, 1963}

Leschenaultia nuda Thompson, 1963:288 (localidade-tipo: Trinidad, 
"Brasil" (village)); Guimarães, 1971:186 (catálogo).

Diagnose. Garras tarsais curtas e sintergito $1+2$, tergitos 3 e 4 sem cerdas marginais medianas.

Distribuição geográfica. TRINIDAD.

Comentário. Thompson (1963) citou apenas a localidadetipo do macho e da fêmea, não designando o holótipo. Os síntipos desta espécies estão provavelmente depositados na CNCI. Segundo Thompson (1963), Leschenaultia nuda entra como L. leucophrys (Wiedemann, 1830) na chave de BroOKS (1947), enquanto que na chave de Townsend (1936), o macho corre para Parachaeta Coquillett, 1897, por não possuir cerdas marginais nos sintergito $1+2$ e tergito 3 , e a fêmea para Leschenaultia Robineau-Desvoidy, 1830. O mesmo autor sustentou que, apesar da fêmea e o macho serem diferentes, ambos pertencem à mesma espécie e que é possível separar $L$. nuda de L. leucophrys com base na morfologia do ovo e larva de primeiro ínstar, embora haja semelhança entre adultos destas espécies.

Um exemplar fêmea examinado, proveniente de Trinidad e com o mesmos dados do tipo, com exceção da data, conferiu exatamente com a descrição de $L$. nuda e com os exemplares fêmeas associados à L. leucophrys, excetuando a fileira de cerdas discais do tergito 4 interrompida lateralmente. Por outro lado, a descrição do macho é próxima à de L. bicolor (Macquart).

Por não serem avaliadas a morfologia do ovo e da larva de primeiro ínstar, L. nuda é mantida como espécie nominalmente válida.

Material examinado. TRINIDAD. 1 fêmea (CNCI).

Leschenaultia nigrisquamis (Townsend, 1892)

Blepharipeza nigrisquamis Townsend, 1892:80, holótipo macho, sem menção sobre depósito do exemplar-tipo (localidade-tipo: Jamaica: Portland); Aldrich, 1905:473 (catálogo).

Leschenaultia nigrisquamis; Guimarães, 1971:186 (catálogo).

Comentário. Não foi examinado material dessa espécie. Townsend (1892c) descreveu L. nigrisquamis com base num exemplar macho, que não foi localizado. Pela descrição original, essa espécie assemelha-se à L. arnaudi sp. nov., pelo flagelômero cerca de três vezes o comprimento do pedicelo, pela garra tarsal curta e pelo conjunto denso de macroquetas abdominais. No entanto, o conhecimento mais detalhado do padrão de quetotaxia abdominal é necessário para esclarecer a identidade de L. nigrisquamis.

Espécies não reconhecidas:

\section{Leschenaultia trichopsis (Bigot, 1887)}

Blepharipeza trichopsis Bigot, 1887:cxl, (holótipo macho perdido) (localidade-tipo: México).

Leschenaultia trichopsis; Guimarães, 1971:186 (catálogo).
Comentário. Bigot (1887) submeteu à Sociedade de Entomologia da França diagnoses de algumas espécies novas que seriam posteriormente redescritas num memorial a ser apresentado à mesma Instituição. Uma das diagnoses apresentadas nessa data foi a de Blepharipeza trichopsis. No entanto, Bigot (1888), ao redescrever as espécies do trabalho do ano anterior, não redescreveu Blepharipeza trichopsis. Essa espécie só veio a ser listada novamente por Guimarães (1971) sob Leschenaultia, como espécie não reconhecida. $\mathrm{O}$ presente trabalho a mantém assim, porque é impossível reconhecê-la através da sua diagnose, e o seu exemplar-tipo está perdido.

\section{Leschenaultia hirta Robineau-Desvoidy, 1830}

Leschenaultia hirta Robineau-Desvoidy, 1830:325, sem menção de sexo, exemplar-tipo perdido (localidade-tipo: desconhecida).

Comentário. RobineAu-Desvoidy (1830), ao descrever Leschenaultia hirta, comentou desconhecer sua localidadetipo. Não há conhecimento de citação dessa espécie em nenhum trabalho subseqüente.

Agradecimentos. Aos responsáveis pelos empréstimos de material: Dra. Caroline Chaboo (AMNH), Dr. Nigel Wyatt (BMNH), Dr. Claudio José B. de Carvalho (DZUP), Dra. Alissa Salmore (MCZC), Dr. Brian Kopper (KSUC), Dr. Axel Bachmann (MACN), Dra. Francisca do Val (MZSP), Dr. A. Sharkov (OSUC), Dr. Cheryl Barr (CISC), Dr. F. W. Merickel (UICM), Dr. L. Cloutier (UM), Dr. Norman Woodley (USNM), Dr. James O'Hara (CNCI). Aos dois últimos pesquisadores e também ao Dr. Paul Arnaud (California Academy of Scinces) pelos esclarecimentos sobre as sinonímias de Rileymyia. Aos Doutores Adrian Pont (Oxford University Museum) e Loïc Matile (MNHN) pelas informações sobre alguns exemplares-tipos. Aos doutores Claudio José B. de Carvalho, Luciane Marinoni, Danúncia Urban, Keti M. R. Zanol, Sônia C. Prevedelo (UFPR) e Márcia S. Couri (MNRJ), e aos doutorandos Gustavo Gracioli e Luís Gonzaga dos Santos Neto (UFPR) pela leitura e sugestões. Ao Dr. Ubirajara Martins (MZSP) pelos esclarecimentos de dúvidas sobre o Código Internacional de Nomenclatura Zoológica.

\section{REFERÊNCIAS.}

Aldrich, J. M. 1905. A catalogue of North American Diptera. Smithsonian Miscellaneous Collections 46:1-680.

AldRich, J. M. 1927. Redescription of types of American muscoid flies in the collection of the Vienna Natural History Museum with incidental notes. Proceedings of the United States National Museum 72 (7): $1-35$

Bess, H. A. 1936. The biology of Leschenaultia exul Townsend, a tachinid parasites of Malacosoma americana Fabricius and Malacosoma disstria Hübner. Annals of the Entomological Society of America 29 (4): 593-613.

Bigot, J. M. F. 1857. Dipteros. p. 328-349 (pls. 20. de insetos e crustáceos vinculados ao vol. 8). In SAGRA, R. de la (ed.). Historia fisica, politica y natural de la isla de Cuba. Paris, Bertrand, 7, $371 \mathrm{p}$.

Bigot, J. M. F. 1887. Diagnoses de quelques espèces novelles de Diptères. Annales de la Société Entomologique de France ser. 6,7 (Bull.): cxxxix-cxlii.

Bigot, J. M. F. 1888. Diptères noveaux on peu connus, 33 partie, XLI: Tachinidae. Annales de la Société Entomologique de France ser. 6,8: $77-101$

Blanchard, E. E. 1942. Nuevos dípteros y Himenópteros parásitos de la Republica Argentina. Revista de la Sociedad Entomológica Argentina 11: $340-379$. 
Blanchard, E. E. 1959. Dípteros parásitos de orugas de Arctiidae ("gatas peludas"). Revista de Investigaciones Agrícolas 13: 157-182.

Brauer, F. 1897. Beiträge zur Kenntniss der Muscaria Schizometopa. Bemerkungen zu den Original exemplaren der von Bigot, Macquart und Robineau-Desvoidy, beschreibenen Muscaria Schizometopa aus der Sammlung des Herrn G. H. Verral. Sitzungsberichte der Mathematisch-Naturwissenschaftlichen Classe der Kaiserlichen Akademie der Wissenschaften. Abteilungen I, 106:329-377.

Brauer, F. 1898. Beiträge zur Kenntniss der Muscaria Schizometopa. Bemerkungen zu den Original exemplaren der von Bigot, Macquart und Robineau-Desvoidy, beschreibenen Muscaria Schizometopa aus der Sammlung des Herrn G. H. Verral. Sitzungsberichte der Mathematisch-Naturwissenschaftlichen Classe der Kaiserlichen Akademie der Wissenschaften. Abteilungen II, 107:495-529.

Brauer, F. \& J. E. Von Bergenstamm. 1889. Die Zweiflügler des Keiserlichen Museums zu Wein. IV. Vorarbeiten zu einer Monographie der Muscaria Schizometora (exclusive Anthomyidae). Pars I. Denkschriften der Kaiserlichen Akademie der Wissenschaften, (MathmatischNaturwissenschaftiche Classe) 56: 69 - 180. (Também impresso separadamente em "Wien", 1889, 112p.).

Brauer, F. \& J. E. Von Bergenstamm. 1893. Die Zweiflügler des Keiserlichen Museums zu Wein. VI. Vorarbeiten zu einer Monographie der Muscaria Schizometora (exclusive Anthomyidae). Pars III. Denkschriften der Kaiserlichen Akademie der Wissenschaften, (Mathmatisch-Naturwissenschaftiche Classe) 60: 89 - 240. (Também impresso separadamente em "Wien", 1893, 152p.).

Brooks, A. R. 1947. A revision of the North American species of Leschenautia sens. lat. (Diptera, Larvivoridae). Canadian Entomologist (1946) 78: 169-182.

Coquillett, D. W. 1897. Revision of the Tachinidae of America north of Mexico. A family of parasitic two-winged insects. United States Department of Agriculture. Division of Entomolgy (Technical series) 7: 1-156.

Coquillett, D. W. 1910. The types-species of the North American genera of Diptera. Proceedings of the United States National Museum 37:499-647.

ConTÉs, R. 1983. Tachinidae Flies (Diptera: Tachinidae) from Tarapacá and Antofagastta Provinces, Chile III. Addendum. Florida Entomologist 66 (4):377-389.

Crosskey, R. W. 1984. Annotated keys to the genera of Tachinidae (Diptera) found in Tropical and Southern African. Annals of the Natal Museum 26: 189-337.

Curran, C. H. 1934. The families and genera of North American Diptera. New York, Ballou, $512 \mathrm{p}$.

Giglio-tos, E. 1894. Ditteri Del Messico. Memorie della Reale Accademia delle Scienze di Torino 44: 473-546.

Guimarães, J. H. 1971. Family Tachinidae. In PAPAVERO, N. (ed.). A catalogue of the Diptera of the Americas South of the United States. São Paulo, Museu de Zoologia, Universidade de São Paulo, v. 104, $333 \mathrm{p}$.

Guimarães, J. H. 1977. Host-parasite and parasite-host catalogue of South America Tachinidae (Diptera). Arquivos de Zoologia 28 (3): 1131.

Harris, T. W. 1835. VIII Insects. In Hitchcock, E. (ed.). Report on the geology, mineralogy, botany and zoology of Massachusetts. Massachusetts, Amherst, $702 \mathrm{p}$.

Loew, H. 1872. Diptera Americae septentrionalis indigena. Centuria decima. Berliner Entomologische Zeitschrift 16: 49-115.

Macquart, J. 1835. Histoire Naturelle des Insectes Diptères. Paris, Roret, vol. 2, 803p.

MacQuart, J. 1843. Diptères exotiques nouveaux ou peu connus. Mémoires de la Société des Sciences, de l'Agriculture et des Arts de Lille 1842: 162-460. (Também impresso separadamente como "Diptères exotiques nouveaux ou peu connus. v. 2, pt. 3, 5304 p., Paris, 1843).

Macquart, J. 1846. Diptères exotiques nouveaux ou peu connus. Mémoires de la Société des Sciences, de l'Agriculture et des
Arts de Lille (1845) 1844: 133-364, 20 pls. (Também impresso separadamente como "Diptères exotiques nouveaux ou peu connus. Supplément I, 5-238 p., Paris, 1846).

MACQuART, J. 1848. Diptères exotiques nouveaux ou peu connus. Suite de seconde supplément i.e., Troisième supplément. Mémoires de la Société des Sciences, de l'Agriculture et des Arts de Lille 1847 (2):161-237. (Também impresso separadamente como "Diptères exotiques nouveaux ou peu connus. Supplément III, 1-77 p., Paris, 1848).

MACQUART, J. 1855. Diptères exotiques nouveaux peu connus. Supplément V. Mémoires de la Société des Sciences, de l'Agriculture et des Arts de Lille 1854: 25-156. (Também impresso separadamente como "Diptères exotiques nouveaux ou peu connus. Supplément V., 5-136 p., Paris, 1855).

Mcalpine, J. F. 1981. Morphology and terminology, p. 9-63. In MCALPINE, J.F. et al. (eds.). Manual of Neartic Diptera. Ottawa, Agriculture Canada, Research Branch Monograph 27, vol. 1674 p.

O'haRA, J. \& D. M Wood. 1998. Tachinidae (Diptera): nomenclatural review and changes primarily for America North of Mexico. Canadian Entomologist 130: 751-774.

Poole, R. W \& R. E. Lewis. 1996. Nomina Insecta Neartic. A check list of the insects of North America. Diptera, Lepidoptera, Siphonaptera. Rockiville, Maryland, Entomological Information Services, vol.3, 1143p.

ReINHARD, H. J. 1952. New genera and species of muscoid Diptera. Bulletin of the Brooklyn Entomological Society 47: 1-12.

Robineau-Desvoidy, J. B. 1830. Essai sur les Myodaires. Mémoire présentés par divers Savans à l'Acaddémie Royale des Sciences de l'Institut de France (ser. 2) 2: 1-813.

RÖDER, V. Von. 1885. Diperen von Insel Portorico, erhalten duch Herrn Consul Krug in Berlin. Entomologische Zeitung 46: 337-349.

Sabrosky, C. W. \& P. H. Arnaud Jr. 1965. Tachinidae. In STONE, A. et al. (eds.). A catalog of the Diptera of America north of Mexico. Washington, United States Department of Agriculture Handbook 276, 1696 p.

Schaffner, J. V. \& C. L. Griswold. 1934. Macrolepidoptera and their parasites reared from collections in the Northeastern part of the United States. United States Department of Agriculture. Miscellaneous Publications 188: 1-160.

Schiner, I. R. 1868. Diptera. In WÜLlERSTORF-URBAIR, B. Von (ed.). Reiser der Österreichschen Fregatte Novara. Wien, Kaiserlich-Königlich Hof-und Staatsdruckerei (Abt. 1., Sect. B), vol. 2, $388 \mathrm{p}$.

Thompson, W. R. 1963. The tachinids of Trinidad. III. The Goniines with microtypes eggs (Diptera, Tachinidae). Studia Entomologica 6 257- 404.

Townsend, C. H. T. 1892a. Notes on North American Tachinidae sens. str. With descriptions of new genera and species. Transactions of the American Entomological Society 19: 88-132.

Townsend, C. H. T. 1892b. Notes on North American Tachinidae, with descriptions of new genera and species. Paper V. Canadian Entomologist 24: 64-70.

Townsend, C. H. T. 1892c. New North America Tachinidae. Entomological News 3: 80-81; 129-131.

Townsend, C. H. T. 1893a. Review - Part III of Brauer and Bergenstamm's Monograph of the Muscaria Schizometopa. Entomological News 4: $276-277$.

Townsend, C. H. T. 1893b. A catalogue of described South American Species of Calyptrate Muscidae. Annals of the New York Academy of Sciences (1892) 7: 1-44.

Townsend, C. H. T. 1895. Contributions to the dipterology of North America. II. Tabanidae, Conopidae, Tachinidae, etc. Transactions of the American Entomological Society 22: 55-80.

Townsend, C. H. T. 1908. The taxonomy of the Muscoidean flies includind descriptions of new genera and species. Smithsonian Miscellaneous Collections 51: 1-138.

TownsEND, C. H. T. 1912. Descriptions of new genera and species of Muscoid flies from the Andean and Pacific Coast regions of South America. Proceedings of the United States National Museum 
43: 301-367.

Townsend, C. H. T. 1915. New Neotropical muscoid flies. Proceedings of the United States National Museum 49: 405-440.

Townsend, C. H. T. 1916. Designations of muscoid genotypes, with new genera and species. Insecutor Inscitiae Menstruus 4: 4-12.

Townsend, C. H. T. 1917. Second paper on Brazilian Muscoidea collected by Herbert H. Smith. Bulletin of the American Museum of Natural History 37 (6): 221-233.

TownsEnd, C. H. T. 1927. Synopses dos gêneros Muscoideos da região Humida tropical da América, com gêneros e espécies novas. Revista do Museu Paulista 15: 203-385.

Townsend, C. H. T. 1928. New Muscoidea from Humid tropical South America. Wiener Entomologische Zeitung 44: 143-154.

Townsend, C. H. T. 1931. Notes on American Oestromuscoid types. Revista de Entomologia 1: 157-183.

Townsend, C. H. T. 1932. Five new Brazilian oestromuscoid genera. Revista de Entomologia 2 (1): 105-107.

Townsend, C. H. T. 1936. Manual of Myiology, in twelve parts. Oestroid classification and habits (Dexiidae and Exoristidae). São Paulo, C. Townsend \& Filhos. Pt. 1V, 303p,.
Townsend, C. H. T. 1941. Manual of Myiology, in twelve parts. Oestroid generic diagnoses and data (Goniini to Trypherini). São Paulo, C. Townsend \& Filhos, Pt. XI, 342 p.

WALKER, F. 1852. Diptera (cont.). In SAUNDERS W. W. (ed.). Insecta Saundersiana. London, J. van Voost. vol. 1, 414 p.

Wiedemann, C. R. W. 1830. Aussereuropäische zweiflügelige Insekten. Hamm, Schulzischen Buchhandlung. vol. 2, 684 p.

Williston, S. W. 1886. Dipterologiacal notes and description. Transactions of American Entomological Society and Proceedings of the Entomological Section of Academy of Natural Sciences 13:287-307.

Williston, S. W. 1893. List of Diptera of Death Valley Expedition, p. 253-259. In Riley, C. V. (ed.). Report on a small collection of insects made during the Death Valley Expedition. Washington, North America Fauna, 7: 235-268

Wood, D. M. 1987. Tachinidae. In MCALPINE, R.F. (ed.). Manual of Neartic Diptera. Otawa, Agriculture Canada, Research Branch, Monograph n. 28, v. 2, 1332 p.

Wulp, F. M. van der. 1883. Amerikaanshe Diptera Exotiques [concl.]. Tidjschrift voor Entomologie 26: 1-60. 